\title{
THE IMPACT OF CHANGES TO THE NEW ZEALAND AID POLICY ON NON-GOVERNMENTAL ORGANISATIONS
}

\author{
Valeria Openko
}

A thesis submitted to the Victoria University of Wellington in fulfillment of the requirements for the degree of Masters in Development Studies

School of Geography, Environment and Earth Sciences

Victoria University of Wellington 


\begin{abstract}
The election of the National Party Government in 2008 led to a significant reshaping of the New Zealand aid programme. The changes became the subject of strong criticism from the New Zealand aid community in terms of the main policy underpinnings, funding schemes for (Non- Governmental Organisation) NGOs and the altered relationships between the government and development NGOs. While the literature reveals some critical observations about such changes, not much is known about the impacts of New Zealand's Official Development Assistance (NZODA) policy on New Zealand development NGOs. This research aims to better understand the impacts of the changes to NZODA policy on the NGO sector to improve knowledge about the subject that could be applied in order to strengthen the long-term partnership and increase the effectiveness of NZODA. To achieve this goal twenty one New Zealand NGOs were interviewed regarding their views on the policy, impacts on NGO operations and policies, effects on in-country partners and relationships with the government. The criticisms of the aid community were also analysed and compared with the research findings. The research findings showed that the expressed views of NGOs indicted a wide variety of opinions on the policy changes and there was a diverse range of negative, neutral and sometimes positive views on the effects on NGOs. While the National Government's policy agenda has dramatically affected development work of NGOs and their relationships with the government, NGO policies were less affected in some aspects. It is concluded that, whilst the relationship between the official government aid programme and the NGOs has been altered and adversely affected, there is still the basis for an effective partnership that can be reshaped and strengthened in future.
\end{abstract}

Key words: impacts; New Zealand ODA; NGOs; Government. 


\section{Acknowledgement}

I would like to sincerely thank NGO representatives and MFAT officials who agreed to participate in the study and contribute their time and thoughts to the research project. It was absolutely enjoyable to discuss the research topic and learn from development professionals with extensive expertise and experience.

I am grateful to my supervisor, Prof John Overton for providing regular distance consultations, his expert opinions that helped me to build the structure of the thesis. I do appreciate your positive attitude and assistance.

Particular thanks go to my good friend Prof Don Fuchs from the University of Manitoba who has inspired me to apply for a master degree and also supported me during hard times of writing the thesis.

I express my appreciation to Joanna Spratt and Michael Vujnovich who gave me their critical opinions on the value and applicability of the chosen topic. My deepest gratitude should go to Deborah Laurs, Samuel Anderson, Fran Garside, Nick Pimenov and Andrea Deans for their great reviewing and editing skills. Thank you my dear friends for your time.

Words could not express my gratitude to my dearest parents who were constant support for me and inspiration to complete the research project successfully. I am so lucky to have you. Thank you for going through the difficult and enjoyable time of this research work. A special thank you goes to my friends Julia and Irina for their words of encouragements.

I appreciate financial support of the Victoria University of Wellington for awarding me with 2013 VUW Equity Grant. 


\section{Table of Content}

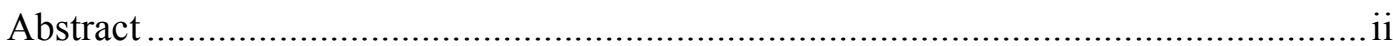

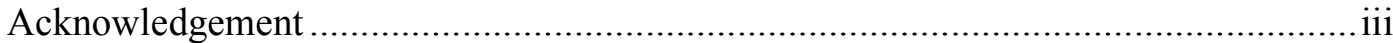

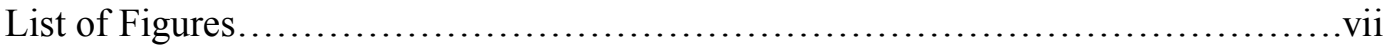

List of Tables...................................................................

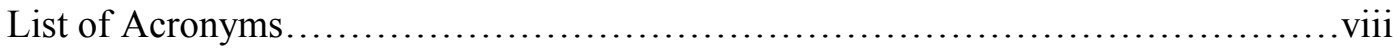

CHAPTER ONE - INTRODUCTION..........................................1

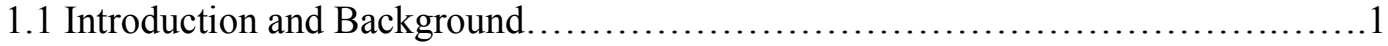

1.2 Problem Statement.............................................................

1.3 Research Question and Objectives.........................................4

1.4 Applicability of the Study.............................................. 5

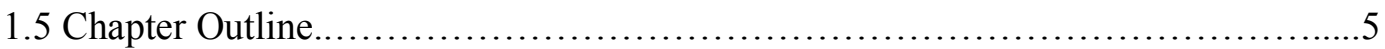

CHAPTER TWO - THEORETICAL AND POLICY UNDERPINNINGS OF GOVERNMENT - NGO RELATIONSHIPS.......................................7

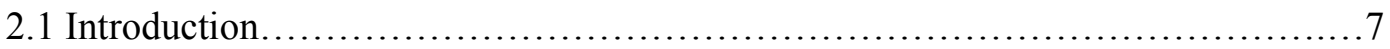

2.2 Government -NGO Relationships as a Response to Sector Failures.................7

2.2.1 Government and Market Failures - Existence of the Voluntary Sector............8

2.2.2 Voluntary Failure and Rationale for Government-NGO Relationships............9

2.3 Government-NGO Relationships in Cross-Sectoral Frameworks...................11

2.4 Partnership - Theoretical Reflection on Government-NGO Interaction...............14

2.5 Characteristics of Government-NGO Relationships.......................... 17

2.6 Partnership and Aid Effectiveness.......................................... 19

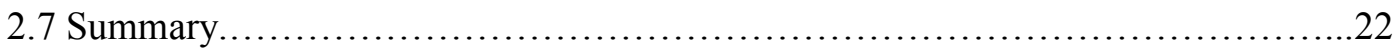

CHAPTER THREE - RESEARCH DESIGN.................................24

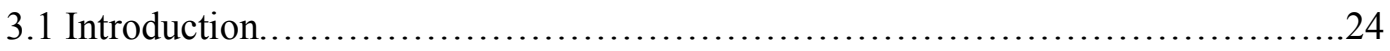

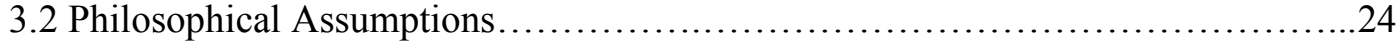

3.2.1 Realism and Modified Objectivism................................... 25

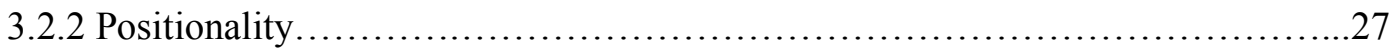

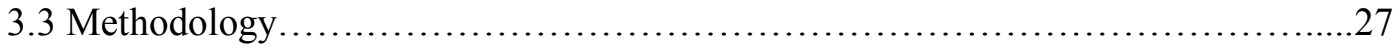

3.3.1 Mixed- Method Approach................................................ 28 


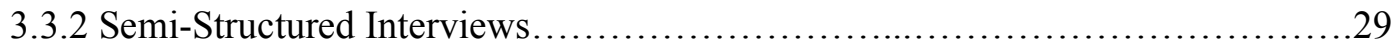

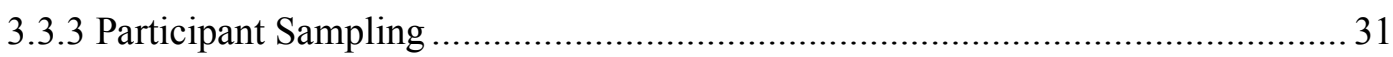

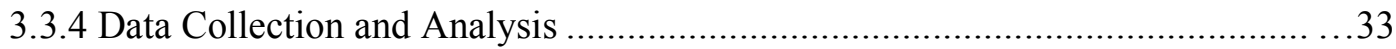

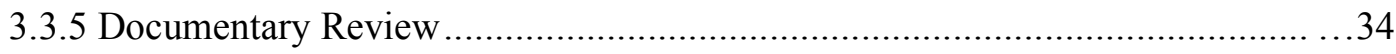

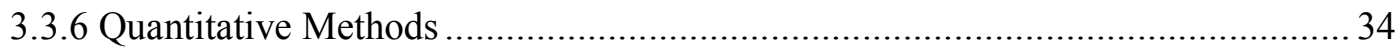

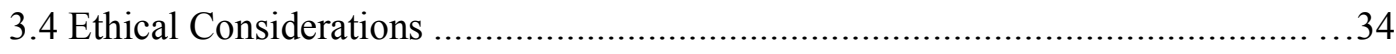

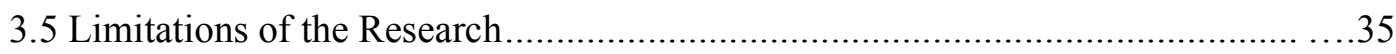

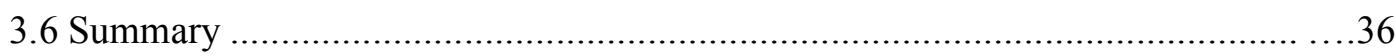

CHAPTER FOUR - CHANGES TO NEW ZEALAND AID POLICY

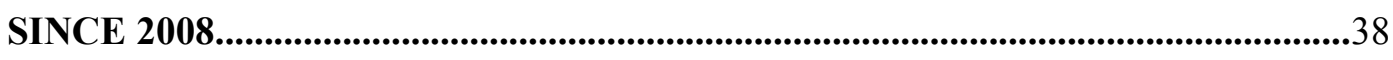

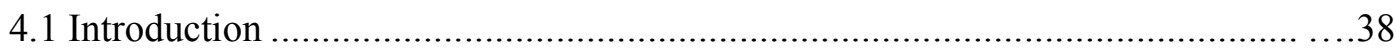

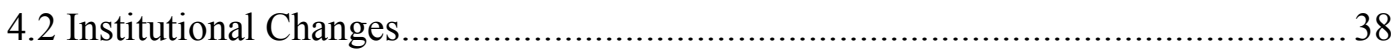

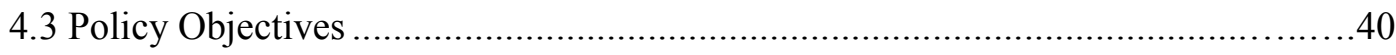

4.4 Effectiveness, Efficiency and Accountability ............................................43

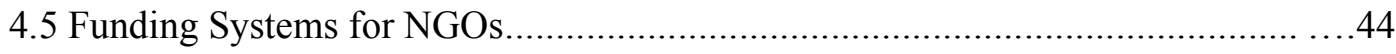

4.6 Response of New Zealand Aid Community to Changes to the NZODA Policy.....47

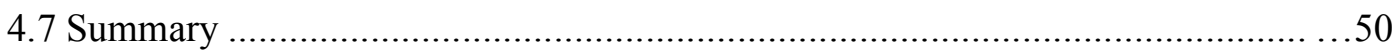

\section{CHAPTER FIVE - IMPACT OF CHANGES TO NZODA POLICY ON}

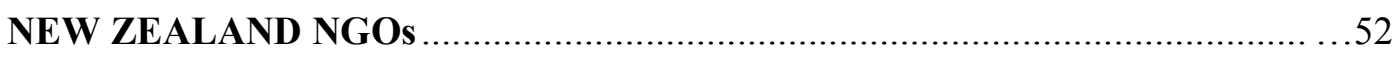

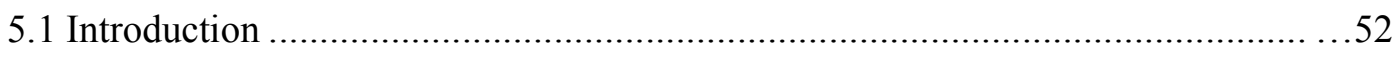

5.2 NGO Views on the New Policies and Instruments used by MFAT Since 2008 .....52

5.2.1 Geographical Priorities and Sustainable Economic Development .................... 52

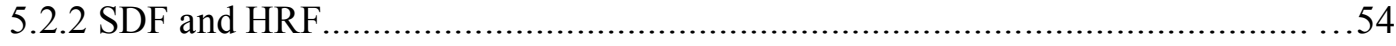

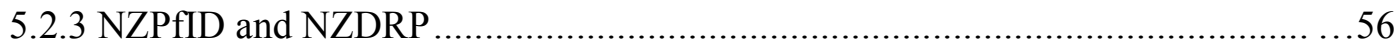

5.3 The Effects on NGO Operations and Policies ..............................................59

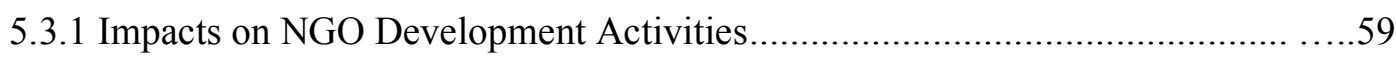

5.3.2 Effects on NGOs Development Instruments .........................................65

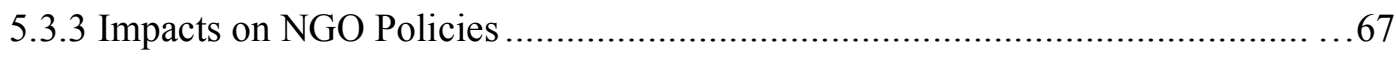

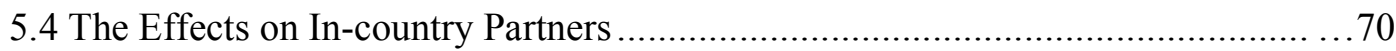


CHAPTER SIX - RELATIONSHIPS BETWEEN THE NGO SECTOR AND THE NEW ZEALAND AID PROGRAMME .................................................... 74

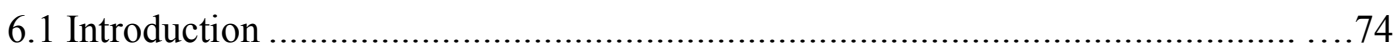

6.2 Relationships between NGOs and the New Zealand Aid Programme.................... 74

6.3 Types of NGO-Government Relationships ............................................... 79

6.4 Recommendations for Improvement of Relationships with the New Zealand Aid

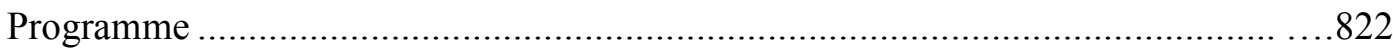

6.5 Recommendations for Policy Development .................................................. 844

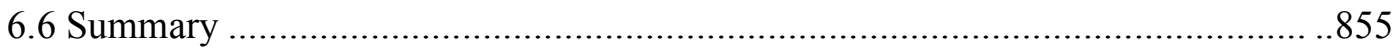

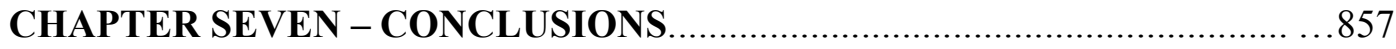

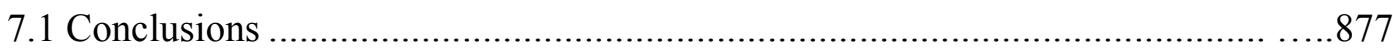

7.2 A Review of NGO Views on the New Policies......................................... 87

7.3 A Review of Effects on NGO Operations, Policies and Country Partners............89

7.4 A Review of Relationships between NGOs and the New Zealand

Aid Programme......................................................... 90

7.5 A Review of Recommendations for Improvement of the Relationships and

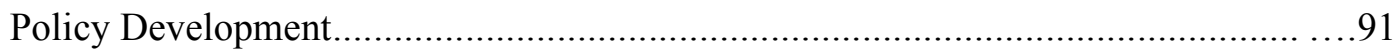

7.6 Genuine Partnership: Too Close to Comfort or Contract for Services? ................91

7.7 Limitations and Directions for Future Research........................................ 944

7.8 Final

Remarks.

References.............................................................. 96

6

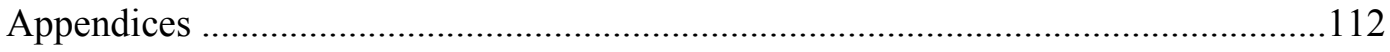

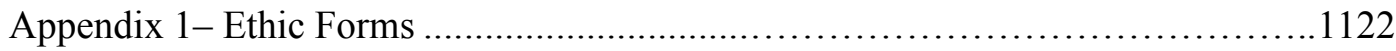

Appendix 2 - Figures and Tables 


\section{List of Figures}

Figure 4.1 Focus on New Zealand's Comparative Advantage........................40

Figure 5.1 CID Member Income by Source 2005-2011 ........................61

Figure 6.1 Young's Model of Relationships between New Zealand NGOs and

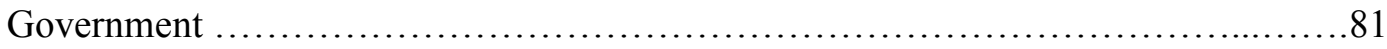

Figure 6.2 Lewis's Model of Relationships between New Zealand NGOs and

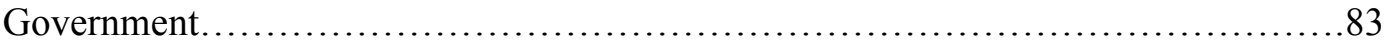

Figure A.1 NGOs' Income from the New Zealand Government in 2009...............121

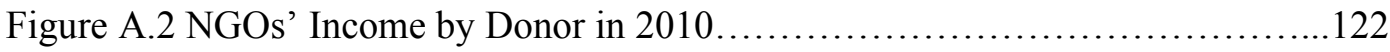

Figure A.3 NGOs' Income from the New Zealand Government in $2011 . . . . . . . . . . . .123$

Figure A.4 NGOs' Income from the New Zealand Government in 2012...............124

Figure A.5 NGOs' Income from the New Zealand Public in $2009 \ldots \ldots \ldots \ldots \ldots \ldots \ldots \ldots \ldots \ldots$

Figure A.6 NGOs' Income from the New Zealand Public in $2011 \ldots \ldots \ldots \ldots \ldots \ldots \ldots . . . \ldots 126$

Figure A.7 NGOs' Income from the New Zealand Public in $2012 \ldots \ldots \ldots \ldots \ldots \ldots \ldots \ldots . \ldots 127$

Figure A.8 KOHA-PICD Sample Process.................................... 128

\section{List of Tables}

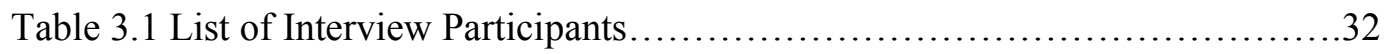

Table 4.1 Size of NZODA between 2007 and 2012 .............................42

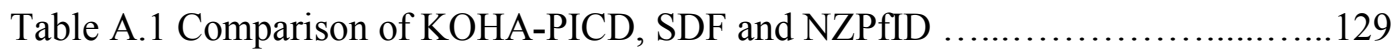

Table A.2 Comparison of HAF, HRF and NZDRP .......................... 140

Table A.3 Administration Costs of New Zealand NGOs............................148

Table A.4 Dependency Ratio of New Zealand NGOs on Government

Grants/Contracts........................................................... 150 


\section{List of Acronyms}

ADD

BG

CID

CSOs

CWS

DAC

DRR

GFA

HAF

HRF

IDG

IP

KOHA-PICD

$M \& E$

MDGs

MFAT

NGO

NZAID

NZDRP

NZODA

NZPfID
Activity Design Document

Block Grant

The Council for International Development

Civil Society Organisations

Christian World Service

Development Assistance Committee

Disaster Risk Reduction

Grant Funding Arrangement

Humanitarian Action Fund

Humanitarian Response Fund

International Development Group

Individual Projects

Kaihono hei Oranga Hapori o te Ao - Partnerships for International Community Development

Monitoring and evaluation

Millennium Development Goals

New Zealand Ministry of Foreign Affairs and Trade

Non- Governmental Organisation

New Zealand Agency for International Development

New Zealand Disaster Response Partnership

New Zealand Official Development Assistance

New Zealand Partnerships for International Development 
ODA

OECD

SDF

VASS

VSA
Official Development Assistance

Organisation for Economic Co-operation and Development

Sustainable Development Fund

Voluntary Agencies Support Scheme

Volunteer Service Abroad 


\section{CHAPTER ONE - INTRODUCTION}

\subsection{Introduction and Background}

Following 2008 election of the National Government, New Zealand's aid programme - its Official Development Assistance (ODA) - underwent significant changes that are still considered controversial by many political and development commentators. The changes involved several key elements: the alignment of NZODA with the New Zealand foreign policy objectives; the reintegration of New Zealand Agency for International Development (NZAID) into the wider Ministry of Foreign Affairs and Trade (MFAT) and the loss of NZAID's semi-autonomous status; the change in strategic direction of the policy from poverty elimination to sustainable economic development; and the increased emphasis on the Pacific region. Significant also was the change in the main instruments for distributing NZODA to New Zealand development NGOs. The previous system involving the Kaihono hei Oranga Hapori o te Ao - Partnerships for International Community Development (KOHA-PICD) and the Humanitarian Action Fund (HAF) were replaced with the Sustainable Development Fund (SDF) and the Humanitarian Response Fund (HRF); these in turn being recently substituted by the New Zealand Partnerships for International Development (NZPfID) and the New Zealand Disaster Response Partnership (NZDRP). New effectiveness, efficiency and accountability requirements were also introduced.

These transformations were a subject of strong criticism and concern among academics and development practitioners. Challies, McGregor and Sentes (2011) state that the new international development policies of the New Zealand Government created tensions between the Government, New Zealand NGOs and their partners in developing countries. They also added that "the changes ... highlight the weakness of government aid, where political ideology supersedes good judgement based on sound evidence. In this case the government donor pulled out of a mutually-negotiated partnership funding model to unilaterally restructure the aid sector" (Challies, McGregor \& Sentes 2011, p.13). Banks, et al. (2012, p. 183) suggested that NGOs were placed in the "uncomfortable position" when they had to focus and adjust to the foreign policy changes instead of concentrating on an effective delivery of development projects.

Christian World Service (CWS) were one of the few development NGOs to openly criticise the new policy and its spokesperson doubted whether NZODA's focus 
on promoting New Zealand expertise and advantages was appropriate: "this can run counter to good development practice where decision-making belongs with the local community" (CWS 2011a). Barry Coates, Oxfam New Zealand's Executive Director, claimed that the reintegration of NZAID with MFAT threw back NZODA to the time before NZAID was founded when ODA was featured with "mixed agendas" and "disorganised, unstructured, haphazard and arbitrary" initiatives (Oxfam 2009b). He further argued that an economic development focus does not help the poor but rather already rich social classes. In addition, many NGOs were not satisfied with many aspects of the newly-introduced funding schemes. They were critical of expenses involved in preparing applications, the necessity to conduct numerous reviews of financial and project documents, the lack of feedback on applications, and the lack of transparency in the appraisal process (NGO Consultative Group 2012). The other major concern was an absence of a proper review that would underpin the validity of the new policy settings. Two quick reviews were conducted by the State Services Commission and MFAT in 2009. There was also criticism of the limited possibility of public engagement or consultation with the development community regarding the changes. The Council for International Development (CID) is an umbrella organization for development NGOs in New Zealand, yet it was barely consulted by the new government: "the CID Board, made up entirely of member NGOs, met twice with the Minister to express concerns about the proposed changes to NZAID's mission and structure. It appears, however, that the concerns raised by CID were not taken seriously" (Challies, McGregor \& Sentes 2011, p.16). Meanwhile, a peer review conducted by the Development Assistance Committee (DAC) of the Organisation for Economic Co-operation and Development (OECD) in 2010 also expressed mild concern. The report indicated that "following the election of the government in October 2008, New Zealand support to NGOs entered a period of uncertainty" (OECD 2010, p. 54).

Thus, it is clear that the changes in New Zealand's aid programme since 2008 have potentially significantly adversely affected and reshaped relationships between the Government and New Zealand NGOs. 


\subsection{Problem Statement}

Understanding the impact of the new NZODA environment on the development community is important and topical because it has a direct impact both on the effectiveness of the work of NGOs and on relationships between New Zealand NGOs and the New Zealand Aid Programme. The relationships are critical in achieving development goals. A Ministerial review of NZODA stated that "effective aid depends on building relationships ... the processes of partnership dialogue and negotiation may well be as important as the specific interventions which agencies fund in trying to achieve benefits for the poor" (Ministerial Review Team 2001, pp. 34-35). Brinkerhoff (2002d) and Banks et al. (2012) also argue that partnering and sharing experiences, knowledge and best practices between NGOs and policy makers is an effective and essential instrument for achieving aid goals.

Research on the relationship between government and NGOs requires urgent attention since NZODA policy is still committed to engage strategically with NGOs to build solid and durable relationships (OECD 2010; Cordery \& Halford 2010). Moreover, in the official 2010 publication Guidelines to Work with Civil Society Organisations it is mentioned that the Government "recognises the role and potential of civil society organisations (CSOs) in addressing poverty and promoting sustainable economic development worldwide" (NZAID 2010, p. 4).

An analysis of existing literature shows that there is not much information available on impacts of the policy changes on the NGO sector and evaluation of relationships between New Zealand Government and NGOs. This especially relates to the period of the last five years when the major changes in NZODA took place. An initiative to evaluate the impact of the National Party policy changes to NZODA was recently undertaken by Challies, McGregor and Sentes. In their work "The Changing Landscape of International Development in Aotearoa/New Zealand" (2011) the scholars provide a historical overview of NZODA and New Zealand NGOs between the 1940s and 2008. Despite the fact that authors do not present a detailed analysis of the policy influences on each NGO they reveal common consequences for the development community. Among them are: significant cuts in budgets particularly of CID and Global Focus Aotearoa; a high number of declined NGO applications for the contestable funds; and delays in implementation of development projects caused by the unclear mechanism of the funding schemes. The authors also examined government and civil society voices and found out that a dialogue between these stakeholders was interrupted (Challies, 
McGregor \& Sentes 2011). The main conclusion of the work is a recommendation and hope that "the partnership between the government of New Zealand and New Zealand civil society in the development sector can be restored on principles of mutual respect, dialogue, transparency and accountability" (Challies, McGregor \& Sentes 2011, p.20). Banks et al. (2012) analysing the new political environment in their paper "Paddling on One Side of the Canoe? The Changing Nature of New Zealand's Development Assistance Programme" argue that many ongoing NGOs' development projects did not fit new requirements of the international aid policy. They also add that "the power of NGOs has been undermined considerably by the constraints placed on their funding arrangements" (Banks et al. 2012, p. 183). To understand better the SDF scheme a private sector organisation Development Action conducted an analysis of NGOs' applications for the SDF Round One in 2011and this involved applying MFAT's own criteria to the applications. The results of the research were unexpected. Development Action concurred with MFAT's decisions only $20 \%$ of the time while this rate was expected to be about 75\% (Development Action 2011). The work further illuminated the lack of transparency in the process of allocating funding and underlined the frustrations felt by NGOs.

Given this (albeit limited) published work on the impact of changes on the relationship between the government's aid programme and development NGOs in New Zealand, this thesis addresses the need to understand what these impacts have been and how they have been experienced by NGOs.

\subsection{Research Question and Objectives}

The central research question of this thesis is: what have been the impacts of the changes to NZODA on the NGO sector in New Zealand since the election of the National Government in 2008 ?

In order to answer this research question a set of objectives was defined:

- To examine New Zealand NGOs' views and experiences on the main changes to the NZODA policy.

- To investigate what were the greatest impacts on NGOs and how they affected NGO operations, policies and country partners. 
- To evaluate current relationships between New Zealand NGOs and the New Zealand Aid Programme.

- To present NGOs' recommendations for improvement of relationships with the New Zealand Aid Programme including proposals for policy development.

\subsection{Applicability of the Study}

The main general output of the research will be a contribution to the development literature on government-NGO relationships. As Pickard noticed "knowledge grows incrementally with each new contribution, however small or localized that contribution might be" (Pickard 2007, p.51). Research findings aim to benefit both NGOs and the Government by providing evidence that could be used to strengthen long-term partnerships and increase the effectiveness of NZODA. They will also help to reveal NGOs' voices as well as give a reflection of the Government's position.

\subsection{Chapter Outline}

The thesis contains seven chapters. Following this introduction, Chapter Two introduces the theoretical underpinnings of government-NGO relationships and outlines some characteristics of the relationships. The chapter particularly focuses on partnership as a common form of interaction between government and the NGO sector as well as illustrating the partnership phenomena in an international context of aid effectiveness.

Chapter Three provides an overview of a research design covering philosophical assumptions, and methodology and describes major ethical considerations and limitations of the research.

Chapter Four introduces the main changes to NZODA since 2008 paying particular attention to institutional changes, alignment of NZODA and foreign policy goals, strategic and geographical shifts, new funds for NGOs as well as effectiveness, efficiency and accountability requirements. Early responses of New Zealand Aid community on the new policy settings will be also presented.

Chapter Five illustrates research findings on the impacts of the changes to NZODA on New Zealand NGOs revealing NGOs' views on the new policies used by 
MFAT since 2008, the effects on NGO operations and policies, and impacts on NGOs in country partners.

Similarly Chapter Six reflects research results on NGOs perspective on current relationships between the New Zealand Aid Programme and NGO sector classifying them within some types of NGO-Government relationships. It also provides NGOs' recommendations for policy development and improvement of relationships with the New Zealand Aid Programme.

Chapter Seven finishes the thesis with main conclusions of the research project. 


\section{CHAPTER TWO - THEORETICAL AND POLICY UNDERPINNINGS OF GOVERNMENT - NGO RELATIONSHIPS}

\subsection{Introduction}

NGO-government relationships have not inherited a strong theoretical foundation. A lack of conceptual understandings is acknowledged by many scholars such as Salamon (1987b), Fisher (1995), Coston (1998), Smillie and Helmich (1993), Hulme and Edwards (1997), Waddell (1998) and Young (1999). Yet there are some frameworks that can be utilised.

Existing theoretical underpinnings on NGO-government relationships are divided into two blocks (Teamey 2007). One presents theories that allow interpretation of relationships through differing theoretical lenses. Such theoretical contributions to NGO-government relationships include a variety of approaches such as the concepts of power, civil society and social capital, resource dependency theory, and organisational and principal agent theories. New institutional economics theory and ecological and social origins theories (including trust and discourse theories) have also contributed to understanding of NGO-government relationships (Teamey 2007). Of importance to this thesis is the role of sector failure theory and related to this are the concepts of partnership and third party government. The second block refers to a new approach cross-sectoral models - that aim to systemise and classify relationships. Because partnership has become a dominant concept of government-NGO relationships and received widespread attention from scholars it will be analysed. The chapter further explores a theoretical reflection of characteristics of government-NGO relationships that outline the character of the interaction. To conclude, government-NGO relationships in a context of aid effectiveness as one of the dominant international development regulations followed by the New Zealand Government will be outlined.

\subsection{Government - NGO Relationships as a Response to Sector Failures}

To understand the rationale behind government-NGO relationships and explain the necessity for mutual collaboration from a theoretical perspective, government, market and voluntary sector failure theories will be discussed. 


\subsubsection{Government and Market Failures - Existence of the Voluntary Sector}

Theories of government and market failures are invariably associated with demand side economics. This provides a useful framework for the examination of government-NGO relationships and gives an insight into the genesis of the relationships.

Government failure theory finds its roots in welfare system theory. Economist Weisbrod (1977) claimed that due to political objectives governments are not able to provide enough public goods to satisfy demands of the population. The main reason is heterogeneity of the population and government tendency to meet the needs only of major voting groups (Weisbrod 1977). Therefore, consumers, left without any commodities, tend to purchase services from other parties. In a similar manner but through a normative approach, Lipsky and Smith (1990) consider a government's inability to satisfy public demand due to a governmental responsibility to follow legal mandates and provide equity with limited resources. Thus some citizens receive help and others do not. Empirical contribution to this theory was made by Salamon and Anheier (1998), Matsunaga and Yamauchi (2004) who practically examined theory's hypothesis and concluded its high credibility. Empirical data indicated that increasing diversity of population correlated with an expanded NGO sector (Salamon \& Anheier 1998) (See also Matsunaga \& Yamauchi 2004). Conversely, Grand (1991) challenges government failure theory, specifically the theoretical base of equity and efficiency of government instruments. Through an analysis of consequences of government's supply, subventions and rules, he states that government does not always fail. A degree of government failure depends on the type of governmental initiatives. Meanwhile, the government failure theory helps to reveal weak points of the government system and has a potential to turn them into a theory of success with mutual collaboration between other sides of goods provision such as the market and NGO sectors.

Similarly, the market failure theory recognises inefficiency of a market mechanism to allocate resources or failure to achieve Pareto efficient allocation (Bator 1958). For instance, contract failure, due to asymmetry of information results in consumers being unable to assess the quality of provided services because they are not the first purchasers (Hansmann 1987). Firms taking this opportunity tend to deliver fewer services than they initially guaranteed causing the failure of the contract (Hansmann 1987). Anheier and Seibel (1990, p.229) concur with Hansmann and 
propose a "proxy" that gives a guarantee of satisfactory level of services. This proxy role is given to nonprofit organisations due to their trustworthiness. Despite a wide representation of empirical analysis of the contract failure and its main underpinnings in the literature (Nelson \& Krashinsky 1973; Arrow 1963), Wang (2006) questions nonprofits' trustworthiness. This leaves a space for a further investigation of the contract failure theory that is beneficial to understanding of government-NGO relationships. It outlines imperfections of the private sector and respectfully accepts a role for NGOs as a faithful service provider that is supported by its mission and values rather than a profit motive.

Government and market failures form a theoretical basis for an existence of the voluntary sector as an equal party in a distribution of public goods and services. The existence of the volunteer sector was further strengthened by supply-side theories and advanced by the reassessment of the NGO role. Yet they are out of scope of the current research. Current observed literature theorises the existence of the voluntary sector not only by proving inefficiency of government and market sectors but by reinforcing NGO's capacity to satisfy demands of the population. For example, the majority of scholars outline that a client's trust in NGO services is the most important reason for NGOs existence (Salamon \& Anheier 1998; Hansmann 1987). However, trust is only one aspect of the phenomenon. Lipsky and Smith (1990) suggest a high responsiveness to people's needs, high tolerance to a selection of clients and preference for a high number of customers as essential to the success of the NGO within civil society. Further, Powell and Steinberg (2006) present a wide discussion on NGO's capacity as a valuable service provider; distinguishing its self-governance, an ability to take risk, have low level of accountability, high flexibility and access to certain resources. The theoretical discussion around the genesis of the voluntary sector is important because it determines capacities and a supplementary or complementary position of non-profit organisations to government services.

\subsubsection{Voluntary Failure and Rationale for Government-NGO Relationships}

Voluntary failure or interdependence theory developed by a leading expert in the field of policy, Salamon, justifies the importance of government-NGO cooperation by 
recognising voluntary failures to satisfy public demand (Salamon 1987a). His research outlines four voluntary vulnerabilities: philanthropic insufficiency, philanthropic particularism, philanthropic paternalism and philanthropic amateurism (Salamon 1987a). Similarly, Kramer (1981, pp.265-266) concurs with imperfections of the voluntary sector and determines them as "institutionalization", "goal deflection", "ineffectuality" and a focus on "philanthropic origin" instead of "clientele". Voluntary failures face significant criticism in the literature. For example, Hamilton stresses that "the idea of voluntary failure is too vague" (Hamilton 2004, p. 15) and it is unclear when it happens and who determines it. He also adds that the theory reflects only a snapshot of the failure and does not consider it in dynamics. Anheier and Ben-Ner (2003) see a weakness of the theory in a depreciation of voluntary sector's roles as a capable partner and supplier of public goods. While some critique of the voluntary failure theory is well argued, it requires an empirical justification. In general, the literature review demonstrates a lack of empirical studies that aim to test the theory and main Salamon's conclusions.

The voluntary failures framework leads to the logical conclusion that government and NGOs should collaborate. A cornerstone of the concept lies in a voluntary sector inability to provide public goods due to its failures, thus resulting in the necessity of government investment to cover NGO shortcomings. Salamon goes further to suggest that relationships formed on the basis of governmental correction of voluntary failures reveal themselves in mutual complementarity. Thus "the voluntary sector's weakness correspond well with government's strengths, and vice versa" (Salamon 1987a, p.42). That is why partnership for him is a logical answer to the failures rather than a substitution of one sector for another.

Examining relationships between government and NGOs he goes one step further advocating for a third-party government theory where an essential element of a government system is contract arrangements with the NGO sector. Salamon's contribution to interpreting partnership is widely recognised in the literature (Maroney \& Dollery 2004; Anheier \& Ben-Ner 2003). At the same time the theory led to wide critical discussion. Although Anheier and Ben-Ner (2003, p.174) claim that Salamon managed to determine a position for NGOs regarding government and boost further development of theories around this issue, they addresses some "annoying questions". They question the validity of the theory, its static position, its geographical context (it is an American-centric theory), and its applicability to diverse NGO sectors with a different level of government assistance (Anheier \& Ben-Ner 2003). Similarly, 
Hamilton (2004) emphasises that the theory is being placed in a vacuum, it does not take into account possible government failures, there is a slow response to voluntary shortcomings and there is a complexity of social and political processes. As such he agrees with Douglas' assessment of voluntary failure and "theoretical limits on the instrumentalities of government" (Douglas 1983, p. 160). Powell and Walter suggest that while Salamon explains the reason of government-NGO transactions, conditions for development of cooperation are not analysed (see also Steinberg \& Young 1998).

Analysis of academic literature indicates that although government and market failure theories do not explain relationships between nonprofit organisations and government they do introduce imperfections of sectors and unify them together. A review of the literature on the voluntary failure theory and concept of governmentNGO partnership leads to the conclusion that they are still incomplete. While some scholars' arguments present quite constructive criticism, it is necessary to give credit to Salamon's theory because it is the one of not many concepts that gives a clear theoretical rationale of the origin and interaction between government and NGOs. These are thus the first theoretical seeds of collaboration. It is important to note that theories of government-NGO relationships are further advanced in cross-sectoral models and a concept of partnership that will be discussed later in this chapter.

\subsection{Government-NGO relationships in Cross-Sectoral Frameworks}

A diversity of government-NGO relationships is reflected in a variety of crosssectoral frameworks and models. Government-NGO relationships are classified according to different criteria: a level of power, formality, dependency, similarity of goals and instruments, extent of interaction and policy dialogue. The current research will examine only cross-sectoral frameworks that have brought significant contribution to understanding of the relationships and that are particularly applicable to the research question.

Young's (2000) model of government-NGO relationships reflects the nature of the relationships through lenses of the economic theory. He distinguishes three types of relations supplementary, complementary and adversarial.

The supplementary model assumes that an independent NGO meets the demand of public goods left unsatisfied by government and therefore supplementing the latter. The complementary model supposes partnership relationships between both parties for 
supplying services funded through government streams. Finally adversarial interaction reflects relations when government and NGO influence each other's work. Therefore, an NGO attempts to engage in policy dialogue and recommend improvement in policy and conversely government authorities affect the NGO sector by applying different sanctions (Young 2000). Teamey (2007) stressed an obvious limitation of the model. The scholar claims that while the framework throws light on a main character of the interaction, in reality the relationships are much more complex and usually fit more than one type of relationships (Teamey 2007). Brinkerhoff (2002d) finds support for Young's research in his empirical analysis of the application of the theoretical framework to contexts of the UK, United States, Japan and Israel that proves the complexity of government-NGO relations. Najam calls Young's model "simple but elegant" stressing that it is one of not many frameworks that describes governmentNGO relationships from "both sides" (Najam 2000, p.382). I believe that Young's model attracts with its simplicity and indeed gives if not a full description of the relationships but definitely indicates their direction. Due to the advantages of the model it was introduced to the research participants to evaluate their relationships with New Zealand Government (results findings could be found in Chapter Six).

Lewis (1997) presents a comprehensive framework and criteria used for describing government-NGO relationships. Depending on role, origin, goals, risk level and communication type NGOs are distinguished by an active and dependent partnership. Active partnership is depicted as a "process" with "negotiated, changing roles" where risks are shared by partners who constantly share information and learn through "debates and dissent" (Lewis 1997, p.39). This partnership has "activity-based origins" (Lewis 1997, p.39). In contrast, a dependent partnership is a "fixed-term" scheme with "rigid roles", unclear linkages where partners pursue "individual interests" and reach a "consensus" grounded on "poor communication". Dependent partnerships are endowed with "resource-based origins" (Lewis 1997, p.39). The literature does not reveal a wide discussion around Lewis's model of partnership. Meanwhile, Lister's (2003), Besley and Ghatak's (2001) studies are supported with Lewis' research findings in Bangladesh. Despite the fact that the framework did not receive a much application in empirical studies the active and dependent partnership classification is very useful in terms of examining the nature, character of government-NGO collaboration and ability for self-identification. Similar to Young's model the framework is introduced in this study of New Zealand NGOs to characterise their current partnership with the New Zealand Aid Programme. 
Najam (2000) attempted understand the nature of government-NGO relationships by applying a theory of strategic institutional interests. His Four-C's model outlines that both government and NGO have goals or ends achieved through following certain strategies or means. Depending on a combination of ends and means, he highlights four types of possible interactions. The fifth option he leaves for no interaction. A cooperation relationship incorporates a similarity of shared ends and means, confrontation assumes an opposition to both government's and NGO's strategies and goals, and complementarity is a situation when state and NGO have common objectives but consider different ways of achieving them. Finally, when government and NGO applying identical means achieve dissimilar goals, the relationship can be termed co-optation (Najam 2000). Najam's model received a wide response from scholars. For example, Zimmer (2010) considers its ability to embrace a diversity of partnerships and its applicability in a context of different geographical scopes, useful. However, Najam claim that government-NGO relationships could exist within different types of classification at the same time was empirically proved by Sood (2000) and Ramanath (2005). Although Ramanath (2005) recognises a usefulness of the Four-C model she critiques the model for only attempting to address superficial issues of these relationships. Further, Ramanath introduced a "repertoire of tactics" or different actions within a chosen strategy. She concludes that achieving similar goals NGOs could apply different actions to solve the same problem (Ramanath 2005, p.74). On review, Najam's framework has high empirical significance in viss-a-vis other theoretical frameworks. It also helps to investigate the relationships through a different prism of strategic institutional interests.

Brinkerhoff (2002a, p.224) considers government-NGO relationships as partnerships; essential criteria for partnership are "mutuality and organisation identity". She determines mutuality as a degree of organisations' interconnection, an ability to take decisions and practice rights on an equal basis. Organisation identity, she detects as a partner's capability to retain its mission and values (Brinkerhoff 2002a). An application of these indicators forms four types of relationships: partnership, contracting, extension and gradual absorption or co-optation. Partnership refers to the relationships with a high mutuality and organisational identity. Contracting is relevant when "contracted organisation's mission is made to coincide with that of the contractor" (Teamey 2007, p.60). Extension is when one organisation has a predominant position and the other one pursues it due to low organisational identity. Finally, gradual absorption, when an organisation gives up its values and identity due to certain reasons 
(Brinkerhoff 2002a). The framework also received a wide recognition in empirical studies. For example, Wetterberg's (2011) case study of better factories Cambodia illustrates how organisational identity and strengths are important for effective partnership and achieving mutual goals. Probandari et al. (2011) merits the framework, considering its utility above all other partnership models. He examined partnerships in the delivery tuberculosis care in hospitals in Yogyakarta Province. Echoing Probandari, Horton, Prain and Thiele stress that "the matrix [Brinkerhoff's model] could inform continuing theory building and practical experimentation with partnership" (Horton, Prain \& Thiele 2009a, p. 20). Mahanty et al. (2009) applying Brinkerhoff's model to natural-resource management further advanced the concept of trust suggesting relationships between individuals within organisations as a driving force for building partnership. Conversely, Bailey and Dolan (2011) declared that partnership with an equal degree of shared information is improbable due to a complexity of environment that is caused by languages, geographical differences and a mutual understanding of partnership between parties. They add that in order to build good relationships it is important to examine obstacles for partnership. However, the partnership model does not incorporate them. Although Brinkerhoff's framework has several weaknesses it represents a high level of applicability in different fields. It illustrates a topical problem of government-NGO relationships pertaining to the dependency and loosening of organisational identity a common phenomenon in modern international development.

\subsection{Partnership - Theoretical Reflection on Government-NGO Interaction}

A discussion point on partnership pertains to definitions of partnership, its role and outcomes as the most gainful type of relationships, its instruments to achieve effective partnership and the different assessment frameworks.

Academic literature does not account for one commonly recognised definition of partnership. Instead, Haque (2004) claims it was developed from concepts of coalition that culminated into a more advanced form of collaboration (Siddiqi \& Oever 1998; Lister 1999). A common form of partnership is between two parties that entered collaboration on a basis of mutual objectives and goals that otherwise were unattainable (Barnett et al. 1999; Tojrman 1998). A more complex approach to definition of partnership was introduced by Picciotto who besides common objectives considers 
partnership as "a means to an end" incorporating "shared responsibility for outcomes, distinct accountabilities and reciprocal obligations" (Picciotto 1998, cited in Abugre 1999, p.7). In contrast, Brinkerhoff understands the same concept as a mean and an end simultaneously where the first one is a tool of effectiveness and the last one stands for “expression of values" (Brikenkorrf 2002c, p.17). Brinkerhoff went one step further by drawing some important issues that underpin a theoretical foundation of partnership. She claims that definitions are not always practically oriented or geographically applicable. It often reflects subjective views (Brinkerhoff 2003). Fowler (2003) analyses the partnership concept through critical lenses of development practice. He stresses that the term has lost its original meaning because it is misapplied (Fowler 2003). Although partnership reflects a collaborative nature of the phenomena in the academic literature, scholars interpret it in their own way marking out certain partnership principles and features. Furthermore, it is hard to disagree with Melville's (2008) statement that to achieve established goals it is important that both parties of partnership have the same unambiguous interpretation of the concept.

Faith in the partnership concept as the most gainful relationships between state and the NGO sector relies on outcomes and implications. Scholars highlight an advantage of this as the capacity to increase efficiency and effectiveness through mutual strengths and a wider rational mobilisation of public goods (Caplan 2001; Brinkerkoff 2002c; Ullah et al. 2006; Lipsky \& Smith1990). It is also commonly considered in the literature that partnership promotes public accountability, community engagement, consensus building, enhances creativity and innovation, furthers democracy an solidarity (Lasker, Weiss \& Miller 2001; Gomez-Jauregui 2004). While Brinkerkoff gives a more systematic approach examining implications of partnership from normative, reactive and instrumental perspectives, Ullah provides with a detailed illustration of benefits and contributions for government and NGOs (Brinkerhoff 2002b). Meanwhile, above approaches of eulogizing of partnership are matched by some exceptions. For example, Cecchini et al. (2000) prepared a list of partnership pitfalls including an unequal distribution of power, hidden partners' prospects and loosening of organisational identity due to tied funding (Cecchini et al. 2000). Horton, Prain and Thiele consider partnership as inherently a conflict of interest problem with differing standards of accountability (Horton, Prain, \& Thiele 2009b). Although a significant number of studies illustrate diverse positive advantages of government-NGO partnerships it is necessary to take into consideration a discussion on partnership's failures to establish effective relationships. 
Effective partnership is a governmental intention and ability to engage in partnership with the NGO sector (Brinkerhoff 2002d; Moran 2006). Mayhew (2005) contends that effective collaboration is unachievable without a highly professional and independent civil society and a government responsibility to improve policy legislation. Others consider concrete recommendations for effective partnership. For example, Brown and Ashman (1996) analyse the role of social capital in successful partnerships founded on the mutual partners' ability to affect each other. Likewise Hudson and Hardy (2002) have a more practically oriented view and suggest six principals of effective partnership:

Acknowledgement of the need for partnership; clarity and realism of purpose; commitment and ownership; development and maintenance of trust; establishment of clear and robust partnership arrangements; monitoring, review and organisational learning (Hudson \& Hardy 2002, pp.53-61).

In contrast, many scholars declare that there are no universal factors that could lead to effective partnership but the context of reality. Lewis (1998) considers partnership a contextually conditioned phenomenon defined by the environment and its existing demands. Thus theoretical factors of effective partnership should not be neglected but rather used as general guidelines. These precepts are based on the best development principals and could be adjusted according to partnership goals.

Assessment of partnership is illustrated with two main perspectives. Firstly, the theme has captured attention on an assessment of partnership outcomes. Secondly, it presents evaluation of partnership relationships as a means to produce positive outcomes. The outcome evaluation approach refers to general evaluation frameworks that embrace self-defined indicators directly aligned with the goals of partnership. For example, Brown, Tucker and Domokos (2003), Burch and Borland (2001) assess effectiveness of healthcare partnerships suggesting such performance measurements as a degree of availability of services and an indicator of quality of delivered resources. Greig and Poxton (2001) provide a more satisfactory indicator as patient's quality of life. A distinctive approach on evaluation of partnership was offered by Lasker, Weiss and Miller (2001). Inspired by Fawcett, Francisco, Paine and Fawcett, Taylor-Powell, Rossing and Geran, the scholars advanced the concept of synergy: "the proximal outcome of partnership functioning that ... captures the mechanism that makes collaboration especially effective" (Lasker, Weiss \& Miller 2001, pp.182-183). The effectiveness of partnership increases a synergy that incorporates partners' reserves and abilities. In turn, it empowers partners to improve planning, analytical and 
communication skills. This approach whilst attractive has not undergone empirical testing.

The second perspective as represented in Provan and Milward (2001), proposes a model to assess public partnership relationships from community, organisational and network perspectives. Although the scholars demonstrated a number of precise indicators their work is often critiqued for a lack of recommendations for further improvement of partnership. Considering government-NGO interaction from the economic point of view Shah and Singh's supply-chain assessment framework stands out (Shah \& Singh 2001). The supply-chain performance is analysed with such evaluation measures as length of the supply chain stages, "internal supply chain inefficiency ratio", "internal supply chain working capital productivity" (Shah \& Singh 2001, p. 43). Unlike Provan and Milward findings, this framework helps to identify weak points in the performance and thus provides an opportunity to advance partnership effectiveness. However, economic tools should not ignore exogenous variables, for instance, the public sector and its non-profit nature. Brinkerhoff proposes an innovative approach that embraces an assessment of partnership relationships and outcomes in her “continuous, process-oriented and participatory, and developmental" evaluation model (Brinkerhoff 2002a, p.215). The model includes an assessment of correspondence with pre-conditions of successful interaction, extent of partnership (mutuality and organisation identity), partnership outcomes, performance and efficiency (Brinkerhoff 2002a). Despite all the benefits of the model like a systematic character, dynamism and methodological justification it did not find empirical support and was refused to be applied by non-profits and private companies for not being enough specific. To conclude, both perspectives contribute to a broader and deeper understanding of partnership effectiveness and thus will be equally advantageous in the evaluation process.

\subsection{Characteristics of Government-NGO Relationships}

There is little literature that analyses features of government-NGO relationships. Instead, characteristics of the relationships are embedded in a discussion around government-NGO interaction. Jennifer and Derick Brinkerkoff (2002d) attempt to systematise these observations. They ascribe blurring of borders between two sectors to one of prominent features of government-NGO relationships. The reason for this 
phenomenon is increased interaction between non-profit organisations and government in recent decades (Brinkerkoff 2002d). Despite the fact that the paper reveals roots of the features, there is no empirical testing of this hypothesis. Park (2008) undertook similar investigations, specifically cooperation patterns between the sectors. The scientist proved that in the result of cooperation between government and non-profit organisations boundaries become unclear, new "network structures" between the sectors appeared and importance of non-profits increases at the strategical and regulative levels (Park 2008, p.81). These findings also explained the existence of cross-sector strategic partnership framework. However, the fact that it was not considered in competitive environment indicates a limitation of the research.

Institutional isomorphism or homogeneity of structures and processes between institutions provides further insight into government-NGO relationships. DiMaggio and Powell (1983) analysed mechanisms leading to isomorphism and hypothesis that put pressure to adjust to new structures. Thus not just achieving of effectiveness but a lack of correlation between organisational ends and means, significant dependency on the other institution, high level of established objectives, importance in employing highly educated and professional personnel, active involvement in professional societies, high dependency of the sector upon one funding mechanism; a large number of agreements with government; inaccessibility of different organisational structures, technological issues are the preconditions of the homogeneity in the structure and processes in the organisation and industry (DiMaggio \& Powell 1983). Despite the reasonableness of presented discussion the hypothesis are not tested.

Isomorphism is regarded not necessarily as a concept with negative implications but also as the one that results in improving collaboration between the government and the NGO sector. On the one hand, academics such as Ramanath (2009), explain explicitly an ability of NGOs to copy governmental instruments in order to contribute to effective partnership, receive substantial financial resources and possibility to impact policy development. Bouget and Prouteau (2002) with their observations on European Union-NGO relationships proved that isomorphism could be considered as an immediate positive phenomenon in its ability to influence processes. On the other hand, Brinkerkoff (2002d), Heijden (1987) claim a serious problem with isomorphism stating that it leads to a high financial dependency and loss of organisational autonomy and identity. Kramer managed to depicture the whole problem with a colorful African aphorism "if you have your hand in another man's pocket, you must move when he moves" (Kramer 1981, p.158). Analysis of features of government-NGO relationship 
requires further empirical observations. Also this proves the fact about complexity of government- NGO relationships and particularly the case of the isomorphism.

\subsection{Partnership and Aid Effectiveness}

In order to better understand NGO-Government relationships in the context of modern international development practices and regulations it is important to consider international obligations and commitments, particularly those that belong to aid effectiveness. Recent international development agreements like the Paris Declaration on Aid Effectiveness, Accra Agenda for Action and Busan Partnership for Effective Development Cooperation are key documents within aid effectiveness. They were supported by the New Zealand Government and their principles were embedded into government's guidelines to increase effectiveness of NZODA.

In 2005 the Paris Declaration on Aid Effectiveness prompted developed and developing countries to "take far-reaching and monitorable actions", to deliver effective aid initiatives especially with a forthcoming examination of Millennium Development Goals (MDGs) (OECD 2005). It was based on principals of improved "ownership" of developing countries; adjustment of donors' assistance to national policies of countries receiving aid; "harmonisation" of aid delivery; enhanced results management and "mutual accountability" (OECD 2005). One of the significant advantages of the document noted by New Zealand Government was a practical aspect of recommendations and established line of concrete indicators to measure the progress (The New Zealand Aid Programme 2008). However, the same benefits are considered as a limited "technical approach" by some CSOs (ITUC 2008). The Busan Partnership for Effective Development Cooperation recognises the Paris Declaration as not paying attention to a diversity of development stakeholders (OECD 2011a). A recent OECD's evaluation report "Aid Effectiveness 2005-2010: Progress in Implementing the Paris Declaration" has revealed that only one ("co-ordinated technical co-operation") of 13 targets for 2010 has been achieved (OECD 2011b). Despite sharp criticism of the Paris Declaration it was an agreement that reflected topical issues of development with increasing global aid resources and a procrastination in achieving agreed targets.

Two years later, it was decided to hasten the progress on the Paris Declaration and the Accra Agenda for Action was approved at the Third High Level Forum. While it was still based on principals of the Paris Declaration, it addressed such challenges as 
"country ownership", "inclusive partnership", more effective accomplishing and reporting on development outcomes (OECD 2008). In terms of growing country's ownership, it recommended to developing country governments to incorporate CSOs, the private sector and other stakeholders into an active policy dialogue (OECD 2008). In terms of development of inclusive partnership it was agreed to establish a supportive environment for developing of partnerships, enhance the working processes of partners and attract "all development actors" (OECD 2008). A significant role was given to CSOs that were considered as equal contributors to development and thus engagement with the sector was considered important and should be empowered. The countriessignatories promised to "improve co-ordination of CSO efforts with government programmes", "enhance CSOs accountability for results", "improve information on CSO activities", "provide an enabling environment that maximises their contributions to development" (OECD 2008). Although CSOs were not signatories, they had a chance to contribute in the Forum discussion. More than six hundred CSO representatives addressed a statement to Third High Level Forum to acknowledge a role of the civil society and create an environment allowing them to participate in a dialogue at different levels (Better Aid 2008). An OECD evaluation report assessed the progress of Accra Agenda for Action. It presented mixed findings from great success in some countries to minimum advancement in other countries-signatories. For example, participation of CSOs in the policy dialogue varied from high engagement, to a limited contribution to policy development (OECD 2011b). Despite challenges and missing established targets within Accra and the Paris Declaration, OECD states that they have improved development practices and contributed to Istanbul Principles, the Bogotá Statement and the Dili Declaration (OECD 2013). OECD has also made a strong point arguing that the progress of Accra Agenda mostly depends on political will and the commitment of country-partners and developed countries to implement the agreement at the national and local levels.

The complexity of development challenges and the impending expiry of the MDGs in 2015 underpinned the Busan Partnership for Effective Development Cooperation that was agreed at the Fourth High Level Forum on Aid Effectiveness in 2011.With a shift from aid development to development effectiveness, co-operation and partnership have taken a "catalytic role" (OECD 2011a). The Busan Partnership is underpinned with principles of "ownership of development priorities by developing countries", "focus on results", "transparency and accountability to each other" and “inclusive development partnerships". The last principle includes "openness, trust, and 
mutual respect and learning [that] lie at the core of effective partnerships in support of development goals, recognising the different and complementary roles of all actors" (OECD 2011a, p.3). Understanding of development partners has been extended within the Accra Agenda and further reinforced with the Busan Partnership. There is now an emphasis on effective development co-operation between CSOs, the private sector, state actors, and different forms of public-private partnership as well as South-South and triangular co-operation (OECD 2011a). Significance of private sector organisations in development has increased. The role of CSOs as an independent actor is reinforced again but in comparison with an earlier agenda, there is there is little change. The focus is still on creating an enabling environment for CSOs and increasing their accountability. Moreover, the role of local authorities was stressed as a mediator in collaborations with the civil society and government to pursue established development outcomes. The Busan Partnership itself considers the agreement more inclusive in terms of development actors and complexity of co-operation. One of the achievements of the Busan Partnership was that CSOs officially participated in the Forum. Observers noted that the agreement brought a necessary focus on development and facilitated practical tools for better partnership (Bena 2012; Green 2011). In contrast, Bodo Ellmers from Eurodad critiques the Busan Partnership for a lack of framework for the private sector so that enterprises did not have to take any obligations and responsibilities. This also provided an access for many of companies to benefit from ODA. The advocacy officer further claimed that no particular indicators were established to help to achieve the Busan Partnership commitments and easily translate them into actions (Ellmers 2011). Taking into consideration all critiques, the Busan Partnership has managed to build a foundation for development co-operation between diverse groups of actors and direct them on achieving development effectiveness. Civil society, and thus development NGOs, have been accorded a more prominent role in ensuring development effectiveness than had been the case with the government-centred Paris Declaration. Thus, this analysis of international documents on aid effectiveness reveals that cooperation between the government and NGO sectors has lost its borders. The new era of development considers new actors like private organisations, state companies, and institutions key to shaping international development assistance. 


\subsection{Summary}

This chapter has presented a literature review of theoretical underpinnings of government-NGO relationships as well as their status in the context of international commitments of aid effectiveness. The analysis reveals a lack of a strong conceptual understanding of relationships between two sectors. Theories of government and market failures explain the genesis of government-NGO relationships. Although they do not throw light on government-NGO relationships they reveal weaknesses of government and private sectors thus leaving space for development of the voluntary sector. In this respect, Salamon's theory of voluntary failures and partnership gives a clear theoretical rationale of origin and interaction between government and NGOs. Later governmentNGO relationships were further theorised and framed into cross-sectoral models. Young's model stands out with its simplicity and extensive empirical data available for observation. Lewis's framework contributes to a better understanding of the nature and character of government-NGO collaboration. Both models will be further applied during the fieldwork. Najam's Four-C's model seems more practical than the other theoretical frameworks. It helps to investigate the relationships through the different prism of strategic institutional interests and thus could be used as an additional analytical instrument for description of the phenomena. Although Brinkerhoff's framework has several weaknesses it represents a high level of applicability in different fields and illustrates a very topical problem of government-NGO relationships around the dependency and loosening of organisational identity.

This literature review did not reveal a commonly recognised definition of partnership. Although definitions of partnership reflect the collaborative nature of the phenomena scholars interpret it in their own way pointing out certain partnership principles and features. A significant number of studies illustrate diverse positive advantages of government-NGO partnership describing them as the most gainful relationships between state and the NGO sector. Meanwhile, to pursue advantageous relationships it is necessary to take into consideration a discussion of partnership failures. In order to achieve that successful partnership scholars offer general and quite concrete factors of effective partnership. Government and development NGOs should recognise them as guidelines that are based on the best development principals and could be adjusted according to partnership goals. The assessment of successful partnership is considered from two perspectives, partnership outcomes, and the process that produces positive outcomes. Each perspective contributes to a broader and deeper 
understanding of partnership effectiveness and thus will be equally advantageous in the evaluation process.

Academic literature does not illustrate a large number of research works dedicated to an in-depth analysis of features of government-NGO relationships. Most distinguished features of partnership recognised a blurring of borders between sectors and dynamism of the relationships.

Considering NGO-Government relationships in terms of international obligations of aid effectiveness, it becomes obvious that within a last decade the partnership concept has increased its significance in development. However, within the new era of development the partnership focus has shifted to more inclusive cooperation, not only between government and CSOs but also private organisations, state companies, institutions and other players that also shape the character of partnership and international development assistance.

The literature review findings contribute to better understanding of the reality of the relationships between New Zealand development sector and Government. The absence of consensus on concepts of government-NGO relationships signifies a necessity to look at the relationships from NGOs and government perspectives. That will be achieved through conducting semi-structured interviews with the New Zealand Aid Programme and the development community. Theoretical considerations of partnership outcomes, instruments to achieve effective partnership and different assessment framework help better analyse partnership relationships from the perspective of NGO's recommendations on improving relationships with Government. In addition, new directions of aid effectiveness will contribute to better understanding of the changes to the NZODA policy and determine if there were any influences. 


\section{CHAPTER THREE - RESEARCH DESIGN}

\subsection{Introduction}

The chapter provides an insight into the research design of the study starting with a description of philosophical assumptions, ontology and epistemology of the research followed by the researcher's positionality. Then the methodology and methods such as semi-structured interviews, documentary review and quantitative methods are discussed. The process of selecting participants for interviews and processes of data collection and analysis are then outlined after a presentation of the semi-structured interview method. The chapter finishes with ethical considerations and limitations of the research.

\subsection{Philosophical Assumptions}

Any research project is grounded on two essential philosophical assumptions: ontology and epistemology. Ontology determines what the researcher's views are on reality and the world. In other words, what are his/her assumptions about the nature of the world that he/she examines and relates to. Different systems of researchers' convictions were formed under different philosophical theories and paradigms. Epistemology is distinguished from ontology in a way that it answers a different research question. It looks at how an investigator considers and obtains knowledge about the world. Maynard gives the most complete definition of epistemology claiming that "epistemology is concerned with providing a philosophical grounding for deciding what kinds of knowledge are possible and how we can ensure that they are both adequate and legitimate" (Maynard 1994, p.10). Certain assumptions about the nature of knowledge and its relationships with a researcher were conceptualised in different philosophical stances. Objectivism and subjectivism are the most common among them.

A representation of research philosophical assumptions is important due to several reasons. First of all, a chosen philosophical stance helps to understand a researcher's position on reality and knowledge thus to determine under what perspective the research question will be answered and how the investigator will deal with the data. In other words, "how should observers of our research ... regard the outcomes we lay out before them? And why should our readers take these outcomes seriously?" (Crotty 
1998, p.2). The second reason lies in a justification of a chosen method and methodology of the research work. A philosophical paradigm creates a foundation of the research design and guides the scholar to adopt a certain methodology and methods.

\subsubsection{Realism and Modified Objectivism}

This research is couched with a realist paradigm. This philosophical concept was applied to the study since it fits closely the researcher's views on understanding and explanation of reality, knowledge, society and a role of a researcher.

Realists believe that the real world is a complex system that is independent from our observations, beliefs and knowledge about it (Partington 2002; Outhwaite 1987; Boyd 1983; Gregory et al. 2009). An initiator of the philosophical movement of critical realism, Bhaskar states that the "world consists of things ... [that] are complex objects, in virtue of which they possess an ensemble of tendencies, liabilities and powers" (Bhaskar 1975, p.51). It is important to notice that realists agree not only on understanding complicated reality but also on the fact that some of these structures still subsist even when a researcher does not know about their existence. This argument leads to a conclusion among followers of realism that theoretical knowledge is limited by the nature of the reality. Since knowledge is based on observed phenomena it is limited by an ability to identify things (Boyd 1983; Bhaskar 1975). Thus, knowledge as a social product is relevant but not absolute. It "consists in some sense in the permanent and cumulative capture of true propositions corresponding to the world" (Hesse 1974, p. 290).

Realism gives a crucial role to human experiences in social sciences. Realists claim that "society does not exist independently of human activity" (Williams 1981, p.36). Recognising the empirical world, realist philosophy goes one step further from a positivist perspective. For example, Blaikie describes this world as the world of human experiences gained by using different senses (Blaikie 2007). In the realist's empirical world "[participant's] perceptions are being studied because they provide a window on to a reality beyond those perceptions" (Healy \& Perry 2000, p.120). Participants' views being initially subjective are a part of the reality and thus an object of the current study.

The other reason of appealing to the realist ontology is its stand on causal relationships. Realists aim to investigate social facts through the uncovering of causal relations (Lawson \& Staeheli 1990; Sayer 2000). It is important to notice that the 
philosophy not only determines cause and effect relationships but also investigates the nature of change. According to Sayer a realist analysis includes "finding out what produces change, what makes things happen, what allows or forces change" (Sayer 1985, p.163). An idea of characteristics or tendencies of research objects that generate cause effect chains was named by realists as a generative mechanism. Understanding features of objects through the generative mechanism helps to explore complex causal effect relationships and reveal new causalities and early unobservable consequences. The nature of the current research topic is also represented by complex state-NGOs correlations some of which are unknown and expected to be detected. Also realists state that a society is an open system and cause effect relationships depend on a context. As Healy claims "social phenomena by their nature are fragile, so that causal impacts are not fixed but are contingent upon their environment" (Healy \& Perry 2000, p.123).

A realist's research goal reflects the goal of the current study. A realist approach aims to investigate processes and relations within a particular space and time frames (Lawson \& Staeheli 1990). Outhwaite very precisely determines a role of a researcher claiming that "the social scientist will typically seek to redescribe ... an object so as to bring out its complexity, the way in which it is determined by its internal and external environment as an outcome of a multiplicity of interacting tendencies" (Outhwaite 1987, p. 57). This goal is determined in the study in a way of examining the complexity of relations between changes to the international aid policy and their impacts on local NGOs in a context of New Zealand political transformations. The main indicative output of the research is to produce a high quality analysis and knowledge that will be beneficial to the development field.

From the above discussion and the nature of realism philosophy, it could be stated that the epistemology of the research project is modified objectivism. This epistemology rests on an assumption that "findings [are] probably true" (Healy \& Perry 2000, p. 119). In this research project the researcher considers knowledge outcomes as not absolute truth but an attempt to get closer to the reality of the impact of political changes on the development sector through NGOs opinions and experiences. In addition, modified objectivism states that it is impossible to be absolutely objective in a research work. This research project admits this fact and considers it as a limitation of the study that will be discussed later in this chapter. 


\subsubsection{Positionality}

A researcher's positionality has a direct impact on shaping the research bias and formulating research findings. "Positioning is ... the key practice grounding knowledge" stressed Haraway (1991, pp. 193). Rose further explained this argument noting that "position" indicates the kind of power that enabled a certain kind of knowledge" (Rose 1997, p. 308). To illustrate a researcher's positionality her professional background, field of interests and intentions will be demonstrated.

My professional background included work experience in regional government in the Russian Federation where I held an official government position for almost two years before coming to New Zealand. That experience has built my understanding on governmental procedures and processes that are a part of my general governance knowledge. To obtain practical experience in the international development field, I worked voluntarily for World Vision New Zealand and ChildFund New Zealand. During that time I came across the SDF and HRF in practice for the first time. I assisted the ChildFund New Zealand team in an application for MFAT grant funding, reviewed proposals and examined and implemented budgets. This experience gave me a great insight into working practices of an NGO and its collaboration with the Government. Being an insider in a public organisation and an NGO has expanded my vision of functioning and interaction of both sectors.

A passion for international development particularly for impact assessment and interest in NZODA policy have definitely narrowed my choice of themes for the thesis. A will to provide a practically applicable and useful research project for the development community and the New Zealand Government motivated me to choose the current theme of the research work.

\subsection{Methodology}

While philosophical assumptions define the theoretical perspective of the research, a methodology is a general approach or strategy responsible for a design of methods. It designates what method or a system of methods is the most appropriate for a particular research within a stated paradigm. It is necessary to admit that for some scholars a methodology should be strictly adopted according to a chosen philosophical stance. They consider a methodology as "macro-level frameworks that offer principles 
of reasoning associated with particular paradigmatic assumptions that legitimate various schools of research" (O'Leary 2010, p.88). However, the most practically orientated and predominant point of view on a methodology is its relevance to research objectives and feasibility of a fieldwork in sometimes complex environments. Thus the goal of a methodology is not simply to choose suitable methods but select those that will be the most effective for data collection and resolving a research question. Crotty acknowledges this viewpoint offering a valuable insight into a methodology. He states that "[it is] lying behind the choice and use of particular methods and linking the choice and use of methods to the desired outcomes" (Crotty 1998, p.3).

\subsubsection{Mixed - Method Approach}

A mixed-methods approach that has been examined by scholars for more than twenty years, takes its place between two competing philosophical lines: quantitative and qualitative stances. Thus mixed methods approach embraces both qualitative and quantitative methods. I find Chen's definition of mixed-methods research very compelling. He states that "mixed methods research is a systematic integration of quantitative and qualitative methods in a single study for purposes of obtaining a fuller picture and deeper understanding of a phenomenon" (Chen, cited in Johnson, Onwuegbuzie \& Turner 2007, p.119). This purpose of a methodology ultimately meets the objective of the current study - conducting a deep analysis and obtaining a holistic picture of the impact of changes to NZODA on the development sector.

The mixed methods approach is applied to the current evaluation and explanatory research project due to its methodological capacity to answer the research question. If initially an evaluation was based mostly on quantitative data recently it has included an application of qualitative findings. Hall argues that a reason for addressing qualitative methods together with quantitative methods is an opportunity to "tell the full story" (Hall 1981, p. 127). In the same way the mixed-methods approach enables a researcher to utilise quantitative as well as qualitative methods. The chosen methodology provides the evaluation research inquiry with necessary qualitative and quantitative information and thus gives instruments to a researcher to conduct a deep investigation, find observable and unobservable correlations, and answer the research question. Also taking into account the complexity of the research question it is appropriate to illustrate Hesse-Biber's view on the mixed methods approach that 
highlights that studies with a mixed methods methodology are more useful for resolving difficult research goals and objectives as they take into consideration the "the dynamic interconnections that traditional research methods have not adequately addressed" (Hesse-Biber 2010, p. 17).

The mixed-method methodology also forms a corresponding framework for data collection due to several features. Flexibility of the mixed methods approach allows a researcher to choose any method that is considered the most useful and effective for gathering data. Also due to Johnson's and Turner's fundamental principle of mixed research or as some other scholars call it a complementary strength, the mixed-methods approach makes it possible to apprehend different sides of a phenomena through improving strengths of one qualitative or quantitative method and neutralising weaknesses of the other one (Sale, Lohfeld \& Brazil 2002; Johnstone 2004; Madey 1982).

Despite the fact that the mixed methods approach is poorly explored within a realist paradigm, it is relevant and has common ground with main philosophical standpoints of realism. Considering the world as a hard reality that exists independent from human cognition and at the same time accepting, valuing human experiences, that are a reflection of reality, realism comprises both aspects of quantitative and qualitative research. Leaders in mixed methods methodology, Maxwell and Mittapalli, find realism as a "productive stance for mixed methods research" due to its ability to provide a greater cooperation between qualitative and quantitative stances and solve problems of other philosophical perspectives (Maxwell and Mittapalli n.d., cited in Creswell and Plano Clark, p. 45). Greene goes one step further claiming that the mixed methods approach is connected to realism through its one reasoning - getting closer to the truth. She also adds that scientists could get much better results by exercising different mixed methods (Greene 2008). This leads to a conclusion that the mixed methods approach empowers realists to answer a fundamental philosophical question of the absolute truth.

\subsubsection{Semi-Structured Interviews}

Due to its features a semi-structured interview is chosen as the most reliable instrument for collection of evaluation data and uncovering policy's impacts through a mirror of NGOs' experiences. Finding itself between structured and unstructured interviews, semi-structured interview is endowed with unique characteristics. It 
provides a researcher with flexibility to address open-ended questions in real time and in any order, not depending on an interview guide but rather "reading" a conversation and reactions of interviewees. Semi-structured interviews also give an opportunity to ask follow-up questions and keep open space for new issues not presented on the agenda but caused by importance of a discussed topic. This approach of building a dialogue through stabilising a balance of power between a participant and researcher allows an interviewer to go into the roots of a subject and gather detailed information. Harvey-Jordan and Long describe openness of semi-structured interviews in a very metaphorical manner arguing that "the frankness of opinions can get to the heart of the matter" (Harvey-Jordan \& Long, 2001, p. 219).

The characteristics of a semi-structured interview mentioned above reflect not only Kvale's 'construction site of knowledge' but also embody a construction site of experiences. By a construction site of experiences I assume a possibility to express opinions and attitudes freely. Echoing a realist approach, semi-structured interviews study a topic through investigating participants' world of experiences, attitudes and perceptions and thus help a researcher to get closer to the reality through a "window on to a reality" (Healy \& Perry 2000, p.120).

Semi-structured interviews are an appropriate method not only for explanatory and evaluation research but also for studying sensitive topics. Its ability to understand participants' needs and respond to them in an ethical and respectful manner enables participants to tell "the stories" and a researcher to hear "these stories" (Matthews \& Ross 2010). And I believe this is very topical for the world of political discourse that requires a genuine ability of respectful listening and dialogue. In addition, the format of semi-structured interviews fits the context of New Zealand's working culture. With its "frankness", semi-structured interviews perfectly project kiwi business culture that covers an absence of complex social and business norms, indistinct working subordination, informal style of business negotiations and relationships dominated by personal contacts and interrelations. Following the arguments presented above a semistructured interviews method is beneficial not only to the current politically sensitive research project but also fits the local cultural context. 


\subsubsection{Participant Sampling}

Participant sampling is a paramount factor that affects the quality of collected data and the whole research. For the particular research project a judgment or purposeful sampling technique was applied. This technique assumes that a researcher defines "the most productive sample" to achieve the research objectives by establishing a set of criteria for sampling and following the researcher's knowledge and judgment (Marshall 1996, p.523). To collect reliable data, a diversity of NGOs was taken into consideration and applied to the selection procedure. This included size, number and sectoral focus of activities, geographical focus of work, religious and non-religious basis of NGOs, registration status, year of establishment of organisation was taken into consideration and applied to the selection procedure. In total, twenty one New Zealand NGOs working in the international development filed were chosen based on relationships that they have or had with the MFAT. It is important to mention that receiving funding from the Government or participation in contestable funding were not

necessary criteria for the selection. The primary source of the selection of NGOs was a web portal of the CID and Charities Commission website.

In addition, a semi-structured interview with one the New Zealand Aid Programme representative was conducted in order to reveal relationship status between two sectors from a Government's perspective and present voices of both sides. 
Table 3.1 List of Interview Participants

\begin{tabular}{|c|c|c|}
\hline Code Number & Participant & Date of the interview \\
\hline Interview 1 & $\mathrm{NGO}$ & 16 November 2012 \\
\hline Interview 2 & NGO & 19 November 2012 \\
\hline Interview 3 & $\mathrm{NGO}$ & 19 November 2012 \\
\hline Interview 4 & $\mathrm{NGO}$ & 20 November 2012 \\
\hline Interview 5 & $\mathrm{NGO}$ & 22 November 2012 \\
\hline Interview 6 & $\mathrm{NGO}$ & 22 November 2012 \\
\hline Interview 7 & $\mathrm{NGO}$ & 26 November 2012 \\
\hline Interview 8 & NGO & 27 November 2012 \\
\hline Interview 9 & $\mathrm{NGO}$ & 30 November 2012 \\
\hline Interview 10 & $\mathrm{NGO}$ & 4 December 2012 \\
\hline Interview 11 & NGO & 11 December 2012 \\
\hline Interview 12 & NGO & 11 December 2012 \\
\hline Interview 13 & $\mathrm{NGO}$ & 13 December 2012 \\
\hline Interview 14 & NGO & 17 December 2012 \\
\hline Interview 15 & NGO & 18 December 2012 \\
\hline Interview 16 & $\mathrm{NGO}$ & 20 December 2012 \\
\hline Interview 17 & $\mathrm{NGO}$ & 7 December 2012 \\
\hline Interview 18 & $\mathrm{NGO}$ & 8 December 2012 \\
\hline Interview 19 & $\mathrm{NGO}$ & 11 February 2013 \\
\hline Interview 20 & NGO & 14 February 2013 \\
\hline Interview 21 & NGO & 23 February 2013 \\
\hline Interview 22 & MFAT & 28 March 2013 \\
\hline
\end{tabular}




\subsubsection{Data Collection and Analysis}

An interview check-list with thirteen general open ended questions was developed and sent to participants in advance. More detailed and follow up questions were asked at the interviews that normally lasted a bit more than one hour. Some of the interviewees dedicated up to two hours to these interviews. In general the development community showed a high level of response and interest in the research. Out of twenty six chosen NGOs twenty one organisations agreed to participate in the study.

It is necessary to mention that most of the interviews were conducted in person and at the NGOs' offices where it was more convenient for the participants and this enabled them to speak openly. To do this, researcher travelled to three towns. However, it was not always possible to do the interview in person and some interviews were conducted via skype calls, e-mails and phone. All the interviews were recorded and later transcribed.

It is important to notice that collecting data from participants who the researcher had already established relationships with was easier. Meanwhile, the majority of NGO representatives felt free to discuss the topic, sharing many confidential details. This was revealed not only in sharing a lot of confidential information from their practices and dialogues with colleagues from other NGOs and conversations with the MFAT staff but also in using informal language with lots of jargon, metaphors, epithets and humour. There was only one NGO representative who really watched the language and the speech had a formal character. When the recording was stopped the professional felt more relaxed and added extra comments.

Data analysis started with transcription of interviews and thinking of sub sections and extra emerging themes from interviews. It was decided not to separate information in the process of analysis to maintain the logic and meaning of raw data. Instead, coded notes helped to process information in excel format and to identify patterns or diversity of phenomena. A data analysis process was quite challenging due to a high volume of gathered information. The other challenge was a large diversity of collected data and a necessity to link it. The researcher had to constantly make sure that translated data and participants' opinions had the same meaning and the extracted quotes from the transcripts reflected absolutely the same sense in the thesis. The other difficulty was conflicting to each other statements of the same participant. In this case, a proper researcher's remark was outlined. 


\subsubsection{Documentary Review}

The documentary review included an analysis of documents from several types of sources. First of all, it included international and New Zealand legislation like MFAT's Statement of Intent, Cabinet's papers, New Zealand Aid Programme guidelines and other materials. Secondly, CID's surveys and annual reports, NGOs' annual reports were analysed to conduct an analysis of NGOs financial performances. Thirdly, civil society reports and findings contributed to the research projects.

\subsubsection{Quantitative Methods}

Some quantitative analysis was conducted based on descriptive statistics of aid and NGO data. Basic computer software including work with MS Excel was used to process collected information from interviews, to evaluate NGOs' financial data such as administration expenses, dependency ratio of New Zealand NGOs on government grants, total income of CID's members and allocation of NZODA. According to Vaus, importance of using a quantitative method is revealed in its ability to generate descriptive and fact-based data that represents "the hard evidence" (De Vaus 2002, p.5). Kelly stresses that "the statistical method takes into account at least implicitly the 'complexity, variability or uniqueness' of social phenomena” (Kelle 2006, p.305).

\subsection{Ethical Considerations}

Research ethics" or what Gray refers to as the "science of morality" is an important component of any research that provides security of a project to be conducted with a respect and responsibility towards its participants (Gray 2009, p. 69). To correspond to research ethics, the researcher had to meet Victoria University of Wellington Human Ethics Committee requirements for conducting research work. Other ethical considerations like sensitivity of the research topic for both NGO and Government sectors had to be acknowledged as well.

Receiving approval from the Human Ethics Committee before undertaking any fieldwork was mandatory because the University requires it for research that involves human participants. To obtain the University's permission to conduct the research, an 
application for approval of research projects and designed participant information sheet, consent form and interview checklist were submitted (see Appendix 1). These forms helped participants to understand the goal of the study, their role, conditions of voluntary participation and withdrawal and such important issues as security of data, confidentiality including coding of participants and using of quotes.

It is important to notice that the research theme is quite a sensitive topic (given the importance of government funding for many NGOs) and many participants required a verbal confirmation of confidentiality of the research findings before the interviews. It is necessary to stress that all participants who agreed to participate in the study allowed the discussion to be recorded and showed trust in the researcher. Only one NGO requested to see a draft of the thesis before an official submission. The researcher, understanding the rationale behind this, was absolutely happy to do this. To show appreciation to participants for their time and trust it was decided to send a summary of the results of this research so a graph for the email and post address was embedded into the consent form. An absence of a conflict of interest helped the researcher to deal with the sensitive nature of the topic more easily. To maintain professionalism and respect to NGOs and Government it was useful to remind myself constantly not to ask leading questions or express opinions while conducting interviews. Also to reinforce constructive criticism of the Government policy, participants were asked to provide examples. In addition, questions if NGOs experienced any positive influences or any other consequences were addressed.

The interview with the MFAT representative required particular attention and a different approach. An information sheet, consent form and interview check list were specifically developed for MFAT (Appendix 1). In designing questions for the MFAT official, the researcher had to keep in mind that the officer would be able to present only the views of the Government, so questions that included personal opinions were excluded from the interview guide. Addressing questions during the interview, it was important to remember to avoid any follow up questions that might require personal views of the official on the investigated subject. It was also requested to review the draft of the thesis by the Government before its public submission.

\subsection{Limitations of the Research}

The research project has its limitations like a problem of subjectivity, attribution, selective representation of research findings and limited qualitative analysis. 
Despite the fact that the research project is founded on the realist paradigm the work could not be considered completely objective. In fact, any evaluation will include subjectivity and tell a story of an investigator. Moon, Dillon and Sprenkle (1991, p.174) explains this with the "inability of the observer to be wholly separated from the observed". The other issue was a problem of attribution that is recognised by many scholars as one of the most significant and common issues in the impact assessment process. Although it was seriously taken into consideration and the researcher tended to ask if an outcome was an impact of the policy, it was not always possible to track the correlation. Reported impacts that did not have a cause-effect relation with the NZODA policy were excluded from the observation. However, sometimes it was hard to define interdependence even by participants themselves. In these cases the influences were not taken into the scope of the research work. For the most part, it is acknowledged that the impacts observed in this research are those that were perceived and articulated by the NGOs, rather than any quantitative measurement.

A possible limitation of the work is an inability to present a detailed picture of the impact of the changes to the NZODA policy on New Zealand NGOs due to the word limit for the thesis. Rather than present every response on all matters discussed, it was decided to outline only the main trends and impacts. To fulfill this task the researcher analysed influences according to a number of organisations that pointed out the same or similar impacts. In addition, significant impacts on the organisations were evaluated even if they were identified within one or two NGOs.

It is also important to notice that the research project aimed to evaluate the impact of the policy on NGOs development work from quantitative and qualitative perspectives. However, often qualitative analysis was limited due to the researcher's obligation to keep participants' names confidential, so some responses could not be used as the detail may have revealed the respondent.

\subsection{Summary}

The research is grounded on the realist paradigm with the modified objectivism epistemology. The most effective methodology chosen for answering the research question was the mixed-method approach with semi-structured interviews, documentary review and quantitative methods to assess the policy impacts on local NGOs and explain findings with descriptive statistics and NGO's experiences. Judgment or 
purposeful sampling technique was applied for choosing participants of the research project. Positionality, ethical considerations and limitations of the research were briefly illustrated in the section as well. 


\section{CHAPTER FOUR - CHANGES TO NEW ZEALAND AID POLICY SINCE 2008}

\subsection{Introduction}

This chapter gives an insight into the main institutional changes, the policy objectives together with new focus on effectiveness, efficiency, accountability and new funding systems for NGOs. A response to these changes from New Zealand aid community perspective will also be considered. It provides the background from which the impacts can be identified and analysed in chapters five and six.

\subsection{Institutional Changes}

The National Party started its reform of international development policy with fundamental changes to NZAID in April 2009. New Zealand's government aid agency, NZAID, had been established in 2002 as a semi-autonomous body to put in place recommendations on improvement of NZODA from a number of reviews at the time. It had adopted a strong poverty focus as its guiding principle, it moved to a tighter geographical focus and, significantly, it strengthened its relationships with civil society to help deliver a wide range of aid programmes. It oversaw a large increase in the aid budget during the 2000s. In 2009 NZAID was effectively disestablished as a semiautonomous agency and brought back within MFAT. The role of delivering NZAID's functions was given to the new International Development Group (IDG) within MFAT. However, while the semi-autonomous status was lost, the ODA budget vote was preserved and even increased slightly in absolute terms, even if this represented a slight decline in the aid budget as a percentage of GNI.

Reasons for these changes are presented in New Zealand Cabinet papers. According to one of the papers there was a need to reduce high "transaction costs", mitigate "accountability risks", standardise the MFAT's structures "in terms of being a department that administers multiple programmes" and "maintain the benefits achieved in recent years for aid delivery that aims to be in line with international best practice" (New Zealand Government 2009a, s.42). These decisions drew upon on a report in 2008 from the Auditor-General and feedback from Ministers and other stakeholders. The institutional arrangements were also issued in consultation with the State Services 
Commission and embraced some views from Treasury, even though these were equivocal about the proposed gains to be made from the reintegration.

One of the main and most significant changes that led to criticism from the development community was the alignment of NZODA with wider New Zealand foreign policy objectives. According to the Statement of Intent NZODA is determined to assist MFAT's mission which is that "New Zealand's security and prosperity interests are advanced and protected, our voice is heard abroad" (MFAT 2008, p.6). Similarly, the Cabinet's paper three on Mandate and Policy Settings outlines "New Zealand's ODA outcomes should be consistent with, and support, New Zealand's foreign policy and external relations outcomes under the direction of the Minister of Foreign Affairs" (New Zealand Government 2009d, s.4). Meanwhile, the foreign policy objectives in the Pacific are targeted firstly to contribute to its prosperity and stability, secondly to increase population's self-reliance, thirdly to "minimise influences that do not have the best interests of the region at heart" and finally to promote national interests in particular areas (New Zealand Government 2009c, s.1). These statements marked a clear shift away from the overriding poverty focus and indicated that the aid programme was to be used explicitly to further New Zealand's economic and political interests.

The international development policy statement reinforces and further explains this concept. The core idea behind the alignment of ODA and foreign policy is the contribution of NZODA through reaching effective development outcomes (New Zealand Aid Programme 2011). The alignment of policies is particularly sought in the areas of investment, trade, migration and environment (New Zealand Aid Programme 2011). The Government also aimed to apply New Zealand's advantages and expertise to solving partners' development issues and needs. Graphical alignment of New Zealand foreign policy, comparative advantages and development needs is illustrated below (see Figure 4.1): 


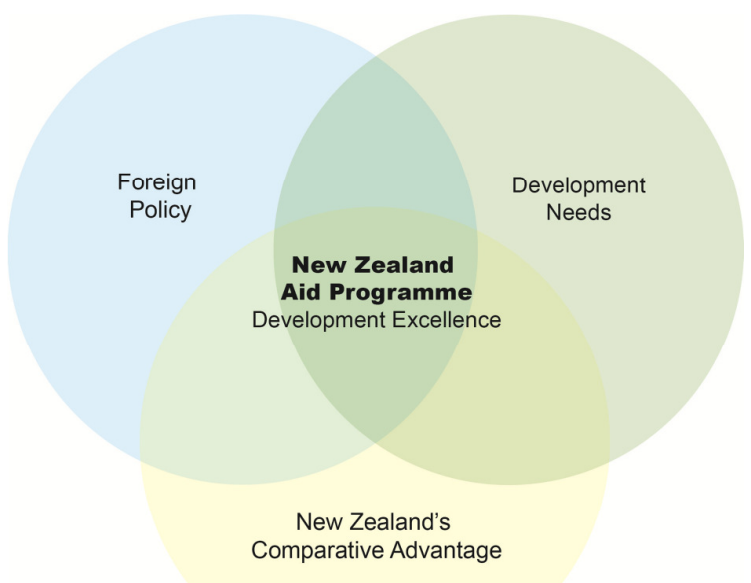

Source: New Zealand Aid Programme 2011

\subsection{Policy Objectives}

The other major change in policy setting was a shift in the mission and focus of NZODA. Within the previous policy setting prior to 2008 the NZAID vision was established as "a safe and just world free of poverty" with its main outcome of "poverty eliminated through development partnerships" (MFAT 2008, p.16). With the election of the National Party the mission of the New Zealand Aid Programme was reframed to "support sustainable development in developing countries, in order to reduce poverty and to contribute to a more secure, equitable, and prosperous world" with the central focus on sustainable economic development (New Zealand Aid Programme 2011, p.2). The economic focus was explained with an ability to increase trade and economic results (New Zealand Government 2009c) as well as alignment of the focus with "multilateral and regional engagements" (New Zealand Government 2009c, s.2).With this shift, poverty was shifted from being the core objective of New Zealand's aid efforts merely to being a desirable outcome of its new prime objective - sustained economic growth.

To support the sustainable economic focus the Government also introduced four core themes: "investing in economic development; promoting human development; 
improving resilience and responding to disaster; and building safe and secure communities" (New Zealand Aid Programme 2011, p.3). A strong role was given to the first theme that incorporates drivers and enablers of economic development that aim to promote business partnership in the Pacific and New Zealand. Drivers are defined as agriculture, fisheries, tourism and trade that contribute to food provision and significant increase of income. Enablers of economic development are classified as "transport services", "renewable energy" to reduce environmental effects and dependency on diesel and "business enabling environment" that is responsible for building the capable workforce, improving environmental standards and conditions for business startups and development (New Zealand Aid Programme 2011, pp.3-4).

Within the human development theme the major areas of development were left for "basic education", "secondary and tertiary education", "technical and vocational training", "scholarships", "good health", "water quality and sanitation" (New Zealand Aid Programme 2011). To improve resilience and respond to disasters MFAT focused on disaster preparedness, addressing humanitarian emergencies and "climate change adaptation" (New Zealand Aid Programme 2011, p.5). The last theme of pursuing secure communities embraces free elections and support of public sector and CSOs (New Zealand Aid Programme 2011).

As well as the above mentioned changes the stronger emphasis on the Pacific region was announced by the Foreign Affairs Minister McCully to a meeting of the New Zealand Institute of Foreign Affairs on 1 May 2009. By re-strategising NZODA to the Pacific the Government aimed to make "a significant difference to improving circumstances in our region and supporting the overarching foreign policy goal of securing the long term health and viability of countries in the region" (New Zealand Government 2009c, s.3). A target was set of 50\% of all ODA is going to the Pacific region, involving $80 \%$ of all bilateral funding. Meanwhile Polynesia was given $50 \%$ of the bilateral NZODA allocated to the Pacific (New Zealand Government 2009c). Another change was a rise in total NZODA and some redistribution of funding within bilateral, regional, multilateral, and NGOs assistance (New Zealand Government 2009b). Cooperation with the Australian Government in terms of development assistance in the Pacific and achieving MDGs was continued within new government Agenda (New Zealand Government 2009c). Alongside the MDGs were placed at the Cairns Compact and the Paris Declaration as guiding principles (New Zealand Aid Programme 2011). 
The increased attention to the Pacific was justified in MFAT's International Development Statement on the grounds of the serious problem of climate change, limited progress in achieving the MDGs, and the strong historical background and continued links with the Pacific region.

Asia, Africa and Latin America received far less attention and support within the new policy settings. Latin America and Africa were targeted for limited assistance mainly in terms of agriculture development initiatives, whilst Asian countries will be focused on education, disaster management, tourism, some infrastructure as well as agricultural activities (New Zealand Aid Programme 2011).

The size of the total amount of NZODA was also rescaled. Forecast of the NZODA according to MFAT's statement of intent within the last five years is illustrated in the table below:

Table 4.1 Size of NZODA between 2007 and 2012

\begin{tabular}{|c|c|c|c|c|c|c|}
\hline & $\begin{array}{c}\mathbf{2 0 0 7} \\
(\$ N Z \text { mill })\end{array}$ & $\begin{array}{c}\mathbf{2 0 0 8} \\
(\$ N Z \text { mill })\end{array}$ & $\begin{array}{c}\mathbf{2 0 0 9} \\
(\$ N Z \text { mill })\end{array}$ & $\begin{array}{c}\mathbf{2 0 1 0} \\
(\$ N Z \text { mill })\end{array}$ & $\begin{array}{c}\mathbf{2 0 1 1} \\
(\$ N Z \text { mill })\end{array}$ & $\begin{array}{c}\mathbf{2 0 1 2} \\
(\$ N Z \text { mill })\end{array}$ \\
\hline & & & & & & \\
NZODA & 358.80 & 428.80 & 494.48 & 474.86 & 537.14 & 562.39 \\
\hline
\end{tabular}

Source: New Zealand Aid Programme n.d; Office of the Auditor-General 2008

Cross-cutting strategies like gender equity, human rights and environment were key cross-cutting themes for NZAID before the change of the Government. The new policy settings reinforced these cross-cutting issues but "not as an end in themselves but as a means to ensure good outcomes and to manage risks" (New Zealand Government 2009c, s.5). The introduction of the cross-cutting issues was based on assumptions of fulfilling the international obligations and intentions to deliver good development practices and reducing the effect of development activities with negative impacts on the communities (New Zealand Government 2009c).

This approach was applied to the MFAT's country activities and programmes at feasibility, design, implementation, monitoring and evaluation (M\&E) stages. The aspects and guidelines were in details explained in Screening Guide for Cross-Cutting Issues, Strengthening the Integration of Cross-cutting Issues into the New Zealand Aid Programme -3 Year Strategy and other documents. 


\subsection{Effectiveness, Efficiency and Accountability}

Effectiveness, efficiency and accountability were stated as cornerstones of the new policy settings and the National Party agenda. Effectiveness in the NZODA context incorporates "more measurable and concrete development impact contributing to sustainable economic development and thereby changing people's lives for the better" (New Zealand Government 2009c, s.6). NZODA moved away from implementation of short-term and relatively small initiatives towards more long-term activities with bigger impacts. Particularly it was stressed that "support will be provided for large, longerterm, comprehensive initiatives which evidence proves are more likely to lead to effective results" (New Zealand Aid Programme 2011, p. 8). This involved the continued use of strategies such as sector-wide approaches. It was also stated that NZODA should be coherent with country-partner strategies and delivered through country-partner systems (New Zealand Government 2009c). The Cabinet paper explained the focus on effectiveness with an obligation to contribute to the Pacific and enhance the current situation, demonstrate efficiency and strengthen support of New Zealand people (New Zealand Government 2009c). It is important to notice that programme approaches are recognised as beneficial ones because they promote community ownership, reduce transaction costs, and promote "systematic development impacts" (New Zealand Government 2009c, s. 6). Yet one of the risks noted by the Government was a low capacity of the recipients and as a result a lot of administrative pressure on partners (New Zealand Government 2009c).

Efficiency is the other instrument of the new policy one of the goals of which is to reduce administration costs of NZODA. The Government assumed that "aid is managed efficiently with reducing overheads over time, as a percentage of an increasing ODA budget" (New Zealand Government 2009c) and this was expressed in terms of a 'value for money' concept:

Achieving the best possible development outcomes over the life of an activity relative to the total cost of managing and resourcing that activity and ensuring that resources are used effectively, economically, and without waste (IDG 2009, p.1)

In terms of development activities value for money should be taken into consideration at all project management cycles. It was also set to strengthen the efficiency and achieve it in business processes and operations within the MFAT and across the aid programme. The obligation to control overheads was given to the Treasury (New Zealand Government 2009c). 
Effectiveness and efficiency are underpinned with an accountability requirement that ultimately caused the necessity to improve monitoring and reporting standards for development initiatives. Government's strong focus on accountability was explained with a need to deliver effective and demonstrated results to the public (New Zealand Government 2009c). One of the additional outcomes that the Government is looking for is enhanced development learning across the New Zealand Aid Programme and ability to embed innovations through managing risks.

\subsection{Funding Systems for NGOs}

Funding schemes have been one of the main instruments of distributing NZODA to New Zealand NGOs. To obtain a full picture of the changes to the funding streams that influenced the relationships between the sector and Government a comparative analysis of six funding streams since 2008 will be illustrated.

KOHA-PICD, SDF, NZPFID

For many years, the basis of government funding for development NGOs was through the Voluntary Agencies Support Scheme (VASS). In 2006 this was renamed KOHA-PICD based on a 2004 review. KOHA-PICD involved the allocation of NZODA funding using a transparent set of criteria and an assessment panel made up of members from the NGO community and NZAID. CID took a central role in facilitating the process. In early 2010 the National Party Government notified CID of its intention to go away with KOHA-PICD and replace it with a new SDF in July that year. Then in 2012 SDF was in turn disestablished and the NZPfID was introduced to utilise "the expertise of New Zealand charitable, other not-for-profit, private, and state sector organisations to help achieve the objectives of the New Zealand Aid Programme" (MFAT n.d, p.4).

The purpose of the funds has changed as well. If the KOHA-PICD was targeted at enhancing people's lives in developing countries by fighting poverty in partnership with New Zealand NGOs, the SDF's purpose was shifted to delivering "effective activities that develop self-reliant communities and complement the New Zealand Government development priorities" (MFAT 2010a, p. 2; NZAID 2008). In 2011 the wording changed to again to providing "development outcomes in developing countries 
through partnerships with New Zealand NGOs" (MFAT 2011, p. 2). In contrast, the NZPfID's objective focused more on the mission and vision of the NZODA and included not only NGOs but other New Zealand organisations, such as the private sector. Thus the NZPfID is aimed to "support sustainable development in developing countries in order to reduce poverty and contribute to a more secure, equitable and prosperous world" ... by "encouraging partnerships between New Zealand organisations and in-country partners" (MFAT n.d., p.4). Correspondingly the focus of the KOHAPICD has shifted from poverty eradication to sustainable economic development under the SDF and NZPfID (See Table A.1 in Appendix 2 for a comparison of funding streams).

In terms of the geographic and focus area of activities KOHA-PICD programmes and projects included a wide range of basic needs, education, health, economic, environmental, good governance and other initiatives across a number of regions, including Africa and Asia. The SDF started to focus in a different way assigning economic development as the leading activity and health, education, basic human needs as well as protection communities from disasters initiatives as supporting activities (MFAT 2011). With the introduction of the NZPfID this focus area of the SDF programmes was continued. Whereas KOHA-PICD funded programes from different geographic locations and did not have any explicit restrictions, the SDF and later NZPfID established priority on the Pacific region with a stated target distribution of $75 \%$ of the government funding to go to the Pacific. Southeast Asia was left with $15 \%$ of the funds' allocation and the rest of the world category received a mere $10 \%$ proportion (MFAT 2011). This also was echoed in the matched funding criterion which requires NGOs to forward financial resources to the activity that is funded by government grants. Matched funding criteria used within KOHA was not embedded in the first and second rounds of the SDF but was returned in the third round of the same fund. It was also decided to retain this condition to the NZPfID as well. What has changed with the SDF and the NZPfID is the linkage of the matched funding to geographic areas (See Table A.1 in Appendix 2).

The funding mechanism within the KOHA-PICD and SDF/NZPfID varied from Block Grant (BG) and Individual Projects (IP) non-contestable system to a contractbased contestable nature (A graphic scheme of BG and IP is presented at Figure A.8 in Appendix 2). Funding under BG usually reached a maximum of $\$ 4$ million and in SDF a project ceiling was not established but preference was given to activities with more than $\$ 500,000$. Project duration lasted up to eight years within KOHA-PICD and this 
seemed to be continued in the SDF's focus on 'bigger, deeper and longer' activities. In the first and second SDF rounds projects were funded for three years at most and only in the last round were some NGO activities approved for longer periods. The same approach is retained in the NZPfID which aims to fund a maximum of five years activities.

Criteria for eligible activities have also changed from KOHA-PICD's promotion of self-reliance, community development and participation, addressing poverty and injustice and other principles (See Table A.1 in Appendix 2 for a full list of KOHAPICD principles) to SDF's and NZPfID's activities that are results focused, consistent with New Zealand aid policy and contributing to outcomes in the Funding Priorities Framework (See Table A.1 in Appendix 2 for NZPfID additional criteria). Gender, equity, environment and human rights are the mainstream strategies and issues of all schemes. In terms of eligibility of applicants, KOHA-PICD and SDF have considered submissions only from accredited New Zealand NGOs. NZPfID has extended this selection to New Zealand charitable organisations, not-for-profit, private and state sector organisations.

With the change from the BG and IP to the contract system, the application process, technical aspects and formats of the proposals, have changed. A decision making mandate went from the Programme Management Committee under KOHAPICD to a (Minister-appointed) 'Independent Panel' and later to an 'External Panel' within the SDF. In NZPfID this role is given to the International Development Advisory and Selection Panel (See Table A.1 in Appendix 2 for description of application and assessment procedures). Reporting requirements have become more detailed and results-based, and have grown through the three rounds of the SDF (See Table A.1 in Appendix 2).

\section{HAF-HRF-NZDRP}

In parallel with funding the development activities of NGOs, significant changes were made in the funding of humanitarian and disaster relief activities. The previous HAF was changed to the HRF in 2010 at the same time as the switch from KOHAPICD to the SDF. One of the main changes with the transition from HAF to HRF was a bigger focus on disaster response activities, pre-positioning of supplies for disaster response and delivering of "fast and effective relief, recovery and reconstruction via NGOs following a disaster" (MFAT 2010b, p.1). HAF had aimed to "save lives, 
alleviate suffering and maintain human dignity during and after emergencies" and allowed NGOs to fund different emergencies. With the HRF the Government started to define the emergency and what could be funded. The other main change between funds was a difference in the allocation mechanism. The funding under HAF was accessed by NGOs in advance so when an emergency happened approved NGOs already had available resources. HRF had a different contestable nature that allowed accredited NGOs to access funds after a disaster occurred by submitting an project application. The other important aspect was that HAF embedded disaster risk reduction (DRR) activities in its focus while under HRF it was given to the SDF (See Table A.2 in Appendix 2). With the introduction of the NZDRP in 2012 the focus of New Zealand humanitarian assistance has not changed significantly. Thus NZDRP included in its purpose providing effective assistance not only after natural disaster but also armed conflict (MFAT 2012a). Incorporation of DRR into the NZDRP is also one of the changes. Emphasis on the Pacific disasters was also mentioned in the guidelines. The matched funding requirement will be not compulsory for the Pacific region but required for the activities outside the Pacific. Funding will be still contestable.

The Strategic Policy Framework for relations between NZAID and New Zealand NGOs working in international development also deserves mention within this section. The strategic policy framework was signed in 2000 to underpin mutual work and strengthen relationships. However, it was not extended within the new policy agenda.

\subsection{Response of New Zealand Aid Community to Changes to the NZODA Policy}

The New Zealand development community has responded to these changes to the NZODA policy from the outset. The response varied from the position of noninteraction on the policy debates to strong criticism like online campaigns "Don't Corrupt Aid" and the Christian Micah Challenge. The "Don't Corrupt Aid" campaign involved a number of leading development NGOs and it tried to forestall Minister McCully's plans to reform the aid programme in 2009. It was critical of the proposed move to step aside from the poverty focus. One of the major expressed concerns was the abrupt nature of the changes to the NZODA policy that were not based on thorough 
reviews or proper analysis (Spratt 2012; Oxfam 2009b; McGregor et al. 2013; Challies, McGregor \& Sentes 2011; Bowden 2010; Stuff 2010). Spratt (2012) conducted an analysis of reasons for the implemented policy changes and came to the conclusion that there was an absence of any sound evidence for the changes. The development community was not satisfied with the fact that no consultations for the changes to NZODA policy were conducted (Spratt 2012; McGregor et al. 2013; Challies, McGregor. \& Sentes 2011; Pacific. Scoop 2009a). In fact, two meetings between CID members and the Ministry were not at all productive from the development community perspective (Challies, McGregor \& Sentes 2011). A lack of transparency characterised the policy transition (Caritas 2009b; McGregor et al. 2013).

The changes reoriented New Zealand ODA to situate it within policy priorities based on New Zealand's short-term commercial and diplomatic interests (Spratt 2012; Banks et al. 2012; Challies, McGregor \& Sentes 2011; TEAR Fund 2009b). Giving priority to New Zealand's foreign policy objectives this approach was regarded as "Doing Well While Doing Good" (Spratt 2012). Examples included subsidized Air New Zealand flights to the Pacific countries or a $\$ 1.3$ million programme bringing young business leaders from Asia, and these have caused concerns in the New Zealand development community. The community further stressed that the policy ignores best development practices (Sprat 2011; Banks et al. 2012) as well as beneficiaries needs (Caritas 2010b). Practical implementation of the policies was also questioned: "new policies ... may be contradictory and unworkable in practice” (Overton 2009, p.8).

A reintegration of the NZAID to MFAT was a common concern in the development community (Challies, McGregor \& Sentes 2011; Pacific.Scoop 2009b). High transaction costs and accountability problems associated with the semiautonomous status of the NZAID were not necessarily actual problems or good reasons for the change (Spratt 2012). Webster (2011) added that it could have been implemented better.

On the other hand, MFAT's statement to increase the size of ODA was very positively met by the development community: "we welcome the signaling of an increase in New Zealand's current aid spending” (Pacific.Scoop 2009b).

The shift to the economic development focus raised wider discussions and criticisms. It was argued that a major concern of sustainable economic development was a danger of dislocating resources from the poorest of the poor and undermining their needs in favour of the "elite or the middle class" (Spratt 2012, p.53; Challies, McGregor \& Sentes 2011; Harvey 2009). This could also promote social instability and political 
insecurity of developing countries (Overton 2009). UNIFEM representative claimed that "the reality of work with people at the grassroots, however, is that it is often necessary to focus on social and environmental development in order to progress to economic development" (UNIFEM 2010, cited in Challies, McGregor, \& Sentes 2011, p.18).

Likewise, funding schemes for NGOs were criticised for their uncertainty (Challies, McGregor \& Sentes 2011; IGPS n.d.), absence of any warnings (Challies, McGregor \& Sentes 2011; CWS 2010b), inflexible nature and one-off contract arrangement (Challies, McGregor \& Sentes 2011; IGPS n.d.). A lack of consultation, full guidelines, transparency of assessment process (Challies, McGregor \& Sentes 2011; McGregor et al. 2013; Development Action 2011) and funding allocations (Challies, McGregor \& Sentes 2011) were common views on the SDF and HRF. Apart from this the development community noticed delays in funding and cuts of resources that negatively affected NGO employees' salaries and delays in supporting partners (McGregor et al. 2013). As a result of SDF requirements, NGOs reoriented the geographical and sectoral shift of activities: "most NGOs have quietly shifted the thematic and geographic focus of their programs to be in a better position to compete for development funding" (McGregor et al. 2013, p.10). Volunteer Service Abroad (VSA) is a good example of this response. This NGO terminated its work in Africa and Asia and re-strategised its programmes to the Pacific: "VSA's new direction reflects the Government's focus on sustainable economic development in the Pacific, and its desire to provide more New Zealanders with the opportunity to volunteer" (VSA 2011). It was further explained that if NGOs intended to be successful they had to adjust to a new "language" of the current Government (McGregor and et al. 2013). Transitional funding was not available in the required amounts and activities supported by NGOs' independent resources were due to be finished in 2010 (Challies, McGregor \& Sentes 2011). Short time frames were also as being very challenging. In general, NGOs development work included fitting in to the new policy requirements rather than pursuing development goals (Banks et al. 2012).

Negative impacts on partners were revealed in increased pressure on staff and undervaluing local expertise (Challies, McGregor \& Sentes 2011; Spratt 2011; Bowden 2010). "This is placing extraordinary pressure on our staff and those of our partner agencies, as well as affecting project planning and design ...”, highlighted Caritas (Caritas 2010b). The introduced changes have also underscored a problem of high dependency of the sector on government funding. The other problem was excluding 
small NGOs from applying for grants due to a lack of capacity and resources (Challies, McGregor \& Sentes 2011).

Relationships with the Government were the other major concern of the development community. The partnership that had existed for more than 35 years, through mechanisms such as VASS, was dropped with the new policies (CWS 2010b). The strategic policy framework for relationships between NZAID and New Zealand NGOs also ceased to exist. Relationships evolved from collaboration to service contracting (IGPS n.d.; Banks et al. 2012). This shift with all its settings has placed significant tension on the relationships and undermined NGOs' value in development (Challies, McGregor \& Sentes 2011; IGPS n.d.; Banks et al. 2012; Wood 2011). NGOs have lost an opportunity to participate in policy development since the proposals they offered had little impact or application (Challies, McGregor \& Sentes 2011; Pacific. Scoop 2009a). They also did not receive adequate feedback on their policy recommendations (Challies, McGregor \& Sentes 2011) and reported poor communication with MFAT (McGregor et al. 2013). To improve the relationships the development community pushed for the re-establishment of a meaningful partnership with the government (Challies, McGregor \& Sentes 2011) and wanted acknowledgement of NGOs' contribution and value in implementation of ODA (McGregor n.d.). It was further suggested to advance New Zealand disaster response particularly its speed by conducting more thorough planning (Stuff 2010).

\subsection{Summary}

The political regime of the National Party Government has brought significant changes to NZODA policy. The changes started with the reintegration of NZAID into MFAT in 2009. With this, NZODA was linked much more explicitly to the foreign policy objectives of the Government and its focus moved from poverty alleviation to sustainable economic development. Changes were also marked with the re-strategising to the Pacific and increased allocation of ODA to that region. Cross-cutting themes have been viewed as means to an end and effectiveness, efficiency, accountability have become the cornerstones of the new policy. Within the last five years the main governmental funding streams of New Zealand NGOs have changed twice. The changes have affected the core nature of these schemes like a funds' purpose, focus, geographical areas, project criteria, mechanism of funding, budget and timeframes of 
the activities, application process and even the eligibility of candidates. The changes received quite strong criticism from the development community that claimed that new policy settings were abrupt and without proper review or consultation. The National Government policy was critiqued for the alignment of the foreign objectives with New Zealand aid policy and the unnecessary reintegration of NZAID into MFAT. Economic development was not widely accepted as an appropriate sole focus of NZODA and the funding schemes received many concerns and dissatisfaction as well. That had several impacts on development work of NGOs and partners on the ground. The major criticism of the development community was a weakened partnership with the New Zealand Government. Taking into consideration both official and critical sides we can ask: what did the NGOs themselves think of those changes and how did it affect their work? This will be further investigated in Chapter Five below. 


\section{CHAPTER FIVE - IMPACT OF CHANGES TO NZODA POLICY ON NEW ZEALAND NGOs}

\subsection{Introduction}

The following chapter illustrates NGOs' views on the main changes to the NZODA policy, its impact on their policies, operations and relationships with incountry partners. Given the concerns noted in Chapter Four above that were raised by sections of the development community in New Zealand in 2008-2010, it is now possible to see after some four to five years how the changes have become embedded with the development NGOs and what their reflections are on how they have worked out. This chapter draws directly from the interviews of representatives of many New Zealand development NGOs in 2012-2013.

\subsection{NGO Views on the New Policies and Instruments used by MFAT}

\section{Since 2008}

The section presents NGO perspectives, together with some comments from the MFAT staff, on changes to the underlying NZODA policy and particularly changes to the geographical priorities, sustainable economic development focus, and various funds available.

\subsubsection{Geographical Priorities and Sustainable Economic Development}

The geographical shift of the NZODA policy to the Pacific led to a varied response from the sector. Five NGO representatives argued in favour of the shift to the Pacific due to the small existing number of donors in the Pacific and acknowledging the region as a neglected area (Interviews 9, 12, 20, 21). One NGO highlighted:

The Pacific represents a very narrow donor call. There are only bilateral donors and the rest of funding is channeled through regional organisations (Interview 12).

Eight representatives indicated that they understood the rationale behind the geographical shift with regard to a Pacific-centric policy (Interviews 6, 9, 11, 12, 13, 14, 
15,16 ); indeed several referred to the Pacific as "our own backyard" (Interviews 6, 13, 16):

We are Pacific nation, a lot of New Zealanders are Pasifika. This is our place and we have a duty to respond to our neighbours (Interview 16).

The reasons other NGOs gave for supporting the shift to the Pacific were similar: they included a more logical and focused approach for New Zealand (Interviews 6, 11, 12) and its strengthened presence (Interview 19) viz-à-viz the growing Chinese influence in the area (Interview 17).

Three NGOs disagreed with the shift, highlighting the unequal percentage of geographical distribution of ODA, an excessive amount of financial resources and undercapacity of the region, the disregard of global poverty issues and the linking of ODA to New Zealand's national interests.

The major concern about the geographic shift was a limited capacity of the Pacific to absorb that level of increased funding (Interviews 3, 6, 7, 8, 13, 14, 15, 19) due to a lack of adequate civil society institutions (Interview 6), the absence of strong history of successful development (Interviews 14, 15), and the small scale of Pacific governments and their heavy burden of work (Interview 7). Among other concerns were a poorly designed shift to the Pacific and role of NGOs in NZODA (Interviews 6, 8,13), the fact that the Pacific already has the highest ODA per capita in the world (Interviews $3,7,10$ ), and the high proportion of SDF allocated per region (Interview 8, 10). In addition, NGOs described the current geographical shift as a narrow minded perspective (Interviews 1, 13) when larger areas of poverty in the world are ignored (Interviews 13, 19).

A discussion about sustainable economic development took place around its political underpinnings, role in development and poverty alleviation as well as confusion about the main theme that guides the New Zealand Aid Programme. The shift from poverty reduction to economic development was described by seven NGOs as a very political decision aligned with New Zealand foreign policy objectives (Interviews $7,9,10,11,13,15,20)$. It was stated that the strategy was not based on research or people's needs rather a "neoliberal agenda" (Interviews 10, 13, 20). In contrast, one NGO highlighted that a certain level of re-strategising was essential for the New Zealand Aid Programme (Interview 6) and another NGO found the change positive as the Government aligned activities to the joint commitment for development (Interview 7). 
The issue of the sustainable economic development focus led to varying reflections. Some argued that economic development and poverty alleviation are not mutually exclusive (Interviews $2,9,13,14,15$ ). In fact, economic development is an instrument for achieving a broader goal of poverty eradication (Interviews 2, 9, 13, 14, 15), aptly put below:

It is not easy like it or don't like it. It is not the point. The point is [that] in terms of poverty alleviation economic development is one subsection of that (Interview 13).

Others went further, noting that a healthy population, strong civil society, cohesive employment and improved women's status are prerequisites for economic development (Interviews 2, 5, 12, 15). One NGO representative depicted these components as building blocks of economic development: without reinforcing these elements sustainable development is not possible (Interview 12).

Several NGOs recognised economic development as a narrow minded objective that ignores a holistic view of people: (Interviews 5, 13, 16, 19) "it is important that we don't see people exist for [an] economy, we see that [an] economy exists for people" (Interview 19). Yet, other respondents indicated that economic development is a powerful instrument, "a compelling part of the pilot if driven at the right level can make a real difference" (Interviews 15, 16, 19).

The economic development priority has also caused some concerns in the development community. Several NGOs declared that the current policy has a real danger of not interacting with most vulnerable groups, so that the richer will get richer and the poor will get poorer (Interviews 3, 9, 8). Other organisations reported a vague interpretation of economic development (Interviews 2, 14). As a result, in the early rounds of the SDF NGO initiatives were related to economic development rather than were about economic development (Interviews 6, 14).

\subsubsection{SDF and HRF}

The SDF has received widespread attention from the NGO sector. The majority of representatives made similar observations about the nature of the SDF. Firstly, the new scheme was designed without an analysis of the KOHA scheme (Interviews 5, 6, $11,15,19)$. It was stated that MFAT did not have a true understanding of the direction, requirements or necessary infrastructure for successful implementation (Interviews 6, 11, 19). Secondly, the scheme was introduced abruptly (Interview 5, 7, 13, 15, 18, 19). 
The changing and reactionary character of the scheme from the first to the third rounds of the SDF and later to the NZPfID was mentioned by several NGOs (Interviews 2, 4, 6, 12, 17, 20). Thirdly, participants described ongoing uncertainty due to constantly changing policy settings. In particular, uncertainty associated with income, an ability to implement development activities and inform partners (Interviews 2, 5, 8, 11, 17, 19). Lastly, interviewees noted the shift to a rigid contract system (Interviews 2, 12, 15, 16) rather than a partnership (Interview 19):

This is also one of the biggest changes when you are contracted with the government to carry out their project. Before it was our project (Interview 2).

From the government side, the MFAT representative stated the change to contracting per activity meant NGOs had to upskill in contract management and understanding terms and conditions (Interview 22).

Other issues associated with the SDF were given as an absence of a learning platform (Interviews 18, 19), the creation of competitive hierarchical nature of the sector (Interview 19) and hard conditions for small NGOs to continue their work (Interviews 13, 19). Essentially the SDF was described as directive, opaque, and administrative- focussed (Interviews 2, 14). In essence it was a bureaucratic mechanism discouraging a bottom up approach (Interview 19).

In contrast, some NGOs ascribed benefits to the SDF: "[the shift was] painful at the time to change ... but it has created opportunities for discussion and development of the scheme", "including a broader thinking" (Interviews 14, 15). Some NGOs saw more benefits in the new processes (Interview 9) as well as an increased professionalisation of the sector with its own advantages and disadvantages (Interview 13). Many participants stressed that they simply had to adapt to the new requirements (Interviews 2, 10, 16).

Interviews with research participants highlighted a significant fundamental shift in the HRF mechanism as well as both its weaknesses and positive experiences. The shift to the HRF scheme was depicted as a very limited humanitarian role when only emergencies that receive New Zealand's attention and are categorised as requiring response could be assisted (Interviews 11, 12, 16, 18). A significant change in the HRF's mechanism was an event-by-event clause for applications (Interview 13, 19). The HRF was recognised as a very reactive political (Interview 18) and media-driven instrument (Interviews 16, 18): "if it is not enough media Government doesn't give funds" (Interview 16). As a result, NGOs argued that complex, nasty and forgotten emergencies were not accounted into the scheme (Interviews 12, 16, 18, 19). Describing 
the problem from a development perspective a participant stressed: "the greatest need does not get the greatest media coverage" (Interview 11).

Timeframes were the other constraint. One NGO representative stated that there was a long decision-making process on the application. Two NGOs agreed mentioning that "HRF was supposed to be a more rapid response ... [but] it was so slow" (Interviews 12, 16). The other issue with timeframes was MFAT's late call for proposals (Interviews 12, 19):

Call went very late. It was a case of not having an access to government funding (Interview 19).

Other weaknesses were no admission of NGO humanitarian funds sent before MFAT's call for applications as matched funding and an inability of small NGOs with a good access to remote areas to access government funds (Interviews 18, 19).

Some positive experiences were also collected. Moving DRR to the SDF scheme as a long term development issue was considered as a positive change (Interviews 4, 19):

It opened new avenues for us ... The HRF promoted further learning on the ground, pointed out some mistakes, helped to implement activities in a short time (Interview 4).

Two research participants mentioned that Government responded to criticism of the HRF slow processes by speeding up the following round (Interviews 9, 16).

\subsubsection{NZPfID and NZDRP}

Interviews with research participants revealed that the NGO sector did not hold identical convictions on NZPfID. In fact, the development community was more conscious about conceptual underpinnings of the scheme and their practical implementation.

One NGO described the NZPfID as a demotion of good practice (Interview 2) and other representatives wished for changes (Interview 4) including a return to the KOHA scheme (Interview 3). A lack of a thorough initial analysis of the scheme, grounded policy frameworks and implementation strategy of the NZPfID were recognised common issues (Interviews 5, 7, 9, 15):

Partnership fund is a very good theory that hasn't been fully thought through in terms of implementation (Interview 15). 
The other concern was a lack in the clarity of what exactly the new scheme is funding (Interviews 16, 20). A difficult position of small NGOs to compete was also mentioned by several NGOs (Interviews 1, 3, 6, 17).

Three representatives of the development community did not see a lot of changes in the new scheme. Instead, NGOs were urged to be more pragmatic about the NZPfID and apply when NGOs have synergy with the government policy (Interviews 2, 12, 14). Reasons for NGO non-participation in the NZPfID were the heavy workload of the SDF (Interviews 2, 13, 14, 19), a need for additional time for preparation (Interview 10,12 ), inconsistency of the matched funding requirement (Interviews 6, 13), and a philosophical mismatch between Governmental and NGO goals (Interviews 2, 4, 18). Other NGOs did not know what to expect and considered an attempt unfavourable (Interviews 3, 19).

It was stated that there are some positive features and a clear rationale behind the NZPfID (Interviews 9, 15, 17, 18). One NGO stressed "I like the concept of it" (Interview 15), the other NGO saw a positive moment in aligning with a company that could provide technological assistance (Interview 18).

An inclusion of the private sector was at the centre of the discussion but responses were mixed. Three representatives noticed that NGOs should not compete with the private sector (Interviews 2, 13, 20): "people from the private and state sector just do not understand our industry" (Interview 2). In contrast, the other participant argued that "other players cannot be involved because they do not understand ... maybe they do. Getting different points of views could be beneficial" (Interview 14). Two other NGOs found the NZPfID an interesting experiment where NGOs should not be exclusive (Interviews 12,16). While two NGOs saw a niche where the private sector adds value (Interviews 6, 13) one NGO expressed confusion:

Private sector is saying: 'what do you want from us?' And we are saying: 'what do you want from us?'... Lets' work together but still there is a lot of misunderstanding (Interview 13).

NGOs showed doubts about the interests of profit making companies and their commitment to do development (Interviews 1, 4, 11, 19). Questions like "where does a company have to make profit? How do you match the profit with development? Where does it go, who gets it and how it is used?" were often asked (Interviews 7, 10, 18, 20). Three respondents stressed that despite the fact that both players contribute NGOs are not allowed to receive the profit (Interviews 7, 18, 20). 
According to the interviews, partnerships between NGOs and the private sector remain a major issue of the NZPfID. A NGO representative called the NZPfID a consortium fund rather than a partnership. Partnerships are built long before financial relationships start whilst "here is all the way around" (Interview 5). The other NGO stated:

True development happens at the intersection of government, NGO and the private sector, and what wasn't thought through is how each of those sectors can be true to their sectors and objectives (Interview 15).

Partnership should not be forced. It is attained if the private sector has a similar philanthropic outcome (Interviews 13, 14, 18). Several NGOs found it hard to engage with private companies (Interviews 6, 12). While one NGO highlighted that a responsibility for finding a partner belonged to NGOs (Interview 13), the other NGO felt that an intention to collaborate in the NGO sector was based only on getting funds (Interview 21). NGO partnering with an enterprise stressed that an application failure was disruptive for future collaboration (Interview 20).

MFAT's official described advantages of the fund as more New Zealand organisations contributing to development and this approach would leverage New Zealand expertise and strengthen collaboration (Interview 22).

Since the NZDRP underwent only few changes the development community did not have many comments. Most of them echoed those for the HRF fund. Several NGOs described the NZDRP as a reactionary mechanism (Interview 18) that made one NGO feel behind (Interview 7). Although one participant stated it worked well (Interview 19) complex emergencies were not taken into consideration (Interviews 18, 19), time frames were short for designing an application (Interview 15) and for fitting matched funding criterion (Interview 18). These NGOs also found that disaster preparedness did not fit easily into the scheme (Interviews 15,18 ).

When MFAT representative was asked about possible impacts of the New Zealand Disaster Response Fund on NGOs the official stated that it was too early to comment as it had only recently been rolled out. However, early indications are showing that the New Zealand Disaster Response Fund is delivering on Government's priorities particularly focus on the Pacific; increased effectiveness of joint New Zealand government response mechanisms; and effective and timely response including mutually agreed time frames (Interview 22).

To conclude, there was no strong unanimous view on the changes to the NZODA policy. Instead, NGOs' opinions varied from high skepticism and positive 
considerations to a clearly distinct rationale with a pragmatic approach to adjust to the changes.

\subsection{The Effects on NGO Operations and Policies}

This section reflects influences on NGO development activities, development instruments and impacts on organisational processes of New Zealand NGOs.

\subsubsection{Impacts on NGO Development Activities}

The number of development activities funded by government was analysed and four trends were apparent. The first one applied to five NGOs that did not experience any fluctuation in the number of activities. The second describes six organisations that indicated a decrease in a number of activities approved by the Government. The third one involved three NGOs that increased their portfolio after a significant drop in the number of projects. Lastly, four NGOs had a significant increase in the number of activities.

The data does not have much meaning without describing funding scales of the activities and their correlation to development projects funded by independent sources. An assessment of governmental funding included only analysis of received government tranches. Four NGOs claimed that the policy changes did not affect the funding scale of development projects. For example, one NGO stressed "we have received the same amount of funding under MFAT but ... it has left us with poor programming portfolio" (Interview 12). The other two NGOs faced a problem of future SDF funding since the policy had changed and the activity no longer fitted later SDF criteria. The officer reported a reduced ability to develop new projects due to a loss of the Partnerships for Development window. NGO had to use supporters' money for project development rather than for matched funding (Interview 17). The fourth NGO highlighted "you cannot put in too much funding because it involves a lot of work" (Interview 4).

An increase in government funding was indicated by eleven NGOs. Many NGOs reported a bigger budget under the current schemes but fewer activities (Interviews 7, $14,18)$. One NGO noted that under the KOHA scheme it had had lots of projects but now it was in a stronger financial position (Interview 7). There were two cases when the 
SDF enabled two NGOs to extend projects. NGOs that reported receiving of bigger government funding raised some issues: "funding opportunities changed and it is so competitive to get significant amount from small funding window" (Interview 18). Indeed, the new scheme had NGOs starting to deliver less innovative and less risky projects; anticipating the compliance requirements of "projected outcomes" associated with any MFAT contract (Interviews 18, 19).

Five NGOs noted a reduction of ODA from MFAT (Interviews 5, 9, 20). One NGO found new donors or managed to maintain activities not financed by the Government with smaller funding. Meanwhile, NGOs stopped a partner activity (Interview 19) or tried to support the same number of partners but not at the same financial level (Interview 2).

Several NGOs commented on the transitional fund. Describing its impact on development work one NGO stressed that some activities were additionally funded but a project that did not receive bridging funds was finished (Interview 11). The transition period was critiqued due to its small funding pool, abrupt character, short coverage and a disruptive effect on overseas partners. A representative explained, "if you did have projects in the second of five year project that was it, you had to do your own arrangements" (Interview 14).

The impact on NGO financial performances differed from one organisation to the other one. In general, income streams of a majority of organisations underwent major cost reduction. The CID survey for 2011reported that total income for CID members was $\$ 187,970,000$ over the last year and exceeded the same figure for the previous year by $\$ 6.5 \mathrm{~m}(\$ 181,470,000)$ (CID 2011). According to 2012 CID's survey 2012 the total income reached $\$ 159,471,100$ last year (CID 2012b). A graphic illustration of NGO income over the last six years is represented in the figure 5.1. 
Figure 5.1 CID Member Income by Source 2005-2011

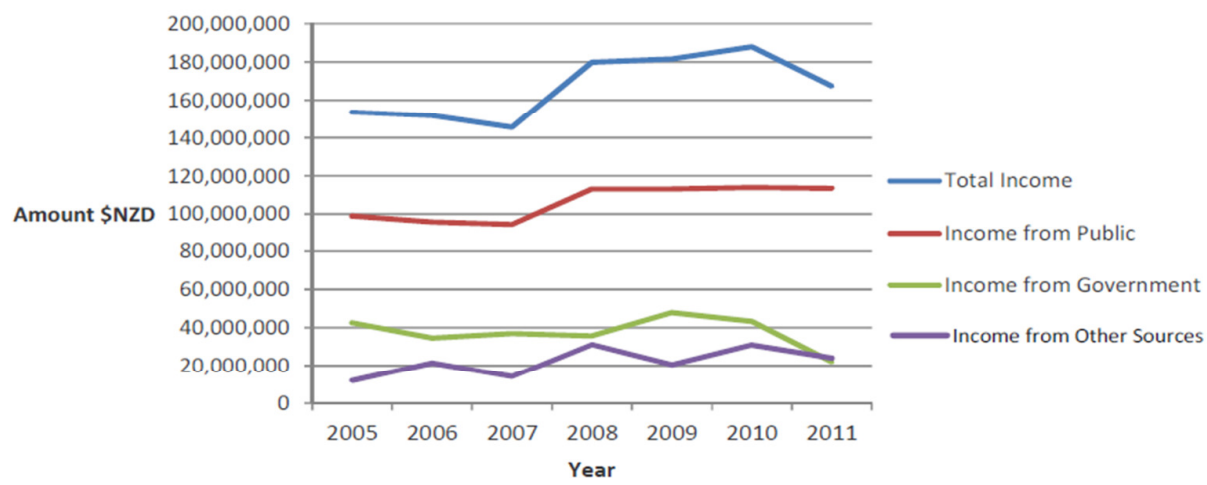

Source: $C I D 2012 b$

According to Figure 5.1, total NGO income was increasing within the stated period and only in 2011 had it reduced. The CID report explains it with a drop in government funding within last two years. This reduction might be not correct because of transition funding and "a lag effect when income has been received, but not spent at time of compiling" (CID 2012b, p.2). Government tranches for a period of eighteen months could also be an explanation. Since 2011, the SDF has provided the major source of aid distribution. Prior to 2011, MFAT's funding stream was the KOHA. Within the indicated period the main proportion of income was formed by public donations and this illustrates a high level of New Zealand generosity ${ }^{1}$.

Looking at the expenditure side of the development community it is important to examine administration costs closely since it was an often topic in the discussion. Five NGOs mentioned that a significant administration costs have been borne by New Zealand-based NGOs (Interviews 3, 11, 12, 15, 17):

There is so heavy administration with new schemes. If you look at what we paid people and what we get in return it doesn't make any sense (Interview 2).

This statement is not surprising due to the now defunct KOHA covered administration costs in its funding (Interviews 2, 12, 18). Consequently, recent analysis of administration costs has sought to quantify involved costs and time of such activities (Interviews 11, 15). Random sampling of 12 NGOs' administration expenses revealed that in 2009 eight NGOs increased administration costs by average of $27,5 \%$. The same figure went up by 29,5\% in seven NGOs in 2011. In 2012 five NGOs decreased the

${ }^{1}$ A detailed description of NGOs' income from New Zealand public and from the Government could be found in Figure A.1- A.7, Appendix 2. 
amount by average of $25,4 \%$ and five NGOs increased this number by $30,2 \%$ (See Table A.3 in Appendix 2). Collected data reflected just the trend of expenditures and should be considered with some skepticism since the methodology of consolidation of administrative expenses varied and included different reporting periods.

Similarly, NGO project costs are discounted in the new policy. "We moved from where we used to get assistance to NGO where we have to put significant money", "we are not even allowed to recover our costs" mentioned two interviewees (Interviews 18, 20). Meanwhile, the MFAT's twenty thousand dollars contribution for development of the final design was regarded as an amount that would just break within this total but not cover staff costs (Interview 18).

From MFAT's perspective the purpose for introducing matched funding was to leverage New Zealand public generosity and reflect a partnership approach. Meanwhile, this requirement caused a serious concern in the development community. Small NGOs were much more affected than bigger NGOs. A common impact was a reduced ability to apply for government grants (Interviews 4, 8, 11, 13, 17). Thus, as one NGO representative claimed, "it cuts back on projects we can apply for as it is no longer fully funded" (Interview 4). "We are getting increasingly more stringent on how many applications we can put into", mentioned the other participant (Interview 11).

There were other impacts on the NGO sector. Two participants claimed that they had to be more careful and look at the bigger picture (Interviews 13, 18). One of them explained that the organisation got up to its limit and had to sustain that limit without a possibility to grow further (Interview 13). In addition, one organisation developed relationships with new partners and aimed to start a new project but opportunities for funding were interrupted with the requirement (Interview 8).

In contrast, one NGO found the 'one to four' matched funding requirement a very helpful and positive experience (Interview 4). The other participant reported that because of a change in the SDF organisation, they were forced to acquire a new funding stream (Interview 8).

The effect of the policy on a focus of NGO activities like economic development, human development, resilience and responding to disasters, safe and secure communities was also investigated. Sixteen organisations claimed that the focus of development work did not change (Interviews 2, 3, 4, 6, 7, 8, 9, 10, 11, 13, 14, 15, 17, 18, 19). However, the way NGOs look at projects has changed (Interviews 6, 9, $13,14,19)$. One NGO had to establish links between health, education and economic development: "the core of projects hasn't changed but we added economic components 
[that would not be included otherwise] to have a better fit with criteria" (Interview 9). Other organisation reframed activities in terms of economic development and used it as a driver for applications (Interview 19). Often NGOs had to adapt a language of applications in terms of economic development, New Zealand comparative advantages, cross-cutting issues and relationships with in-country partners (Interviews 4, 6, 10, 13, 15, 16). Regarding the cross-cutting issues two NGOs experienced more troubles with projects that embraced gender or numeracy components (Interviews 11, 14):

Projects are harder. You have to see and touch things more now (Interview 14).

Four NGOs declared that the focus of activities changed from some extent to a very significant change (Interviews 1, 5, 12, 16). In two cases half the projects were about sustainable economic development (Interviews 1, 16). The other NGO reported "now the projects we managed to get funding are very narrowly defined as economic development" (Interview 12). A participant explained it:

We have to take this economic development piece out and find it and turn it around MFAT's [requirement]. And then trying to put it back in and there are gaps and it doesn't quite fit. It challenges the way we work (Interview 12).

Four NGOs mentioned about positive effects of the SDF. Firstly, NGO field offices developed "really interesting projects" under the new scheme (Interviews 9, 15). Secondly, the SDF impacted across a wider partnership of an organisation and as a representative stressed "it has pushed us to become quite an expert in a certain sense of excellence which is [economic development]" (Interview 16). MFAT's official also reported that the priority of sustainable economic development meant that an increasing number of applications were focused on this rather than activities in other areas (Interview 22).

In terms of the impact on the geographical scope of projects, six organisations reported being directly affected. One of them outlined "we have had some partners who are probably our neediest partners ... we were not able to fund them anymore because they don't fit geographical area" (Interview 11). Two organisations defined no influence (Interviews 3, 15): "we are still able to get a broad geographic spread around the projects that we have. So it has not impacted us" (Interview 15).

Due to the policy changes, one NGO has stopped several projects and launched new activities in the Pacific (Interview 11). "We would never do anymore in Africa, and we would not focus anymore on Asia", stated the other NGO professional (Interview 7). Similarly one NGO highlighted "we are not growing Africa relationships anymore but 
our relationships in the Pacific" (Interview 17). Several projects in Africa and Asia also were closed by one more NGO (Interview 1). The other NGO would not have looked at Pacific projects if not the SDF emphasis on the region (Interview 10).

A discussion around the impact of the NZODA policy on project duration revealed no influence on some NGOs, effects on others in a way that organisations had to adjust to criteria, encouraging longer term and higher value activities. MFAT's official reported that due to this move, an increasing number of activities had become larger and of higher value (Interview 22).

Five NGOs claimed that project timeframes were not affected (Interviews 2, 12, $15,17,19)$. Often projects were the same under the KOHA or simply were in a line with NGO programmes (Interviews 12, 17).

Some NGOs claimed that they adjusted to the requirement or took it into consideration (Interviews 4, 6, 9, 20): "we had it at the back of our minds" (Interview 6). One of them began to fund longer-term projects. In contrast, some NGOs started to deliver shorter duration projects in comparison with the KOHA (Interviews 1, 5, 11, 14): "when it comes to a length [SDF activities] are actually shorter duration projects (Interview 14).”

Two organisations stated that SDF projects were mostly within three year duration instead of KOHA's five or eight years project cycles. Both of them wanted to implement longer activities (Interviews 7, 11). Here attention was attracted to an issue of inability to run more than three years projects under the first two rounds of the SDF:

We prefer five years but it wasn't permissible on the early stages of the SDF (Interview 11).

A challenge for some development organisations was a limitation of the three years project duration. Firstly, it was about developing a design that should work with timeframes. "It is a real challenge and that is why you are making sure you have realistic outcomes", highlighted a representative (Interview 16). Secondly, it was hard to start an economic development project with an expectation to be sustainable just after three years (Interview 11).

Conversely, several NGOs enjoyed the clearly defined objectives within the SDF project cycle (Interview 15). Several NGOs stated that the SDF project duration was a sufficiently long enough period to achieve the stated goals (Interview 17). Further, the three year contract was an embodiment of assurance and stability (Interviews 6, 10, 20):

It means you could be more engaged with the community, you can see results and you can monitor them over slightly a longer period of time (Interview 6). 
An indirect impact was identified in a changed NGO strategy of applying for government assistance. A common approach used by three NGOs was submitting fewer but bigger applications (Interviews 11, 13, 20):

We do try to go over $\$ 500,000$ projects because of the amount of funding that is available for large projects ... there is less competition. It is better to have fewer projects that are bigger because they are easier to manage (Interview 11).

In contrast, several NGOs adopted a mosaic approach to projects, elements that fitted SDF criteria were funded by MFAT, the rest by other donors (Interviews 13, 14). A very measured approach was deliberately undertaken by the other NGO:

So we are putting only projects that are going to succeed. This is competitive; we are going to be competitive. If this is an outcome we will exceed it. We will put whatever things that needed to be there to make this work (Interview16).

\subsubsection{Effects on NGOs Development Instruments}

A wide impact on development instruments of New Zealand NGOs and their incountry partners is illustrated in this section. Eight New Zealand NGOs claimed no changes in their development instruments, delivery, or design of their projects.

Two other organisations agreed that their project application and design became more professional (Interviews 8, 11):

More thought has gone into completing design and working with partners to do a needs assessment, in-country analysis and cooperation with stakeholders (Interview 11).

Four NGOs adapted their projects to the new requirements and templates (Interviews 4, 10, 17, 19): "we have to rephrase what our partners are giving to us into MFAT's templates. And that is not easy to marry" (Interview 19).

In terms of a concept note several development professionals stressed that it is not a bad thing (Interviews 10, 18) and did not require a lot of work from partners (Interview 13). In contrast, one NGO went through a very prolonged process of its negotiation (Interview 3). Meanwhile, MFAT had an intention to simplify the application process, acknowledge that full design as part of the initial application process was very time consuming. The application process now consists of a concept note with the aim of obtaining a business case with clearly stated outcomes to be achieved (Interview 22). 
In terms of changes in the participatory approaches there were not many impacts identified. One NGO started to engage more actively with partners and developed a set of partnership criteria (Interview 1). The other NGO stated that it still uses a participatory design in conjunction with impact studies and a thorough vetting process of potential partners

A widespread attention from the NGO sector was given to M\&E including an activity results framework. Two NGOs outlined that they did not change their practice very much in terms of $M \& E$ (Interview 3, 14). In contrast, three other participants adjusted to a higher level of accountability (Interviews 10, 13, 16,). One NGO developed new indicators for each project based on required outputs (Interview 6). The other organisation revised planning, monitoring processes and put in place a results management framework (Interview 1). Similarly, the other NGO is specific about how it will implement M\&E. It intends it to be based on records against budget lines in the fourth section under New Zealand based costs (Interview 7).

In general new $M \& E$ requirements have positively impacted many organisations and are considered professional and robust (Interviews 1, 4, 7, 8, 9, 11, 12, 13, 17, 18, 19):

It's good to know that you do make a positive difference a little bit more and celebrate success better (Interview 18).

MFAT explained that the focus on results right through the identification, design and implementation had provided greater ability for NGOs and MFAT to articulate results and demonstrate outcomes in a more tangible way. It had strengthened accountability (Interview 22).

NGOs also described challenges associated with M\&E: "it has become process driven rather than outcome driven. They wanted to make it easier but implementation got lost" (Interview 15). In addition, increased results measurement requirements from SDF One to SDF Two and Three have put huge pressure on several NGOs (Interviews 13, 15): "if they grew any further it would be unwarranted pressure" (Interview 13). One development practitioner offered a solution: "they should be looking at the governance level indicators at a higher level and if any issues come through ... then drill down" (Interview 15).

The results measurement table generated discussion. It considered by several NGOs as both challenging and beneficial to their business (Interviews 4, 6, 7, 8, 13, 14, $15,18)$ : 
Partners are going more confident into [project]. It is good to make our partners think beyond outputs and just what they are going to deliver to actually what they are going to achieve (Interview13).

The other participant stressed "a level of rigor was absolutely critical ... to get the quality of application to a certain standard" (Interview 6). However, it was difficult to finalise the table because of inaccurate baseline information and a necessity to update it in early implementation stages (Interview 7).

Several in-country partners did not experience any influences (Interviews 3, 14). Other NGOs simply adjusted to requirements (Interviews 6, 10). Other NGOs had simply to adjust to requirements (Interviews 6, 10).

Due to the aforementioned government requirements, eight NGOs had to deliver extensive consultations to in-country partners (Interviews 9, 8, 10, 11, 12, 16, 18, 19).

We coached, monitored them, travelled to those countries to help to submit proposals (Interview 11).

In some instance it became clear that the previously informal practice of collaborating with in-country partners would no longer suffice (Interview 19). Two professionals stressed that they did not have to assist partners at all (Interviews 7, 14).

Many respondents indicated an increase of burden on their in-country partners in different aspects (Interviews 11, 12, 13, 16, 19). For instance, one NGO pointed out that initially increased workload and iterative changes have been a struggle for partners (Interview 11). In-country partners faced problems with limited budgets and any increase of field trips placed extra burden with partners (Interview 16). Two NGOs also indicated that "now it is tightened, it is a huge risk of inability of partners to deliver outputs" (Interviews 12, 19).

\subsubsection{Impacts on NGO Policies}

The section provides understanding of the policy influence on NGO personnel, a fundraising policy, and organisational strategy.

The redirection of the NZODA policy has significantly affected NGO personnel in terms of employment and workload. Eight organisations have lost at least one development professional and in worst cases, this figure exceeded $50-60 \%$ of staff with an average rate of redundancy of 3 people (Interviews 1, 2, 5, 7, 9, 14, 18, 19). In total 24 professionals are made redundant. The reasons differed from an inability to keep personnel anymore to staff having different philosophical views on the new policy. 
Six NGOs did not change a number of staff positions within the observed period (Interviews 4, 10, 11, 17, 20, 21). As one NGO explained it "we have no changes in employment but we haven't expanded it. No one has a pay rise even to keep up with inflation because we can't afford that" (Interview 11).

Several NGOs managed to employ at least one person or increase professionals' hours at least by 0,5 FTE (Interviews 3, 6, 15, 16). While some NGOs just indicated the increase of positions, one NGO stressed that "we have now one and a half. Even with these resources it is not enough when the reporting comes" (Interview 15).

The reconfiguration of roles often included a stronger emphasis on fundraising (Interviews 2, 12). One NGO considered future collaborations with private sector partners necessitated a need for development commercial managers (Interview 15).

Six NGOs reported increased workload (Interviews 2, 10, 11, 12, 17, 19). One NGO very aptly described it "every person takes more workload while really we have to have more people here" (Interview 11). Two NGOs noticed it in the amount of time and energy that have gone into preparing contestable proposals (Interviews 2, 12) and heavy administrative requirements due to MFAT practices of double checking (Interview 2).

It is important to notice that four NGOs did not upgrade personnel skills (Interviews 7, 16, 18, 20). Seven NGOs mentioned that they had to update employees' skills and capacities in certain ways like doing additional readings, attending government workshops and conducting in-house training (Interviews 9, 12). Two NGOs applied for external informal advice regarding collaboration as per new government policies and the NZ Inc approach (Interviews 2,8). NZ Inc approach is an instrument within NZ Inc Strategy aimed to improve "New Zealand's economic, political and security relationships" with countries that are a particular interest of the Government through development of trade and investments (MFAT 2012b).

In terms of governmental support to the development community one NGO noted that MFAT was not helpful at all (Interview 2). In contrast, the other participant claimed "we appreciated MFAT's training" (Interview 13). The same participant reported that they had to make sure they understood everything correctly. Specifically, an outputs-based budget fitted an outputs-based project design (Interview 13). The other NGO finance team learnt very quickly on reporting according to SDF financial formats (Interview 6). One organisation also conducted training in reporting and financial management. The representative further explained that the work programme team does is strictly contract compliance, with a view to achieving the predetermined outcomes than the supporting of partners (Interview 12). 
With regard to the evaluation of the impact of the NZODA policy it is important to say that ten NGOs did not identify any changes in fundraising policy (Interviews 3, 9, $10,11,12,15,16,17,18,21)$. Meanwhile, three NGOs have increased independent fundraising (Interviews 1, 2, 14). It was stated "even [though] the fundraising campaigns had some success we are not going to replace what we have got from the Government" (Interview 2). Five organisations came to a conclusion to diversify funding streams and increase money from other stakeholders like private companies, trusts and general public (Interviews 5, 7, 8, 19, 20): "it is something that we always tried to do. But we got forced to do it more quickly" (Interview 8). For one NGO the purpose of fundraising has shifted to cover for costs for project development whereas the KOHA covered some of this cost (Interview 17).

The discussion with the development community revealed different positions of NGOs regarding the dependency ration on government resources (See Table A.4 in Appendix 2 for a random sampling of NGOs dependency ratio). Seven NGOs mentioned that a certain degree of independency on government grants had been established before the redirection of the policy (Interviews 3, 9, 10, 12, 16, 17, 18). An NGO stressed, "rather than exceed that [limit of government funding] we will not grow" (Interview 12). Meanwhile, five NGOs came to a conclusion to reduce a dependency ratio after being affected by the changes (Interviews 1, 2, 5, 8, 19). A very painful lesson was also learnt: "NGO must never get itself into a position when it relies on government funds" (Interview 5).

According to gathered data eight NGOs made a major strategic realignment to the Pacific (Interviews 2, 7, 10, 11, 15, 16, 17, 19). The main argument was to stay engaged in the delivery of NZODA (Interview 2). An inconvenience to deal with African and Latin American partners due to differences in languages and time zones (Interview 7) was also a determining factor. It was added:

[Focus on the Pacific] is a positive side shift from policy to us because we do a better strategic decision. It made us look at the area that in other case we wouldn't look at before (Interview 15).

There were also other impacts of the policy on NGO organisational strategies. One NGO carefully reviewed its strategy and concluded that "until 2008 it was clearly a strong alignment with the government and now when government's policies align then the NGO engages" (Interview 14). In general, two NGOs found it difficult to establish a strategic direction due to constantly changing policy settings (Interviews 2, 17). 
Seven NGOs when asked about the impact of the policy on the organisational strategy could not define any effects (Interviews 4, 6, 9, 12, 13, 20, 21). One NGO representative stressed that "we fitted MFAT's requirements into our policy but we haven't shaped our policy based on the things they do" (Interview 13). The other NGO reported "we stayed true to what our strategic plan was, we didn't change that" (Interview 6).

The other important observation was made around a reassessment of NGOs position and the whole sector itself (Interviews 5, 13, 14, 19): "it has made us sit up and reflect on what is the most valuable for us as a NGO". The other NGO stressed that "[the policy changes] have really rattled up the NGO sector. It pushed NGOs to ask who we are. That we should remain independent as the sector and understand this shift" (Interview 13). In terms of organisational repositioning, one of voluntary NGO started to think of becoming not absolutely a volunteer organisation.

It is important to conclude that while NGOs' operations were significantly affected by the new policy settings, NGOs' policies did not undergo substantial changes apart from transformations in employment policies.

\subsection{The Effects on In-country Partners}

The effect of the NZODA policy on in-country partners is presented in terms of relationships and their reporting mechanism between NGOs and their in-country partners. It is essential to remember that only New Zealand NGOs were interviewed and opinions of in-country partners were not investigated and revealed in the current section.

The impact on the relationships was not homogeneous. It was not the same in terms of communication and field visits as well. For example, two NGOs reported that their relationships have been positively affected. In both cases, this change was recorded with increased funding (Interview 21).

Five NGO representatives claimed that their relationships with partners were not affected (Interviews 3, 4, 8, 10, 18). "It hasn't affected our relationships because they understand us and [the policy changes are] outside of our control", stressed one of the participants. The professional further stated "the most disappointed one is that the way we had to approach our partners was always uncertain (Interview 8)". The other NGO 
representative responding if the organisation experienced any significant changes in relationships with partners claimed: "no, only frustration" (Interview 3).

Meanwhile, seven development professionals indicted a significant influence of the NZODA policy in different aspects (Interviews 7, 9, 14, 15, 16, 17, 19). According to five NGOs the policy changes have brought pressure on relationships with in-country partners (Interviews 9, 14, 16, 17, 18):

There were some tensions with partners because of the abruptly changing policy (Interview 7).

In addition, one NGO claimed that "we seem to be more directive than in the past. And that is not always comfortable as it is not the basis of partnership and relationships we have had" (Interview 12). The other organisation highlighted that "[request for information] is just part of communication and partnership". It further added that "it gave an impression of distrust" (Interview 13). As a consequent some NGOs established an open dialogue and translated changes to partners (Interviews 9, 14, 17, 19):

We have maintained an open stance with our partners, keeping them informed of our newly limited ability to meet their requests (Interview 17).

A question of the impact on a level of communication was asked to the development community as well. Thus, six research participants responded that communication with partners was not affected (Interviews 4, 5, 8, 10, 20, 21). One of them also argued that "it was higher engagement [with partners] than it was previously despite a nature of circumstances" (Interview 5). There were also some organisations that indicated improved collaboration with in-country partners (Interviews 9, 11, 15, 16):

We started to interact a bit more. It actually strengthened our relationships (Interview 9).

The quality of communication has improved. We can see issues before the problems become a serious issue (Interview 16).

In terms of a number of visits to in-country partners four development officers stressed that it has reduced since the policy changes were introduced and one participant did not manage to travel at all (Interviews 5, 12, 14, 19):

Travel has been affected considerably by changes because now we don't have funding to travel (Interview 19)

The same professional explained that quite a lot of travelling now has been funded by NGO because received funding could not be used in retrospect of travel (Interview 19). 
Three NGOs' ability to travel was not affected. Two further organisations reported that since travel requirements had gone up they increased a number of visits for the MFAT's projects (Interviews 15, 18).

The other observed impact reported by some NGOs was the actual amount of time spent more in offices liaising with MFAT rather than working with partners in offices or in the field (Interviews 2, 11, 19):

In some cases relationships were not easy to keep them going on the same level. We had more time to work on relationships with partners in previous scheme (Interview 19)

MFAT also recognised some challenges for NGOs and their partners acknowledging that funding is now reliant on successful applications and is not able to be confirmed until the full design has been approved and the grant funding agreement is in place. This meant that relationship and expectations of in-country partners had to be managed carefully (Interview 22). The other challenge outlined was the fact that NGOs may have to identify new partners to work with because of the geographical priorities of the fund (Interview 22).

For many in-country partners the changes in reporting formats were challenging in different aspects (Interviews 10, 12, 16). For example, one partner found it difficult to understand an increased emphasis on economic development because they still saw the importance in reporting on education and health goals (Interview 10). The other NGO described partners' reaction on the changes in this way: "they are enthusiastic and sincerely tried but for many of them it is very difficult, they missed deadlines" (Interview 20). Describing an impact of the changes in the field one NGO outlined:

They found it very difficult to adjust ... more detailed requirement and they felt that we were just being difficult (Interview 16).

Similarly, the other participant mentioned that "here and on the ground is more work about contract compliance" (Interview 12). In contrast, a development professional claimed that although new reporting involved extra work field offices were happy to do it for funding (Interview 9). A more pragmatic response was presented by one NGO that reported: "we made an early decision to get over it and get on with it" (Interview 1). The other participant when asked about the impact on partners answered:

We are often able to help them to work out but overall ... not too bad. It was not tough for partners so far but this related to partners with higher capacities (Interview 14). 
The other NGO also stressed that everything depended on a partnership with offices: "it was a good learning curve. Our existing partners were well with these [new requirements] but new partners struggled" (Interview 11).

To support staff in field offices many NGOs have provided training (Interviews $1,6,8,11)$ : "they need a little bit of capacity building in that area of reporting [outcome and output based reporting] (Interview 8). NGOs also used different instruments to adjust to new reporting standards. For example, one NGO has completely revised the reporting documents with its partners (Interview 1). The other organisation advised its partners: "if you want to have those grants you have to comply, no negotiating" (Interview 18).

Thus, there were no common patterns of impacts on in-country partners. In fact, the changes to the NZODA differently affected relationships and communication including field trips between NGOs and their partners on the ground.

\subsection{Summary}

Overall, though, despite the often quite diverse responses and views of the NGOs, it seems that, after four or five years of the changes in policy, New Zealand development NGOs have learned to adapt to the new environment. Some elements of the new policy have been accepted, sometimes even with a degree of enthusiasm; in other cases they have made changes only grudgingly. The need for NGOs to continue with their work in the new policy environment has forced them to change, whether they like it or not. For many, their original concerns remain: there are still objections to the sustainable economic development focus; many still do not like the blurring of the aid objectives with the wider diplomatic and economic needs of New Zealand; and some are still unhappy with the way the Pacific focus has affected their relationships with partners in other parts of the world. Since development work of NGOs was significantly affected, many NGOs changed the presentation of the programmes and partly decreased length of activities. Additionally, the new policy settings prompted NGOs to reassess their organisational identity and their role as either an independent voice of civil society or a service-delivery arm of Government. This ultimately has affected the essence of relationships between Government and the development community that will be further examined in chapter six. 


\section{CHAPTER SIX - RELATIONSHIPS BETWEEN THE NGO SECTOR AND THE NEW ZEALAND AID PROGRAMME}

\subsection{Introduction}

The following chapter analyses the relationships between the New Zealand Government and the development community following the redirection of the NZODA policy. It provides a theoretical application of a typology of the relationships as an instrument of learning and self-positioning of NGOs in relationship to the Government. It also presents recommendations on how to improve the relationships as well as NZODA policy as offered by the NGO sector.

\subsection{Relationships between NGOs and the New Zealand Aid Programme}

This section reveals NGO views on the current relationships with the New Zealand Aid Programme, as well as such aspects of this interaction as the evolution of the relationships over the past five years, communication with MFAT staff, levels of feedback and dialogue, as well as engagement in policy development. The MFAT's perspective on the current relationships with the development sector will be also reflected.

To describe current relationships with the New Zealand Aid Programme NGOs were asked to evaluate them using a five-point rating scale (See NGO interview checklist in Appendix 1). Twelve out of twenty one professionals think that they have good relationships with MFAT. One NGO highlighted:

I think we are good. Generally we work hard to develop good relationships there. It's been useful because the MFAT team is also working within rigid constraints and we understand that (Interview 16).

The other participant added that there are high level tensions due to people's frustration with the SDF and NZPfID. However, face-to-face relationships are very good (Interview 7). The other professional referred to good relationships due to MFAT staff flexibility to accept delays in getting projects finalised and an opportunity to contact them easily via phone or email (Interview 10). With the new policy regime one NGO had found that it had much more contact with the New Zealand Aid Programme 
than in KOHA days (Interview 13). That was also the reason why the other NGO found that relationships became stronger (Interview 9).

Three development professionals stated that their NGOs have excellent relationships with the Government, "with the New Zealand Aid Programme itself I would say it is really excellent" (Interview 15).

It was also stated by one of the above mentioned professionals that relationships with the New Zealand Aid Programme across the entire organisation have always been good (Interview 14). It was further added that "you have to be in good relationships. You can't say what you think ... they've got power" (Interview 20).

The other three participants found their current relationships with the New Zealand Aid Programme neither good nor poor. Two representatives described it differently:

They are not particularly receptive to responses; they have got their own agenda. And they want a validation of that agenda rather than say: 'Hey you are experts. Look at what you have achieved' (Interview 8).

It is appropriately professional (Interview 18).

The research participant further depicted relationships as "cautious at a distance" arguing that "we are not buying their philosophy and grateful for what they fund. We do not complain about what they do not fund. This is not a true partnership at all" (Interview 18).

Two organisations positioned the relationships on the borders of good and excellent. One of them stated:

I can't say we are happy. We don't think the government is providing the sector with what it should do. Relationships could be good, warm, friendly but behind it all is 'what on the earth are they are up to?' (Interview 3).

NGO that classified the relationships as poor explained it thus: "they do not see us as a big player. They are squeezing us out. We are not asked by politicians to help with the policy" (Interview 2). The same participant also noted that relationships came to filling the ADD and are solely about money. However, the representative characterised the prior relationships with the Government as a partner relationship that also was at the policy level (Interview 2).

It is important to notice that some NGOs are working with MFAT at different levels, not just with the contestable funding schemes. An NGO noted that "The NGO has quite good relationships with the New Zealand Aid Programme and not necessarily related to projects" (Interview 8). The other two NGOs engaging with MFAT in 
different non-project related aspects also agreed (Interview 6, 9). A significant number of NGO representatives stressed that the MFAT staff are good professionals that work really hard (Interviews $8,11,12,13,14,15,16,18,21)$ :

People within MFAT are dedicated people who truly believe in good development principles. It is the system that is somehow broken (Interview 18).

NGOs also appreciated MFAT's understanding and support (Interview 19, 21): Whenever I've got concerns they are always available, very friendly, always explain things (Interview 21).

NGOs also understood that MFAT personnel had to work under high pressure and fulfil their responsibilities as public servants (Interviews 11, 13, 14, 15, 16, 19):

They are public servants and they had to do what the ministry required (Interview 19).

Taking into consideration the constrains that they have they are absolutely a hero. They've done the best they can (Interview 16).

I found them professional and if you willing to work with them and accept the limitations that they have (government policy) they are really good to work with. They have been under huge pressure and massive restriction (Interview 15).

Meanwhile, NGOs mentioned some aspects that directly related to the MFAT personnel and required an improvement. For example, four NGOs noted that there are many staff changes and no consistency (Interviews 3, 9, 11, 20). One of the participants stressed:

The problem has been that there are so many changes in the personnel. You have to start again with a new person all over again (Interview 11).

NGO mentioned above also stated that the SDF personnel were completely different from the NZPfID staff and that it had no communication with a new team. "A little bit isolated, no cooperation", the participant added (Interview 9).

Some discussions took place around a dialogue and meetings arranged by the the New Zealand Aid Programme. One NGO found them acceptable (Interview 4) the other three organisations had different opinions. For example, one professional was not satisfied with face-to-face meetings because the NGO was not given a high level of details (Interview 9). It was also reported that NGO's suggestions were ignored (Interview 3). The other comment was given to a meeting on the NZPfID with private sector organisations that one NGO called a "speed dating". The NGO representative explained it: 
We changed the business cards but it does not mean we are going to partner. It is not the way the partnership works or starts (Interview 18).

MFAT also recognised the fact that changes required a lot of support. Background guidance around the materials was made available and workshops to introduce the new forms and the results framework were provided. MFAT recognised that NGO partners would find the new processes challenging to introduce all at once. To assist with this, the three components of the results framework were introduced incrementally over the three rounds of the SDF (Interview 22).

In terms of the dialogue one research participant stressed that "it is more about an operational dialogue rather than policy" (Interview 10). In terms of government's ability to listen to the development community, one NGO highlighted that "they listened ... people have spoken but no difference" (Interview 3). The other professional saw it differently: "they have not set up structures that would make it a matter of routine [like under the NZAID through CID]. We don't have that dialogue anymore" (Interview 5). However, later the same practitioner added that the dialogue has been good at a personal level and at the organisational level it is improving because of recently started six months meetings with NGOs (Interview 5). The other instrument of communication that was not a problem but worth to mention was MFAT's response on NGO feedback. "They are good at taking our time but they are not often voluntarily coming back to us with small gestures", outlined one of the representatives (Interview 7). By small gestures the professional meant courtesy like informing about a webpage update with feedbacks that NGOs worked on or mentioning of involved NGOs.

A significant number of NGOs claimed that they are not or almost not engaged in policy development with the current Government (Interviews 4, 5, 6, 10, 12, 14, 15, 20). Comments as follows:

If the ex-Government pretended they wanted to know our opinions, now they don't bother to pretend anymore. It is completely without any engagement whatsoever (Interview 20).

At the policy level it is much harder to have a policy dialogue and influence than it used to be (Interview 12).

They told us: the policy is for us and the scheme is for you. Fair enough ... There is expertise in NGOs they could put into and make a better policy. It is a long way to go but they are engaging and open (Interview 15).

In general NGOs that provided a feedback on some policy consultations were not satisfied mainly because they did not feel they were listened to and very few their 
suggestions were implemented (Interviews 2, 3, 9, 11, 16, 18). Research participants reported:

There is a whole impression that a feedback is requested but government make certain decisions to tick the box and they don't really do a lot (Interview 9).

We have given a feedback on policy but ... it is certainly a consultation but not a co-creation (Interview 16).

There is some room for a feedback but it gets taken into consideration if it is in harmony with something that MFAT wants to do. It is limited (Interview 11).

There were also three NGO representatives who felt that they engaged in a policy dialogue and participated in policy development (Interviews 8, 13, 21). When NGO was asked whether it engaged in policy development one of the above mentioned professionals claimed:

Yes, if we have to. We try, we do submissions. With the NZPfID we took an opportunity. But a feedback on the NZPfID did not go at the individual level (Interview 13).

The same participant appreciated a high level of a feedback on the HRF consultation paper:

With the HRF we got an individual response sent to me on my recommendations. I didn't expect that level of a feedback (Interview 13).

MFAT emphasized that while funding mechanisms were a major topic of discussion with NGOs, other parts of the aid programme were engaged with NGOs on wider policy and strategy dialogue (Interview 22).

NGOs were also asked if their relationships with the New Zealand Aid Programme changed within last five years since the National Party came to power. Five NGO representatives mentioned that their relationships became stronger (Interviews 8, $13,15,19,21)$. One of the development professionals noted that "[relationship] has improved ... we worked harder to talk to them and they were much more receptive to hearing what is going on. It is good" (Interview 19). The other NGO officer also noticed that relationships with the Government got better because of NGO's pragmatic approach and MFAT's open communication. The professional added: "five years ago we would not be invited by MFAT to do anything in regard to giving input or reviews when now ... they are coming to see us, they are ringing to ask what we think. Because of this we found that our relationships are better" (Interview 15). One of the above mentioned NGOs further stressed that NGO-government relationships under the NZAID 
were collaborative, "most exciting relationships in the world" and meanwhile NGO admitted that sometimes it was too cosy (Interview 13).

MFAT acknowledged that changes to the funding mechanisms and the introduction of new application processes caused uncertainty for NGOs. However, relationships have since strengthened with the bedding of the new processes and increasing familiarity with the requirements of the funds (Interview 22).

To better understand the relationships between the Government and the NGO sector it is important to describe MFAT's perspective on the relationships with New Zealand NGOs. Like the majority of development NGOs MFAT believed that while change always affects relationships, the relationship with the NGO sector was good. There is greater engagement and partnership and regular communication (Interview 22). To support the sector MFAT tried to respond as much as possible in terms of signalling change well ahead of time, seeking feedback, being available, providing workshops and having regular partnership meetings. It was also stated that MFAT recognised the value of NGO knowledge and expertise and their contribution to development outcomes (Interview 22).

\subsection{Types of NGO-Government Relationships}

It is important to stress that this research aims to take into consideration the complexity of government-NGO relationships and engagement of NGOs and the New Zealand Aid Programme at different levels. However, to understand the character of the relationships simple tables of Lewis and Young were introduced to research participants. A theoretical explanation of these classifications is illustrated in details in Chapter Two.

Nine NGOs have taken a position between supplementary and complementary type of relationships (see the figure 6.1). NGOs explained it as:

Well we don't operate independent anymore. It is getting towards working in partnership. But we are not quite there (Interview 9).

We don't want to be adversarial it is unproductive. We don't want to be mostly financed by the Government. We want to work in partnership (Interview 12).

Two of those nine organisations stressed that they have something from adversarial relationships as well. 
Complementary type of relationships was chosen by five NGOs. The reasons were the following:

It is a partnership in terms of an operational thing but not in policy. We target Government and using government grants to supplement our activities (Interview 10).

Four NGO representatives described the relationships with the New Zealand Aid Programme as supplementary. One of them highlighted: "I don't think we are mostly financed by the Government" (Interview 13).

One of NGOs found itself on the borders between adversarial and supplementary relationships. The NGO representative explained the choice: "we made this decision that we will be a donor-based NGO and the Government will be seen as supplementary. We actually believe that we had this [complementary] for 37 years" (Interview 2). While one of NGOs positioned the relationships on the edge of complementary and adversarial relationships the other organisation has taken a strong adversarial position with the Government. The fact that the majority of the participants found it complicated to affiliate to a particular type of the relationships proved Teamey's and Brinkerhoff's statement about the complexity and dynamics of government-NGO relationships.

Figure 6.1 Young's Model of Relationships between New Zealand NGOs and Government

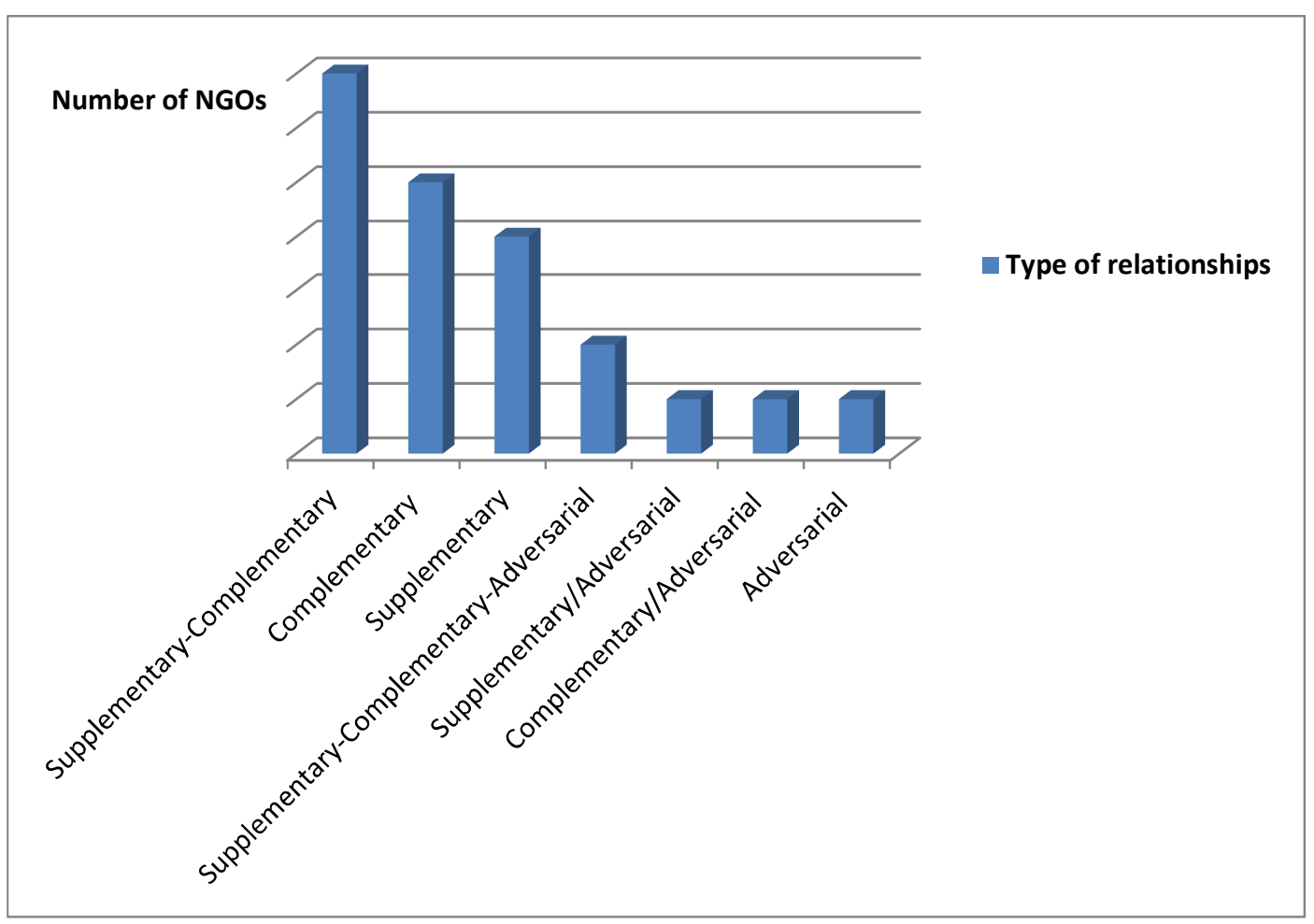


Among those NGOs that associated themselves with a complementary type of relationships, four NGOs supported an active partnership with the New Zealand Aid Programme (see Figure 6.2). Some of them reported:

I would say active but it is a fixed term partnership (Interview 21).

We have confidence to say 'No'. We don't need government funding to survive ... of course we like it but we are not dependent on them (Interview 13).

The other five participants defined their relationships on the borders of dependent and active partnership. These representatives stated:

At the moment we have rigid roles that are currently negotiated, clear purposes there ... very limited debate and dissent ... certainly information exchange happens. We don't have much to say what you get funded for (Interview 5).

Partnership with the Government has clear roles and purposes. We are to a certain degree of shared risk. It is not a long perspective strategy. A move from a partner to a contractor is a retrograde step (Interview 16).

Dependent partnership with the New Zealand Aid Programme was chosen by four development community representatives. Some of them explained this:

It is definitely not a shared risk ... Dependent because of resource based ... we are moving into this direction [active partnership]. But it is footwork of dedicated MFAT officials who are moving us into that direction (Interview 18).

Because they set the policy and set blueprints and roles. They don't invite partnership on policy issues. There is flexibility on forms but no flexibility on the policy (Interview 10).

Two NGOs could not choose between dependent and active partnerships. In contrast, one NGO stressed that it did not belong to the table because it does not work in partnership at all. These findings reflect one possible limitation of Lewis model. Theoretically, there is a very clear border between two types of partnership, however, in reality these borders are blurred. 
Figure 6.2 Lewis's Model of Relationships between New Zealand NGOs and Government

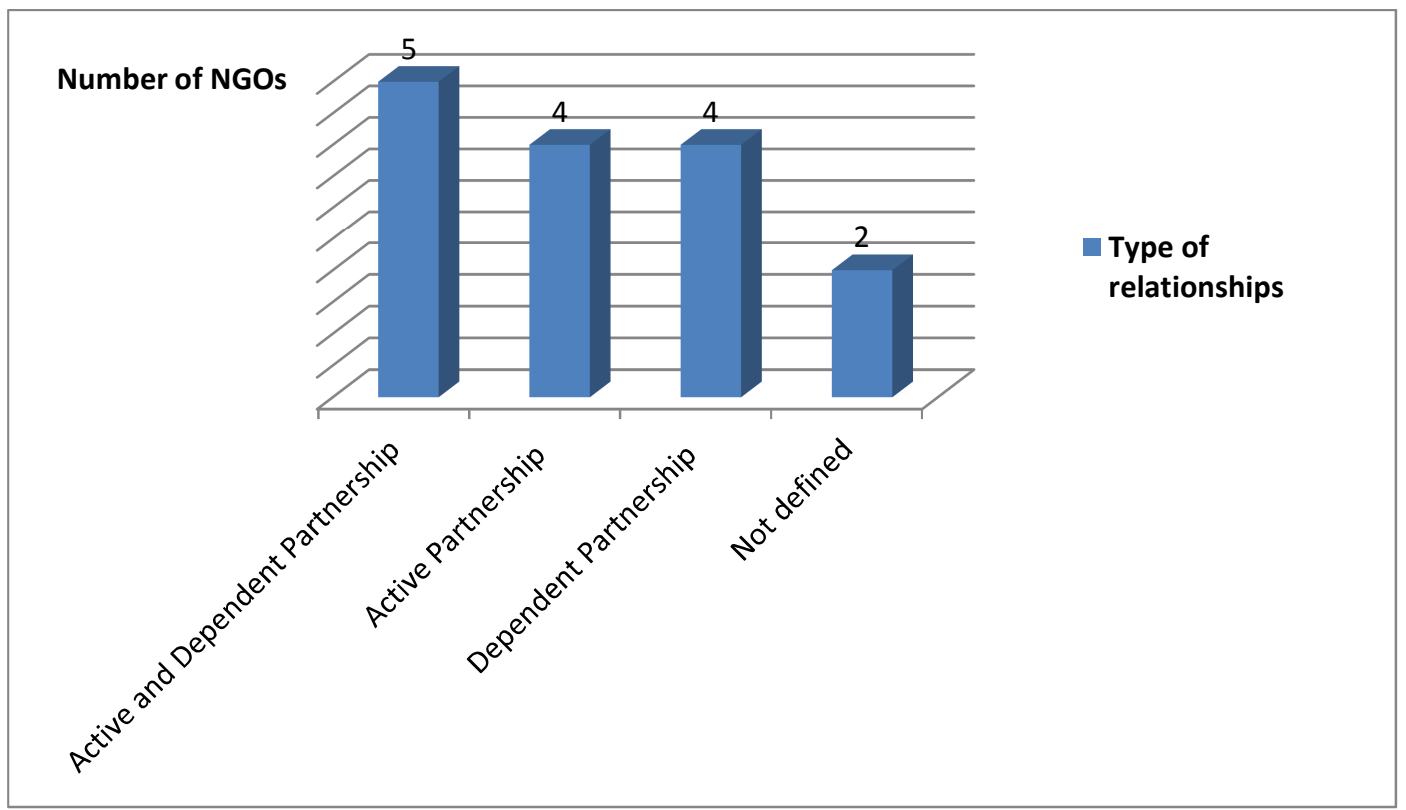

MFAT emphasised that no one relationship was exactly the same as NGOs represented a diverse sector with different areas of interest (Interview 22).

\subsection{Recommendations for Improvement of Relationships with the New Zealand Aid Programme}

The New Zealand development community has given different recommendations on improvement its relationships with the New Zealand Aid Programme from a need to change a character of the relationships to improve methods of communication and staff skills in certain cases.

Six NGOs advocated for a change in the character of government-NGO relationships in particular a re-establishment of trust, forming genuine and active partnership as well as acknowledgement and respect of NGO expertise (Interviews 2, 6, $8,13,17,19)$. One of the participants stressed:

There needs to be a re-establishment of trust so relationships can become a partnership that leads to equality and reciprocity. All these things are not there now (Interview 19). 
It should be a greater focus on a partnership in the delivery of aid programme rather than treating NGOs as contractors for the delivery of a component of the programme (Interview 17).

The other NGO representative additionally advised to "return aid development to developmentalists, people who understand effective and sustainable grassroots development" (Interview 8).

Three NGO representatives of the development community outlined that there is a need for more consistency (Interviews 7, 13, 17):

[MFAT should] provide consistency in the policy settings, and signal any changes clearly and well in advance to allow NGOs to adapt (Interview 17).

One of NGOs also highlighted that it would be beneficial if MFAT could be more flexible in terms of changing things that are not working very well: "make it effective by trying something different" (Interview 13).

New Zealand NGOs were also asked about the usefulness of the strategic policy framework and its renewal. The majority of respondents would like to see the Government revisiting the effectiveness and value of the strategic policy framework (Interviews 1, 2, 5, 8, 11, 12, 16, 18, 19):

I am sad about this. It is a very good document. It was helpful on regular basis to see if we were keeping up our sides of agreement. Now there is no basis for evaluating our partnership (Interview 19).

Yes, it needs to be within the sector as collective ... not going to five bigger players that they like and fit their philosophy (Interview 2).

The other NGO argued that "it probably needed a complete rework anyway ... a lot of changes in accountability processes, results measurement" (Interview 12). While one research participant mentioned that "I am not sure if the strategic document will rebuild this trust" (Interview 18) the other professional highlighted that "similar to this one needs to be renegotiated with good faith on both sides" (Interview 1).

One NGO hesitated in its usefulness since "you can dialogue with the Government but actually how much will be taken on board? So if you have the strategic policy framework the general feeling what is the point?" (Interview 14). Three NGOs did not answer this question (Interviews 7, 9, 10) and two more did not know about it or its termination (Interview 4, 13).

MFAT held its own view on the strategic policy framework. The New Zealand Aid Programme representative acknowledged that the strategic policy framework was an example of a good practice at that time but since it was very focused on the funding mechanism it no longer fitted the new environment (Interview 22). The second reason 
that the strategic policy framework ended was the development of an overarching cross government relationship accord setting out principles and expectations to guide how communities/NGOs and government can work together- The Kia Tūtahi Relationship Accord is an important symbol of commitment between government and communities (Interview 22).

In terms of communication and dialogue one NGO stressed that it wished for more sharing of information (awareness rising about the new NZPfID) including some materials on the website. The other professional added that it needs to be a constructive conversation between NGOs and the Government (Interview 1). Commenting on annual meetings two NGOs noted that there is more need in a dialogue and sharing best practices:

When we have a meeting [it is important] not just to talk to us but also listen to us. It seems to be information sharing sessions not a dialogue (Interview 13).

It is not about technical details but how we collectively apply best practices (Interview 2).

Since MFAT's workshops were held only once in six months and one workshop was just a week before the NZPfID's deadline, without an advance notice two NGOs asked for more planning and communication from the MFAT (Interviews 9, 11).

The other thing that was mentioned was a level of technical skills of the personnel in the New Zealand Aid Programme. One NGO stressed that while some staff were "really experts in something and that was great to deal with. Other officials not really, they don't understand what we are telling them" (Interview 7). It was also advised of employing people who can understand the technical language of the particular industry. According to one NGO a working style of some MFAT personnel required improvement. Particularly that applied to clearer and full comments on a draft of a project:

If somebody has given you a draft you need to provide all comments to it now. You can't give people half of comments and then they write it up and then you come with some more comments (Interview 7).

\subsection{Recommendations for Policy Development}

While only one NGO stated that it does not want to change anything in the policy because it is working well for the organisation the majority of NGOs gave their 
recommendations on conceptual underpinnings of the NZODA policy and its technical aspects.

One of the most topical changes in the NZODA policy was a possibility of NGOs to participate in policy development (Interviews 5, 6, 10, 17, 21): "there is a need in deeper and meaningful engagement in policy issues" (Interview 5). The other participant offered to establish a committee of the organisations funded by MFAT with legitimate interests as well as beneficiaries and individual experts to assess a government strategy and express views (Interview 21).

In terms of comments directly related to the NZODA policy one NGO outlined that "MFAT should recognise that our aid commitments are separate to our foreign affairs and trade commitments" (Interview 13). Talking about the geographical distribution of funds one NGO recommended to keep $10 \%$ for the global category (Interview 17). The other participant advised to focus $50-60 \%$ of funds allocation on the Pacific and give a higher percentage to Africa and Asia that have bigger needs and have New Zealand contacts (Interview 10). There was also a development professional who wished to see a stronger focus on the Pacific (Interview 20). One of the above mentioned participants also wanted flexibility in leaving space for other opportunities not just economic development (Interview 10). It was further requested for modest funding increase to support current core funding activities (Interview 5). One of the professionals asked for a greater recognition and provision for the value of smaller, less than $\$ 500 \mathrm{k}$ grants (Interview 17). In respond to high reporting standards and transaction costs one NGO asked Government to look at the higher level indicators of M\&E and if any issued come through any of those indicators then drill down for a further investigation (Interview 15).

\subsection{Summary}

The nature of the relationship between the NGOs and government has changed markedly. Some good relationships and mutual respect remain with officials working within the MFAT aid programme and NGOs have found ways to accommodate and work within the new environment. Within last five years the relationships have become even stronger for some of them. However, the essence of partnership has changed. It is much less consultative, much more directive and uncertain and much more an environment where NGOs feel they have to respond to leads from government rather 
than focus on their own good development practice. Whilst there was respect for MFAT officials at the personal level and appreciation of their work, the relationship was not nearly as effective at higher levels. For example, many NGOs did not feel engaged in terms of policy development. To improve the relationships NGOs recommended a reestablishment of trust, active partnership with consistency and opportunity to participate in policy development. 


\section{CHAPTER SEVEN - CONCLUSIONS}

\subsection{Conclusions}

This thesis has investigated the impacts of the NZODA policy on the New Zealand development community and revealed the changing nature of relationships between the New Zealand Government (and specifically its aid programme) and local NGOs. It noted the importance of partnerships in promoting effective development something evident in both the theoretical literature on development and in various global agreements on aid effectiveness. Yet it traced the way that politically-inspired changes to the country's aid programme following the election of the National Party government in 2008 both attracted strong criticism from the development community and significantly changed the way the two parties interacted with one another. In Chapters Five and Six the findings of research, in the form of interviews with most of the NGOs concerned, were presented and this revealed both a diversity of views and responses but also the fact that most NGOs have learned to adapt and move forward in the new policy environment. Concerns and criticisms remain but there have been positive aspects and most NGOs have learned to survive in some way, even if the activities of some of them have been severely curtailed.

This chapter outlines concluding remarks on the research question through giving an overview and summary of findings within the research objectives. Where possible the research results are compared with voices of the development community outlined in Chapter Four. A discussion on partnership between New Zealand aid community and the Government as well as some directions for future research is further presented.

\subsection{A Review of NGO Views on the New Policies}

Regarding NGO views on the main changes to the NZODA policy, the response was mixed. It partly reflected criticism and opinions of the development community illustrated in Chapter Four. The fact that many NGOs did not speak out when the changes came out, perhaps limits the research analysis. It could be suggested that because of the almost punitive approach of government in 2009 in cutting the funds of CID and other critics, many NGOs have decided not to engage in open criticism of 
government but rather keep their opinions to themselves or be circumspect in what they say (Challies, McGregor \& Sentes 2011). However, given the assurance of confidentiality, many respondents did feel free to speak openly in this research and criticisms were made.

The cornerstone of the new government aid policy was the shift from poverty alleviation to sustainable economic development as the core focus of the aid programme and focus of aid on the Pacific. Although the shift to the Pacific was met with some degree of understanding by NGOs, concerns still remains particularly in terms of the limited capacity of Pacific institutions to incorporate increased funding. This shift to economic development received much criticism at the time (Spratt 2012, p.53; Challies, McGregor \& Sentes 2011; Harvey 2009; Overton 2009) and it seemed to go against the global trend of poverty-focused aid as seen especially in the MDGs. Five years on, the concerns remain for many NGOs. They are not convinced that economic growth is the best core objective for an aid policy and they raise strong concerns that it does not address the needs of the poorest. However, this research demonstrated that this has not stopped their work, nor except in a small number of cases dramatically altered the way they work with MFAT. It seems as if the core 'poverty versus economic development' debate has not been resolved for the NGOs and government; merely postponed.

In terms of aid delivery and funding systems, a similar picture has emerged. Interview participants concluded that the SDF was not transparent, it had not been well researched, it was abruptly introduced and it was a fund with ongoing uncertainty and a rigid contract as its basis. A problematic position of smaller NGOs due to their limited capacities and resources to allow them to participate in the fund was also mentioned. Additionally participants associated an absence of a learning platform within the SDF. What was interesting that during the operation of the SDF interviewees found some benefits of the scheme for themselves. In other cases NGOs had simply to adjust to its requirements. The silent reaction from some members of the development community outlined by some academics (Challies, McGregor \& Sentes 2011; McGregor et al. 2013) might signify this pragmatic approach.

The HRF has not received much attention neither in the field nor in the literature. The majority of research participants agreed on the political and media-driven nature of the HRF that ignores complex emergencies. Timeframe issues were also outlined as concerns of the fund. The development community did not comment about the HRF much rather characterising both schemes as ones causing uncertainty, lacking flexibility and full guidelines. 
Opinion about the newly introduced NZPfID varied from strong skepticism with some concerns to a situation when NGOs did not see many changes in the new scheme, and finally to a position when many NGOs saw the rationale and positive effects. In terms of concerns NGOs had doubts about the inclusion of the private sector into the scheme, the commitment of private companies to development and complex partnerships between the sectors. Once again NGOs quickly moved to adapt and find ways of working within the policy, looking for positives and opportunities.

\subsection{A Review of Effects on NGO Operations, Policies and Country Partners}

The impacts on NGO operations and policies differed from one NGO to the other. While sometimes there were some common patterns in most cases there were quite diverse outcomes.

Development work of NGOs was significantly impacted by the changes to the NZODA policy. Particularly this was revealed in a dominant trend of a decreased number of government grants alongside increases in funding. Project duration was not affected in some NGOs and in others it became shorter in comparison with the KOHA. A focus of development work in the majority of NGOs has not changed but the way NGOs look at projects has. In contrast, the development community argued that NGOs have shifted project themes and geographical locations (McGregor et al. 2013). Although it was true for some NGOs it was not a common trend. Meanwhile, the aid community argument on adopting the language to fit government requirement and receive grants (McGregor et al. 2013) was proved in practice. In terms of issues such as limited bridging funds, restricted timeframes and greater focus on achieving development targets than on working directly with communities they all are confirmed in this study.

Regarding NGO development instruments the majority of New Zealand NGOs have not experienced significant effects. MFAT's M\&E standards were considered more robust and had a significant impact on the sector. Although introduced requirements were challenging and NGOs had to adjust in different ways they have apparently positively impacted NGOs' accountability. 
NGO policies were less affected by the NZODA policy in comparison with their operations. However, the number of professionals working in the sector has dropped by perhaps 24 employees. Several NGOs did not change the number of staff positions and several NGOs employed at least one person or increased professionals' hours. As the development community suggested (Challies, McGregor \& Sentes 2011; Spratt 2011; Bowden 2010), the changes have brought pressure on NGO staff and that was also found particularly in increased workloads. As a result many NGOs had to upgrade employees' skills. While fundraising policies did not undergo significant changes in the majority of NGOs, an increase of independent fundraising and decisions to diversify funding streams were recorded in several organisations. With the changes the problem of dependency on government for the aid community became an uncomfortable fact. It has led the NGO sector to reassess themselves and reflect on the core reasons for their existence as NGOs.

The impact on NGO partners again varied from no effect on relationships to a significant influence in different aspects with a major impact of placing pressure on relationships. Similarly, communication flow has improved in some NGOs and was not impacted in others. Also the number of trips to in-country partners has been dependent on NGO financial capacities and in general there were decreases in the number of field trips in some NGOs at least. Meanwhile, time on liaising with MFAT significantly increased. In response to established scheme requirements including challenging for partners reporting, NGOs provided trainings to support staff in field offices.

\subsection{A Review of Relationships between NGOs and the New Zealand Aid Programme}

Despite many contradictory changes that recently affected the relationships between the NGO sector and Government, some aspects of the relationship were depicted in a very positive light by both sides. Earlier community critics had stressed that partnership had been weakened. Tension had been placed on the relationships resulting from the move to a more contract for service approach (Challies, McGregor \& Sentes 2011, CWS 2010b). Although such views were expressed in the interviews, most respondents felt that they have good relationships with MFAT. The New Zealand Aid Programme had a similar opinion. For example, MFAT expressed confidence in NGOs to report back about their challenges and issues. Some NGOs went one step further 
claiming that their relationships became stronger within last five years. These improvements or at least the maintenance of good relationships appear to exist at the inter-personal and operational levels of the relationship. In terms of personal relationships MFAT staff were regarded good professionals who work hard under heavy pressure. At the policy, however, the relationship is much less healthy. A significant number of NGOs claimed that they are not or almost not engaged in policy development. Likewise NGOs did not feel they were listened to. Thus we can see a restructuring of the NGO-Government relationship that has some serious strains and it has lost its higher-level of engagement, but it has been maintained through effective lower-level and personal relationships. The very nature of effective 'partnership' between the two thus has become threatened, even if it survives in a practical sense of everyday work.

\subsection{A Review of Recommendations for Improvement of the Relationships and Policy Development}

In terms of the recommendations for improvement of the relationships between the Government and NGO sector, NGOs recommended a revival of trust, genuine and active partnership, more stability, and reconsideration of the strategic policy framework. In addition, NGOs asked for an opportunity to participate in policy development. Such concerns reflect a strong theme that the long term partnership is under threat and echo the critics' calls for a rebuilding of the partnership and a stronger recognition of NGOs value in the country's aid programme (Challies, McGregor \& Sentes 2011, McGregor n.d.).

Other suggestions for change focused on more operational matters. They differed a lot from a suggested change of geographical distribution of funds to a stronger emphasis on smaller grants and simplification of monitoring requirements.

\subsection{Genuine Partnership: Too Close to Comfort or Contract for}

\section{Services?}

Analysis of the impacts of the changes to the NZODA policy on New Zealand NGOs and relationships between the NGO sector and Government showed an evolution 
of the relationships from the formally framed partnership to relationships of a contract provider. This section aims to consider which of these relationships could be regarded as the most effective interaction and could be termed a genuine partnership.

It is a common view, partially confirmed in this research that a genuine partnership was established between the government's aid programme and the NGO sector during the Labour Government's tenure (1999-2008). Indeed, the partnership was founded on principles of equity, trust, transparency, and participation in pursuing similar goals. Yet, these relationships were, in some respects, too 'cozy' to be genuine ones: strong dependency ties had formed. This was revealed later when the National Party introduced new policy changes based on their new policy agenda. They undermined NGO independence and questioned their accountability - essential principles of effective partnership. Interviews with research participants also outlined the dependency problem and good lessons involving not relying solely on Government funding. In addition, despite some challenges and critiques addressed to the new M\&E standards, many NGOs found the new practices more robust and professional than under the KOHA and HAF. On the other hand, strong actions taken by the National Party government did affect the perceived autonomy of NGOs and their ability to be critical. As Challies, McGregor and Sentes (2011, p.20) noted, "loss of autonomy and loss of voice means, in many respects, a loss of reason for existence”. They noted that many NGOs did not speak out about the policy redirection and they have arguably now a weakened role as watch-dogs on aid and development issues. The problem of losing their "reason for existence" was reflected in interviews with participants, some of whom had reassessed themselves as independent NGOs with their own values and goals, now implicitly accepting their fate as more passive contract providers for government.

Such relationships of contract service provider cannot be considered the basis for a genuine partnership. Basically they undermine partnership principals of equity, transparency, trust and value of partnership. The National Government gave a clear message to the development community that it is in charge and that has shifted the balance of power in New Zealand's development and aid landscape. Often, research participants stressed the dominant position of the Government quoting MFAT: "the policy is for us; the scheme is for you" (Interview 15). Lack of transparency of the schemes, lack of ability to participate in policy development and be heard was also mentioned by NGOs. This and other broken promises like an absence of a funding ceiling for projects have significantly disrupted trust in the Government. Arguably the Government had stopped trusting the NGO community even earlier, suspecting them of 
being virtual allies of the Labour Party and accusing them of wasteful and ineffective usage of financial resources. Now the achievement of outputs and outcomes characterise more a contract provision basis for the relationship rather than a true partnership. According to Edwards "the legitimacy of the NGO is no longer based upon values and voluntarism but on its contract to a legitimate agency" (Edwards \& Hulme 1996, p.967). Furthermore, the relationships are not based on long term objectives. In fact, there is no long-term strategy like a previously strategic policy framework that would unite two sectors or show a direction for mutual partnership. Instead, the relationships are framed with policy documents related to all NGOs working in New Zealand. Additional aspects stressing a lack of partnership between the Government and the sector are an absence of a learning platform and particularly institutional mechanism for its functioning as well as a major degree of uncertainty.

The question is where this partnership now exists in the context of NZODA. Partnership under the Labour Party government perhaps was not ideal but was closer to genuine partnership in many aspects mentioned above. It definitely required some "polishing" in terms of accountability issues and strengthening NGO independence. However, the recent contract-based relationships have shifted the sector to the other extreme losing the fundamental elements of a partnership approach. Meanwhile, achieving of effective partnership is crucial in a delivery of good development outcomes and increased aid effectiveness. This has been strongly outlined by academics (Brinkerhoff 2002d; Banks et al. 2012) and in international agreements like the MDGs, the Paris Declaration, the Accra Agenda for Action and the Busan Partnership for Effective Development Cooperation. According to the OECD the basis of effective aid delivery is a "genuine partnership" when both parties "are jointly and mutually responsible for development results" (OECD n.d., p.4). The Accra Agenda for Action stressed importance of the value and contribution of all partners claiming that "partnerships are most effective when they fully harness the energy, skills and experience of all development actors" (OECD 2008, p.17). A solution to get closer to the reality of genuine partnership between New Zealand Government and NGOs is contained in good personal relationships between the sectors, mutual will to pursue common long-term goals and reassessment of roles of partners and partnership itself. 


\subsection{Limitations and Directions for Future Research}

This research project aimed to collect data from a variety of NGOs and reveal a picture of the effects, NGOs experiences and opinions on the changes to aid policy since 2008. With the approach to select "the most productive sample" the researcher selected NGOs based on different criteria like NGOs size, number and sectoral focus of activities, geographical focus of work, religious and non-religious basis of NGOs, registration status, year of establishment of an organisation. Yet, because of time and logistical constraints only twenty one organisations out of fifty CID members of the development community participated in the project. Although many of the participants were well known organisations that had relationships with the Government, voices of the rest of the development professionals were not taken into consideration. Future research could usefully look at a wider sample of NGOs.

It is important to mention that often qualitative analysis was limited due to the researcher's obligation to keep participants' names confidential. So some data could not be included because it may have compromised the confidentiality of the respondents. Particularly this related to the engagement between the Government and a few NGOs that involved work at different policy levels not just projects and programmes. Meanwhile, this aspect of the interaction is an important part of the relationships and sharing of expertise and knowledge between the sectors. A more detailed analysis of the policy level collaboration is suggested for future studies.

Furthermore, the nature of the long term impacts should not be ignored. It is a well known fact that sometimes impacts could be revealed in a long term perspective and as indirect effects of the policies. As Lord noted "in the long-term, improved understanding of social impacts will improve the quality of impact assessment more generally" (Lord 2011, p.65). The other evidence was collected directly from the research participants who stressed that it was too early to assess policy impacts and a revisiting of some aspects of NGOs operations and policies will be required. Thus this research is based on the perceptions of the participants of changes over a relatively short time period rather than solid long term quantitative data. All these factors could form a basis for future evaluation and research. In addition, NGOs opinions and very limited effects of the NZPFID and NZDRP were assessed since these funds had been just rolled out (Interview 22). I believe that in analysing the effects of the new funding streams it would be useful to explore not just NGOs experiences but also examine influence on private sector and state agencies involved in development work. This ultimately extends 
a scope of a prospective research but increases its value in the context of international aid effectiveness agendas.

\subsection{Final Remarks}

Early responses to the government's changes in New Zealand aid policy in 2008-2009 involved both strong reactions from NGOs themselves, through the 'Don't Corrupt Aid' campaign, and strident criticism from academics (see Banks et al. 2012; Challies, McGregor \& Sentes 2011; Spratt 2012; Caritas 2009b; CWS 2010b; Oxfam) 2009b). It seemed as if the relationship between government and development NGOs in the country was heading for significant break down. However, the findings of this research indicate that the sector has demonstrated a wide mixture of responses that have revealed negative, neutral and positive effects on their operations. The new policy settings have significantly affected development work of NGOs and their relationships with the Government in different aspects. It is apparent, then, that NGOs and government have learned to live with each other. Many NGOs have muffled their criticisms and carried on trying to work in the new policy environment. For its part, government has increased aid funding and continued to fund the work of NGOs. However, in the course of these changes, the very essence of the partnership between the state and civil society, in the New Zealand development sector at least, has been transformed and compromised. Despite such a significant shift in the relationships there is still an opportunity to reshape and re-engage in a meaningful partnership and thus to improve the effectiveness of New Zealand aid. 


\section{References}

Abugre, C. 1999, Partners, collaborators or patron-clients: defining relationships in the aid industry. A survey of the issues, viewed 13 June 2013, http://www.ccic.ca/files/en/archives/aid 1999-08-defining_relationships_in_aid _industry.pdf.

Anheier, H.K. \& Ben-Ner A. 2003, The study of nonprofit enterprise: theories and approaches, Kluwer Academic/Plenum Publishers, New York.

Anheier, H.K. \& Seibel, W. 1990, The third sector: comparative studies of nonprofit organizations, De Gruyter, New York.

Arrow, K. 1963, 'Uncertainty and the welfare economics of medical care', American Economic Review, vol.53, pp. 941-973.

Bailey, F. \& Dolan, A. 2011, 'The meaning of partnership in development: lessons in development education', Policy \& Practice: A Development Education Review, vol. 13 , pp. $30-48$.

Banks, G. Murray, W. Overton, J. \& Scheyvens, R. 2012, 'Paddling on one side of the canoe? The changing nature of New Zealand's development assistance programme', Development Policy Review, vol. 30, no. 2, pp. 169-186.

Barnett, B. G., Hall, G. E., Berg, J. H. \& Camarena, M. M. 1999, 'A typology of partnerships for promoting innovation', Journal of School Leadership, vol. 9, no. 6 , pp. 484-510.

Bator, F. M. 1958, 'The anatomy of market failure', The Quarterly Journal of Economics, vol.72, no. 3, pp. 351-379.

Bena, F. 2012, Busan in a nutshell. What next for the global partnership for effective development cooperation? viewed 1 May 2013, http://www.oxfam.org/sites/www.oxfam.org/files/bn-busan-nutshell-globalpartnership-021012-en.pdf

Besley, T. \& Ghatak, M. 2001, 'Government versus private ownership of public goods', The Quarterly Journal of Economics, vol.116, no.4, pp. 1343-1372.

Better Aid, the International CSO Steering Group 2008, A civil society position paper for the 2008 Accra High Level Forum on aid effectiveness, viewed 2 May 2013, http://www.civicus.org/new/media/Making-aid-accountable.pdf

Bhaskar, R.1975, A realist theory of science, Leeds Books, York.

Blaikie, N. 2007, Approaches to social enquiry: advancing knowledge, Polity Press, Cambridge.

Bouget, D. \& Prouteau, L. 2002, 'National and supranational government-NGO relations: anti-discrimination policy formation in the European Union', Public Administration and Development, vol. 22, no. 1, p. 31-37.

Bowden, K. 2010, 'McCully's Pacific aid slashing 'whim' angers grassroots disaster team', Pacific. Scoop, 24 September, viewed 14 June 2013, 
http://pacific.scoop.co.nz/2010/09/mccullys-pacific-aid-slashing-whim-angersgrassroots-disaster-team/

Boyd, R. 1983, 'On the current status of the issue of scientific realism', Erkenntnis, vol. 19, pp. 45-90.

Brinkerhoff, J. 2002a, 'Assessing and improving partnership relationships and outcomes: a proposed framework', Evaluation and Program Planning, vol. 25, pp.215-231.

Brinkerkoff, J. M. 2002b, 'Government-nonprofit partnership: a defining framework', Public Administration and Development, vol. 22, pp.19-30.

Brinkerhoff, J.M. 2002c, Partnership for international development: rhetoric or results?', Lynne Rienner Publishers, Inc., London.

Brinkerhoff, J. \& Brinkerhoff D.W. 2002d, 'Government-nonprofit relationships in comparative perspective: evolution, themes and new directions', Public Administration and Development, vol. 22, pp.3-18.

Brinkerhoff, J. 2003, 'Donor-funded government-NGO partnership for public service improvement', Voluntas: International Journal of Voluntary and Nonprofit Organizations, vol. 14, no. 1.

Brown, L.D. \& Ashman, D. 1996, 'Participation, social capital, and intersectoral problem solving: African and Asian cases', World Development, vol. 24, no. 9, pp. 1467-1479.

Brown, L., Tucker, C. \& Domokos, T. 2003, 'Evaluating the impact of integrated health and social care teams on older people living in the community', Health and Social Care in the Community, vol.11, pp. 85-94.

Burch, S. \& Borland, C. 2001, 'Collaboration, facilities and communities in day care services', Health and Social Care in the Community, vol.9, pp.19-30.

Caplan, K. 2001, Perceptions of partnership: understanding what public, private and NGO partners may offer, BPD Water and Sanitation Cluster, London.

Caritas 2008, Annual report 2008, Caritas, Wellington.

Caritas 2009a, Annual report 2009, Caritas, Wellington.

Caritas 2009b, McCully Misleads over aid review, media release, 8 April 2009, viewed 14 June 2013, http://www.caritas.org.nz/newsroom/media-releases/mccullymisleads-over-aid-review

Caritas 2010a, Annual report 2010, Caritas, Wellington.

Caritas 2010b, Goalposts keep shifting for overseas aid funding, viewed 14 June 2013, http://www.caritas.org.nz/?sid=1246

Caritas 2011, Annual report 2011, Caritas, Wellington. 
Cbm New Zealand (cbm) 2007, Financial statements for the year ended 31 December 2007, cbm, Auckland.

Cbm New Zealand (cbm) 2008, Financial statements for the year ended 31 December 2008, cbm, Auckland.

Cbm New Zealand (cbm) 2009, Financial statements for the year ended 31 December 2009, cbm, Auckland.

Cbm New Zealand (cbm) 2010, Financial statements for the year ended 31 December 2010, cbm, Auckland.

Cbm New Zealand (cbm) 2011, Financial statements for the year ended 31 December 2011, cbm, Auckland.

Cecchini, C., David, L., Argall-Gouin, J. \& Wong-Rieger, D. 2000, Building great partnerships: a step-by-step guide for the voluntary sector', A report prepared by the Canadian Hemophilia Society for Health, Canada.

Challies, E., McGregor, A. \& Sentes, L. 2011, The changing landscape of international development in Aotearoa/New Zealand, NZADDS Working Paper 3, Wellington.

ChildFund New Zealand 2007, Annual report 2006/2007, ChildFund New Zealand, Auckland.

ChildFund New Zealand 2008, Annual report 2007/2008, ChildFund New Zealand, Auckland.

ChildFund New Zealand 2009, Annual report 2008/2009, ChildFund New Zealand, Auckland.

ChildFund New Zealand 2010, Annual report 2009/2010, ChildFund New Zealand, Auckland.

ChildFund New Zealand 2011, Annual report 2010/2011, ChildFund New Zealand, Auckland.

ChildFund New Zealand 2012, Annual report 2011/2012, ChildFund New Zealand, Auckland.

Christian World Service (CWS) 2008, Annual review 1July 2007-30 June 2008, CWS, Christchurch.

Christian World Service (CWS) 2009, Annual report July 2008- June 2009, CWS, Christchurch.

Christian World Service (CWS) 2010a, Annual report 2009-2010, CWS, Christchurch.

Christian World Service (CWS) 2010b, Changes to New Zealand ODA, 3 September, viewed 13 June 2013, http://www.cws.org.nz/take-action/aid 
Christian World Service (CWS) 2011a, An update on changes to government funding for NGOs, press release, viewed 18 November 2012, http://www.cws.org.nz/theissues/development-and-aid.

Christian World Service (CWS) 2011b, Annual review July1, 2010 -June 30, 2011, CWS, Christchurch.

Christian World Service (CWS) 2012, Annual review 2011 - 2012, CWS, Christchurch.

Cordery, C. \& Halford, S. August 2010, Funding social services: an historical analysis of responsibility for citizens' welfare in New Zealand, Paper presented at the Sixth Accounting History Conference, Wellington.

Coston, J. M. 1998, 'Model and typology of government-NGO relationships', Nonprofit and Voluntary Sector Quarterly, vol. 27, no.3, pp. 358-382.

Creswell, J.W. \& Plano Clark, V.L. 2011, Designing and conducting mixed methods research, SAGE Publications, Inc., Thousand Oaks, Calif.

Crotty, M. 1998, The foundations of social research, Allen \& Unwin, St Leonards, NSW.

De Vaus, D. A. 2002, Surveys in social research, Allen \& Unwin, NSW.

Development Action 2011, Development Action analysis: SDF applications, round 1, viewed 8 May 2012,http://www.developmentaction.co.nz/assets/DevelopmentAction-analysis-of-SDF-applications-for-publishing-FINAL.pdf

DiMaggio, P. J. \& Powell, W.W. 1983, 'The iron cage revisited: institutional isomorphism and collective rationality in organizational fields', American Sociological Review, vol. 48, no. 2, pp. 147-160.

Docstoc 2009, KOHA-HAF flowcharts, viewed 5 October 2012, http://www.docstoc.com/docs/114964221/koha_haf_flowcharts.

Douglas, J. 1983, Why charity: the case for a third sector, Sage Publications, Beverly Hills.

Edwards, M. \& Hulme, D. 1996, 'Too close for comfort? The impact of official aid on nongovernmental organizations', World Development, vol.24, pp. 961-973.

Ellmers, B. 2011, Busan partnership for effective development cooperation: some progress, no clear commitments, no thanks to EU, viewed 2 May 2013, http://www.cid.org.nz/news/post-busan-ngo-feedback

Engineers Without Borders New Zealand (EWBNZ) 2008, Annual report 2008, EWBNZ, Auckland.

Engineers Without Borders New Zealand (EWBNZ) 2009, Annual report 2009, EWBNZ, Auckland.

Engineers Without Borders New Zealand (EWBNZ) 2010, Statement of financial performance for the year ended 31 December 2010, EWBNZ, Auckland. 
Family Planning 2009, Annual report 2008-2009, Family Planning, Wellington.

Family Planning 2011, Annual report 2010-2011, Family Planning, Wellington.

Family Planning 2012, Annual report 1 July 2011- 30 June 2012, Family Planning, Wellington.

Fisher, J. November 1995, Government policies towards NGOs in the third world: political context and the growth of civil society, Paper presented at the 24th Annual ARNOVA Conference, Cleveland, Ohio.

Fowler, A. 2003, 'Partnerships: negotiating relationships. A resource for nongovernmental development organisations', Occasional Papers Series, no. 32, pp.1-21.

Gomez-Jauregui, J. 2004, 'The feasibility of government partnerships with NGOs in the reproductive health field in Mexico', Reproductive Health Matters, vol. 12, no. 24 , pp. $42-55$.

Grand, J. 1991, 'The theory of government failure', British Journal of Political Science, vol. 21 , no. 4 , pp. $423-442$.

Gray, D. E. 2009, Doing research in the real world, SAGE, Los Angeles.

Green, W. 2011, Busan Reflections from Wren, viewed 1 May 2013, http://www.cid.org.nz/news/busan-reflections-from-wren

Greene, J. C. 2008, 'Is mixed methods social inquiry a distinctive methodology?' Journal of Mixed Methods Research, vol.2, no. 1, pp. 7-22.

Greene, J. C., Caracelli, V. J. \& Graham, W. F. 1989, 'Toward a conceptual framework for mixed-method evaluation designs', Educational Evaluation and Policy Analysis, vol. 11, no. 3, pp. 255-274.

Gregory, D., Johnston, R., Pratt, G., Watts, M. \&Whatmore, S. 2009, The dictionary of human geography, Wiley, Singapore.

Greig, R. \& Poxton, R. 2001, 'Nice process - but did joint commissioning change anyone's life?' Managing Community Care, vol. 9, pp.16-21.

Hall, J. N. 1981, Evaluation and comparison: social learning curriculum and instrumental enrichment, Final report, U.S. Department of Education, TN: George Peabody College for Teachers, Nashville.

Hamilton, C. H. 2004, Of voluntary failure and change toward a new theory of voluntary-government relations in modern society, The Philanthropic Enterprise Working Paper 10, Carmel.

Hansmann, H. 1987, 'Economic theories of nonprofit organization', in W. W. Powell (ed.), The nonprofit sector: a research handbook, Yale University Press, New Haven. 
Haque, M. S. 2004, 'Governance based on partnership with NGOs: implications for development and empowerment in rural Bangladesh', International Political Science Review, vol. 70, no. 2, pp 271-290.

Haraway, D. J. 1991, Simians, cyborgs and women: the reinvention of nature, Free Association Books, London.

Harvey, S. 2009, 'Changes to foreign aid 'short-sighted', Otago Daily Times, 9 March, p.9.

Harvey-Jordan, S. \& Long, S. 2001, 'The process and the pitfalls of semi-structured interviews', Community Practitioner, vol. 74, no. 6, pp. 219-221.

Healy, M. \& Perry, C. 2000, 'Comprehensive criteria to judge validity and reliability of qualitative research within the realism paradigm', Qualitative Market Research: an international Journal, vol. 3, no. 3, pp. 118-126.

Heijden, H. V. D. 1987, 'The reconciliation of NGO autonomy, program integrity and operational effectiveness with accountability to donors', World Development, vol. 15, pp. 103-112.

Hesse, M.B. 1974, The Structure of Scientific Inference, University of California Press, California.

Hesse-Biber, S. 2010, Mixed methods research: merging theory with practice, Guilford Press, New York.

Horton, D., Prain, G. \& Thiele, G. 2009a, Perspectives on partnership: a literature review, International Potato Centre Working Paper 3, Peru.

Horton, D., Prain, G. \& Thiele, G. 2009b, Perspectives on partnership: highlights of a literature review, viewed 15 December 2012 http://www.cgiar-

lac.org/files/ILAC_Brief25_Partnership.pdf

Hudson, B. \& Hardy, B.2002, 'What is 'successful' partnership and how it can be measured?', in C. Glendinning, M Powell \& K. Rummery (eds.), Partnerships, new labour and the governance of welfare, The Policy Press, Bristol.

Hulme, D. \& Edwards, M. 1997, 'NGOs, States and Donors: An Overview', in D. Hulme \& M. Edwards (eds.), NGOs, states and donors: too close for comfort?, St. Martin's Press, New York.

International Development Group (IDG) 2009, Value for money guideline, IDG, Wellington.

Johnson, R. B., Onwuegbuzie, A. J. \& Turner, L. A. 2007, 'Toward a definition of mixed methods research', Journal of Mixed Methods Research, vol.1, no.2, pp. 112-133.

Johnstone, P. L. 2004, 'Mixed methods, mixed methodology health services research in practice', Qualitative Health Research, vol. 14, no.2, pp. 259-271. 
Kelle, U. 2006, 'Combining qualitative and quantitative methods in research practice: purposes and advantages', Qualitative Research in Psychology, vol.3, no. 4, pp. 293-311.

Kramer R.M. 1981, Voluntary Agencies in the Welfare State, University of California Press, Berkeley.

Lasker, R.D., Weiss, E.S. \& Miller, R. 2001, 'Partnership synergy: a practical framework for studying and strengthening the collaborative advantage', Milbank Quarterly, vol.79, no.2, pp.179-205.

Lawson, V. A. \& Staeheli, L. A. 1990, 'Realism and the practice of geography', The Professional Geographer, vol.42, no. 1, pp.13-20.

Lewis D. J. 1997, 'NGOs, donors, and the state in Bangladesh', Annals of the American Academy of Political and Social Science, vol. 554, pp. 33-45.

Lewis, D. 1998, 'Development NGOs and the challenge of partnerships: changing relations between North and South', Social Policy and Administration, vol. 32, no. 5, pp. 501-512.

Lipsky, M. \& Smith, S. R. 1990, 'Nonprofit organizations, government, and the welfare state', Political Science Quarterly, vol. 104, no. 4, pp. 625-648.

Lister, S. 1999, Power in partnership? An analysis of an NGO's relationships with its partners, Centre for Civil Society, London School of Economics International Working Paper 5, London.

Lister, S. 2003, 'NGO legitimacy technical issue or social construct?', Critique of Anthropology, vol. 23, no. 2, pp.175-192.

Lord, F. 2011 'Understanding social impacts by using new variables and a causal model diagram in New England fisheries', Impact Assessment and Project Appraisal, vol.29, no.1, pp.59-68.

Madey, D. L. 1982, 'Some benefits of integrating qualitative and quantitative methods in program evaluation, with illustrations', Educational Evaluation and Policy Analysis, vol. 4, no.2, pp. 223-236.

Mahanty, S., Yasmi, Y., Guernier, J., Ukkerman, R. \& Nass, L. 2009, 'Relationships, learning, and trust: lessons from the SNV-RECOFTC partnership', Development in Practice, vol.19, no.7, pp.859-872.

Maroney, T. \& Dollery, B. 2004, 'Explaining voluntary sector behaviour: an empirical test using NSW non-profit social service provider data', Journal of Economic and Social Policy, vol. 9, no.1, pp. 1-15.

Marshall, M. N. 1996, 'Sampling for qualitative research', Family Practice, vol.13, no. 6 , pp.522-525.

Matsunaga, Y. \& Yamauchi, N. 2004, 'A panel analysis using US state level data', Annals of Public and Cooperative Economics, vol.75, no. 2, pp. 227-263. 
Matthews, B. \& Ross, L. 2010, Research methods: a practical guide for the social sciences, Pearson Longman, New York.

Mayhew, S. 2005, 'Hegemony, politics and ideology: the role of legislation in NGOgovernment relations in Asia', The Journal of Development Studies, vol. 41, no. 5 , pp. 727-758.

Maynard, M. 1994, 'Methods, practice and epistemology: the debate about feminism and research', in M. Maynard and J. Purvis (eds.), Researching women's lives from a feminist perspective, Taylor and Francis, London.

McGregor, A., Challies, E., Overton, J. and Sentes, L. 2013, 'Developmentalities and donor-NGO relations: Contesting foreign aid policies in New Zealand/Aotearoa', Antipode, vol. 00, no. 00, pp. 1-22.

McGregor, A. n.d., NGOs and NZ Aid the value of civil society, viewed 13 June 2013, http://igps.victoria.ac.nz/events/downloads/2011/Andrew\%20McGregor\%20pres entation.pdf

Melville, R. 2008, Token participation to engaged partnerships: Lessons learnt and challenges ahead for Australian not-for-profits, viewed 13 December 2012, http://www.fahcsia.gov.au/our-responsibilities/communities-and-vulnerablepeople/publications-articles/token-participation-to-engaged-partnershipslessons-learnt-and-challenges-ahead-for-australian-not-for-profits\#a3

Ministerial Review Team 2001, A review of New Zealand's Official Development Assistance Programme: towards excellence in aid delivery, viewed 7 May 2012, http://nzadds.files.wordpress.com/2011/01/ministerial-review-nzoda-2001.pdf

Moon, S. M., Dillon, D. R. \& Sprenkle D. H. 1991, 'On balance and synergy: family therapy and qualitative research revisited', Journal of Marital and Family Therapy, vol.17, no.2, pp. 187-192.

Moran, D. 2006, 'Comparing services: a survey of leading issues in the sectoral literature', Public Administration and Development, vol. 26, no. 3, pp. 197-206.

Najam, A. 2000, 'The Four-C's of third sector-government relations cooperation, confrontation, complementarity, and co-optation', Nonprofit Management and Leadership, vol.10, no. 4, pp. 375-396.

Nelson, R. \& Krashinsky, M. 1973, 'Two major issues of public policy: public policy and organization of supply', in R. Nelson \& D. Young (eds.), Public subsidy for day care of young children, Mass.: D.C. Health \& Co, Lexington.

New Zealand Agency for International Development (NZAID) 2006, Humanitarian Action Fund (HAF): Handbook, NZAID, Wellington.

New Zealand Agency for International Development (NZAID) 2008, Kaihono hei Oranga Hapori o te Ao - Partnerships for International Community Development: KOHA-PICD, NZAID, Wellington.

New Zealand Agency for International Development (NZAID) 2010, Guideline working with civil society organisations, NZAID, Wellington. 
New Zealand Baptist Missionary Society (BANZAid) 2008, Statement of financial performance September 2007 - August 2008, New Zealand Baptist Missionary Society, Wellington.

New Zealand Baptist Missionary Society (BANZAid) 2009, Statement of financial performance September 2008 - August 2009, New Zealand Baptist Missionary Society, Wellington.

New Zealand Baptist Missionary Society (BANZAid) 2010, Statement of financial performance September 2009 - August 2010, New Zealand Baptist Missionary Society, Wellington.

New Zealand Baptist Missionary Society (BANZAid) 2011, Statement of financial performance September 2010 - August 2011, New Zealand Baptist Missionary Society, Wellington.

New Zealand Baptist Missionary Society (BANZAid) 2012, Statement of financial performance September 2010 - August 2012, New Zealand Baptist Missionary Society, Wellington.

New Zealand Family Planning Association 2008, Annual financial statements for the year ended 30 June 2008, New Zealand Family Planning Association, Wellington.

New Zealand Government 2009a, Cabinet Paper: New Zealand Agency for International Development: institutional arrangements, New Zealand Government, Wellington.

New Zealand Government 2009b, Cabinet Paper: New Zealand Agency for International Development: Mandate and Policy Settings, New Zealand Government, Wellington.

New Zealand Government 2009c, Annex 1 to Cabinet Paper: NZAID's mandate and policy settings, Author, Wellington.

New Zealand Government 2009d, CAB Min (09) 13/3C, New Zealand Government, Wellington.

New Zealand Ministry of Foreign Affairs and Trade (MFAT) n.d., New Zealand Partnerships for International Development Fund: Guidelines, MFAT, Wellington.

New Zealand Ministry of Foreign Affairs and Trade (MFAT) 2008, Statement of Intent 2008-2011, MFAT, Wellington.

New Zealand Ministry of Foreign Affairs and Trade (MFAT) 2010a, Sustainable Development Fund: Guidelines, MFAT, Wellington.

New Zealand Ministry of Foreign Affairs and Trade (MFAT) 2010b, Humanitarian Response Fund: Guidelines, MFAT, Wellington.

New Zealand Ministry of Foreign Affairs and Trade (MFAT) 2011, Sustainable Development Fund: Guidelines, MFAT, Wellington. 
New Zealand Ministry of Foreign Affairs and Trade (MFAT) 2012a, New Zealand Disaster Response Partnership: Guidelines, MFAT, Wellington.

New Zealand Ministry of Foreign Affairs \&Trade (MFAT) 2012b, What are NZ Inc strategies?, viewed 15 June 2013, http://www.mfat.govt.nz/NZ-Inc/1About/index.php

Office of the Auditor-General 2008, New Zealand Agency for International Development: Management of overseas aid programmes, viewed 16 May 2013, http://www.oag.govt.nz/2008/nzaid/docs/nzaid.pdf

O'Leary, Z. 2010, The essential guide to doing your research project, SAGE, Los Angeles, London.

Organisation for Economic Co-operation and Development (OECD) 2005, Paris declaration on aid effectiveness, OECD, Paris.

Organisation for Economic Co-operation and Development (OECD) 2008, Accra agenda for action, OECD, Accra.

Organisation for Economic Co-operation and Development (OECD) 2010, DAC peer review: New Zealand, viewed 7 May 2012, http://www.oecd.org/dataoecd/16/22/47468242.pdf.

Organisation for Economic Co-operation and Development (OECD) 2011a, The Busan partnership for effective development co-operation, OECD, Busan.

Organisation for Economic Co-operation and Development (OECD), 2011b, Aid effectiveness 2005-10: progress in implementing the Paris Declaration, OECD.

Organisation for Economic Co-operation and Development (OECD) 2013, The High Level Forum on aid effectiveness: a history, viewed 1 May 2013, http://www.oecd.org/dac/effectiveness/thehighlevelforaonaideffectivenessahistor y.htm\#Paris

Organisation for Economic Co-operation and Development (OECD), n.d. Reaching Our Development Goals: Why Does Aid Effectiveness Matter?, viewed 10 July 2013, http://www.oecd.org/dac/effectiveness/40987004.pdfWorksh

Outhwaite, W. 1987, New philosophies of social science: realism, hermeneutics and critical theory, Macmillan Education, Houndmills, Basingstoke, Hampshire.

Overton, J. 2009, 'Reshaping development aid: implications for political and economic relationships', Policy Quarterly, vol. 5, no. 3, pp. 3-9.

Oxfam New Zealand (Oxfam) 2007, Review 2007, Oxfam New Zealand, Auckland.

Oxfam New Zealand (Oxfam) 2008, Review 2008, Oxfam New Zealand, Auckland.

Oxfam New Zealand (Oxfam) 2009a, Annual review 2009, Oxfam New Zealand, Auckland. 
Oxfam New Zealand (Oxfam) 2009b, Politics and aid don't mix: Oxfam, media release, 3 March, viewed 1 October 2012, http://www.oxfam.org.nz/news/politics-andaid-don-t-mix-oxfam

Oxfam New Zealand (Oxfam) 2010, Review 2010, viewed 2 February 2013, http://www.oxfam.org.nz/about-us/financial-statement/review-2010

Oxfam New Zealand (Oxfam) 2011, Annual review 2011, Oxfam New Zealand, Auckland.

Oxfam New Zealand (Oxfam) 2012, Review 2012, viewed 2 February 2013, http://www.oxfam.org.nz/about-us/financial-statement/review-2012

Pacific. Scoop 2009a, 'Murray McCully's attack on New Zealand's foreign aid programme', 9 March, viewed 14 June 2013, http://gordoncampbell.scoop.co.nz/2009/03/09/campbell-mccully\%e2\%80\%99sattack-on-nzs-aid-programme/

Pacific. Scoop 2009b, 'CID disappointed at change to NZAID status', 7 May, viewed 14 June 2013, http://www.scoop.co.nz/stories/PO0905/S00107.htm

Park, C. 2008, 'Do the boundaries between the nonprofit, public and business sectors blur? Comparing "within the nonprofit sector collaboration networks" and "inter-sector collaboration networks" in the social service field in Pittsburgh, Pennsylvania', International Review of Public Administration, vol. 13, no. 2, pp.81-95.

Partington, D.2002, Essential skills for management research, SAGE, London.

Pickard, A. J. 2007, Research methods in information, Facet Publishing, London.

Powell, W.W. \& Steinberg, R. 2006, The nonprofit sector: a research handbook, Yale University Press, New Haven.

Probandari, A., Utarini, A., Lindholm, L. \& Hurtig, A. 2011, 'Life of a partnership: the process of collaboration between the national tuberculosis program and the hospitals in Yogyakarta, Indonesia', Social Science and Medicine, vol. 73, no.9, pp.1386-1394.

Provan, K.G. \& Milward, H.B. 2001, 'Do networks really work? A framework for evaluating public-sector organizational networks', Public Administration Review, vol. 61, no. 4, pp. 414-423.

Ramanath, R. 2005, From conflict to collaboration: nongovernmental organizations and their negotiations for local control of slum and squatter housing in Mumbai, India, PhD. dissertation, the Virginia Polytechnic Institute and State University.

Ramanath, R. 2009, 'Limits to institutional isomorphism: examining internal processes in NGO-government interactions', Nonprofit and Voluntary Sector Quarterly, vol. 38 , no.1, pp. 51-76.

Rose, G. 1997, 'Situating knowledges: Positionality, reflexivities and other tactics', Progress in Human Geography, vol. 21, no.3, pp. 305-320. 
Salamon, L. M. \& Anheier, H. K. 1998, 'Social origins of civil society: explaining the nonprofit sector cross-nationally', Voluntas: International Journal of Voluntary and Nonprofit Organizations, vol. 9, no.3, pp. 213-248.

Salamon, L. M. 1987a, 'Of market failure, voluntary failure, and third-party government: toward a theory of government-nonprofit relations in the modern welfare state', Nonprofit and Voluntary Sector Quarterly, vol. 16, no. 29, pp.29-49.

Salamon, L. M. 1987b, 'Partners in public service: the scope and theory of governmentnonprofit relations', in W. W. Powell (ed.), The nonprofit sector: a research handbook, Yale University Press, New Haven.

Sale, J. E. M., Lohfeld, L. H. \& Brazil, K. 2002, 'Revisiting the quantitative-qualitative debate: implications for mixed-methods research', Quality \& Quantity, no. 36, pp. 43-53.

Save the Children New Zealand (Save the Children) 2010, Annual report 2009-2010, Save the Children, Wellington.

Save the Children New Zealand (Save the Children) 2011, Annual report 2010-2011, Save the Children, Wellington.

Save the Children New Zealand (Save the Children) 2012, Annual report 2011-2012, Save the Children, Wellington.

Sayer, A. 1985, 'Realism and geography', in R. J. Johnston (ed.), The Future of Geography, Methuen, London.

Sayer, A. 2000, Realism and social science, Sage, London, Thousand Oaks, Calif.

Shah, J. \& Singh, N. 2001, 'Benchmarking internal supply chain performance: development of a framework', The Journal of Supply Chain Management, vol. 37 , no. 1, pp. 37-47.

Siddiqi, N. \& Oever, P. Van Den 1998, Report on Consultative Meeting on Partnerships:Joining Hands with Government and Non-government Development Organizations and Local Communities, Social Development Department, The World Bank, Washington, D.C.

Smillie, I. \& Helmich, H. 1993, Non-governmental organizations and governments: stakeholders for development, Development Center, Organization for Economic Development and Cooperation (OECD), Paris.

Sood, P. 2000, Flowing upstream: the case for co-operative efforts between NGO-state relationships concerning the drinking water crisis in rural Gujarat (India), Masters of Arts thesis, Dalhousie University.

Spratt, J. 2011, Cutting the hand off exploring NZ Aid Programme funding cuts to Pacific organisations, NZADDS Commentary 3, Wellington.

Spratt, J. 2012, A bolt from the blue: examining the 2009 changes to the New Zealand Aid Programme and what they mean now', NZADDS Working Paper, Wellington. 
Steinberg, R. \& Young, D.R. 1998, ‘A comment on Salamon and Anheier's "Social origins of civil society", Voluntas: International Journal of Voluntary and Nonprofit Organizations, vol. 9, no.3, pp. 249-260.

Stuff 2010, 'Aid workers uncertain about funding', 20 April, viewed 14 June 3013, http://www.stuff.co.nz/dominion-post/news/politics/3600269/Aid-workersuncertain-about-funding

Tashakkori, A. \& Charles, T. 1998, Mixed methodology: combining qualitative and quantitative approaches, SAGE, Thousand Oaks, Calif.

Teamey, K. 2007, Whose public action? Analysing inter-sectoral collaboration for service delivery literature review on relationships between government and nonstate providers of services, University of Birmingham, International Development Department, Birmingham.

TEAR Fund 2007, Financial statements for the year ended 30 June 2007, TEAR Fund, Auckland.

TEAR Fund 2009a, Annual report 2009, by TEAR Fund, Auckland.

TEAR Fund 2009b, 'Wider Consultation Needed before Changing NZAID', viewed 14 June 2013, http://www.tearfund.co.nz/about-us/archive.html?articleid=288

TEAR Fund 2010, Financial summary 2010, TEAR Fund, Auckland.

TEAR Fund 2011, Financial statements for the year ended 30 June 2011, TEAR Fund, Auckland.

TEAR Fund 2012, Financial statements for the year ended 30 June 2012, TEAR Fund, Auckland.

The Adventist Development and Relief Agency (ADRA) 2009, Annual review 2009, ADRA New Zealand, Auckland.

The Adventist Development and Relief Agency (ADRA) 2011, Annual report 2011, ADRA New Zealand, Auckland.

The Adventist Development and Relief Agency (ADRA) 2012, Annual report 2012, ADRA New Zealand, Auckland.

The Council for International Development (CID) 2009, CID annual report 2009, viewed 1 May 2013, http://www.cid.org.nz/assets/About/2009Annualreportweb.pdf

The Council for International Development (CID) 2010, Survey 2010: report, viewed 1 May 2013, http://www.cid.org.nz/assets/Members/Member-Surveys/SurveyReport-2010.pdf

The Council for International Development (CID) 2011, Survey of CID members 2011: report, viewed 1 May 2013, http://www.cid.org.nz/assets/Members/MemberSurveys/CID-MEMBERS-SURVEY-2011-FINAL.pdf 
The Council for International Development (CID) 2012a, Feedback summary from SDF survey February 2012, viewed 20 April 2013, http://www.cid.org.nz/assets/Uploads/NGO-Consultative-Group-FeedbackSummary-from-SDF-survey-February-2012.pdf.

The Council for International Development (CID) 2012b, Survey of CID members 2012: report, viewed 1 May 2013, http://www.cid.org.nz/assets/Members/Member-Surveys/2012-Survey-of-CIDmembers-Report.pdf

The Institute for Governance and Policy Studies (IGPS), n.d., NGOs and NZ Aid: lessons on the value of investing well in civil society, viewed 13 June 2013, http://igps.victoria.ac.nz/events/downloads/2011/NZADD\%20Seminar\%20on\% 20NGOs\%20and\%20NZ\%20Aid.pdf

The International Trade Union Confederation (ITUC) 2008, Civil society statement in Accra warns urgency for action on aid, viewed 1 May 2013, http://www.ituccsi.org/IMG/pdf/Final_CSO_Statement_Accra010908.pdf

The Leprosy Mission New Zealand 2008, Annual report 2007-2008, The Leprosy Mission New Zealand, Auckland.

The Leprosy Mission New Zealand 2009, Annual report 2008-2009, The Leprosy Mission New Zealand, Auckland.

The Leprosy Mission New Zealand 2010, Annual report 2009-2010, The Leprosy Mission New Zealand, Auckland.

The Leprosy Mission New Zealand 2011, Annual review 2010-2011, The Leprosy Mission New Zealand, Auckland.

The Leprosy Mission New Zealand 2012, Annual report 2012, The Leprosy Mission New Zealand, Auckland.

The New Zealand Aid Programme 2008, First phase of the evaluation of the implementation of the Paris Declaration, agency level evaluations - NZAID, viewed 1 May 2013, http://www.aid.govt.nz/about-aid-programme/measuringresults/evaluation/activity-reports/2008-review-and-evaluation-reports/firstphase-eval

The New Zealand Aid Programme 2011, International development policy statement, viewed 13 May 2013, http://www.aid.govt.nz/webfm_send/454

The New Zealand Aid Programme n.d., Aid statistics, viewed 15 May 2013, http://www.aid.govt.nz/about-aid-programme/aid-statistics

The New Zealand China Friendship Society Incorporated (NZCFS) 2008, Income and Expenditure statement for the period 1 April 2007 - 31 March 2008, NZCFS.

The New Zealand China Friendship Society Incorporated (NZCFS) 2010, Financial Statements for the year ended 31 March 2010, NZCFS.

The New Zealand China Friendship Society Incorporated (NZCFS) 2011, Financial Statements for the year ended 31 March 2011, NZCFS. 
The New Zealand China Friendship Society Incorporated (NZCFS) 2012, Financial Statements for the year ended 31 March 2012, NZCFS.

Torjman, S. 1998, The good, the bad and the uncertain, viewed 15 December 2012, http://www.caledoninst.org/Publications/PDF/partners.pdf

Ullah, Z.A.N., Newell, J.N., Ahmed, J.U., Hyder, M.K. \& Islam A. 2006, 'GovernmentNGO collaboration: the case of tuberculosis control in Bangladesh', Health Policy Plan, vol. 21, pp.143-155.

Volunteer Service Abroad (VSA) 2011, New direction for VSA, 14 March, viewed 14 June 2013. http://www.vsa.org.nz/about-vsa/news/new-direction-for-vsa/

Volunteer Service Abroad (VSA) 2009, Financial Statements for the year ended 31 March 2009, Volunteer Service Abroad Foundation, Wellington.

Volunteer Service Abroad (VSA) 2010, Financial Statements for the year ended 31 March 2010, Volunteer Service Abroad Foundation, Wellington.

Waddell, S. November 1998, Tri-sector coproduction collaborations: a new type of development organization, Paper presented at the 27th Annual ARNOVA Conference, Seattle.

Wang, S. 2006, Money and autonomy: patterns of civil society finance and their implications, Studies in Comparative International Development, vol.40, no.4, pp. 3-29.

Webster, P. 2011, Paddling in choppy waters the role of politics: a response to paddling on one side of the canoe, NZADDS Commentary 2, Wellington.

Weisbrod, B. A. \& Long, S. H. 1977, 'The size of the voluntary nonprofit sector: concepts and measures', in B. A. Weisbrod (ed.), The voluntary nonprofit sector. An economic analysis, Lexington/ Mass., Toronto.

Wetterberg, A. 2011, 'Public-private partnership in labor standards. Governance: better factories Cambodia', Public Administration and Development, vol. 31, pp. 64-73.

Williams, S. W. 1981, 'Realism, marxism and human geography', Antipode, vol.13, pp. 31-38.

Wood, T. 2011, 'New group monitoring New Zealand aid claims Minister against some NGOs', Radio New Zealand International, 14 February, viewed 13 June 2013, http://www.rnzi.com/pages/news.php?op=read\&id=58751

World Vision of New Zealand Trust Board 2008, Financial statements ended 30 September 2008, World Vision, Auckland.

World Vision of New Zealand Trust Board 2009, Financial statements ended 30 September 2009, World Vision, Auckland.

World Vision of New Zealand Trust Board 2011, Financial statements ended 30 September 2011, World Vision, Auckland. 
World Vision of New Zealand Trust Board 2012, Financial statements ended 30 September 2012, World Vision, Auckland.

Young, D. R. 1999, 'Complementary, supplementary, or adversarial? A theoretical and historical examination of nonprofit-government relations in the United States', in E. T. Boris \& C. E. Steuerle (eds.), Nonprofits and government: collaboration and conflict, Urban Institute Press, Washington, D.C.

Young, D. R. 2000, 'Alternative models of government-nonprofit sector relations: theoretical and international perspectives', Nonprofit and Voluntary Sector Quarterly, vol.29, no.1 pp. 149-172.

Zimmer, A. 2010, 'Third sector-government partnerships', in R. Taylor (ed.), Third Sector Research, Springer Science+Business Media, New York. 


\section{Appendix 1- Ethic Forms NGO PARTICIPANT INFORMATION SHEET}

Title of project: Understanding the impact of changes to New Zealand Official Development Assistance policy on New Zealand non-government organisations

Researcher: Valeria Openko, a Masters student in Development Studies at Victoria University of Wellington. A research project will be undertaken as part of this degree and lead to a thesis. The University requires that ethics approval be obtained for research involving human participants.

The purpose of the study: This study is designed to better understand how a redirection of New Zealand Official Development Assistance (NZODA) policy that took place from 2008, affected local development non-government organisations (NGOs). In other words, the study examines what these changes meant to NGOs and what they led to. The research project aims to collect and analyse data that will contribute to building a strong partnership between New Zealand Government and NGOs.

Participation and withdrawal: New Zealand NGOs working in international development are invited to participate in the study. Participants will be asked to take part in a semi-structured interview. The interview will probably last about one hour depending on how much time you have available. I will record the interviews with your permission. A group of topics and questions for the interview discussion is presented in an interview checklist.

Participation in this study is completely voluntary. If you decide to take part you will be given this information sheet to keep. You will also be asked to sign a consent form and provided with a copy of this. Should any participants feel the need to withdraw from the project, they may do so without question at any time before the data is analysed. The deadline for this is $1^{\text {st }}$ of March 2013.

Confidentiality and security of data: Collected data will form the basis of my research project and will be put into a written report on a confidential basis. Each NGO will be presented under a random case number in the report. Any quotes presented in the research work will be strictly confidential. It will not be possible for your organisation to be identified. In addition, any details which potentially could identify you will also be removed or changed.

All collected materials will be kept confidential. No other person besides me and my supervisor, Professor John Overton, will have an access to the transcripts of your interview. All interview recordings will be destroyed one year after the conclusion of the research. The thesis will be submitted for marking to the School of Geography, Environment and Earth Sciences, deposited in the University Library, presented in research publications and disseminated at professional conferences.

Additional information and contacts: If you have any questions or would like to receive further information about the project, please contact me (ph.: 0212672371 , e-mail: openkovale@myvuw.ac.nz) or my supervisor, Professor John Overton (ph.: 04463 5281, e-mail: john.overton@vuw.ac.nz) at the School of Geography, Environment and Earth Sciences at Victoria University of Wellington, PO Box 600, Wellington.

Signed:

Date: 31.08 .2012

Valeria Openko 


\section{NGO CONSENT TO PARTICIPATION IN RESEARCH}

Title of project: Understanding the impact of changes to New Zealand Official Development Assistance Policy on New Zealand non-government organisations.

Researcher: Valeria Openko, a Masters student in Development Studies at Victoria University of Wellington.

Please tick the appropriate boxes

I have read and understood the project information sheet dated 31.08.2012.

I have been given the opportunity to ask questions about the project and have received satisfactory answers to questions and any additional details requested.

I agree to take part in the research project.

I agree to the interview being recorded.

I understand that my participation is voluntary. I can withdraw from the study (before $1^{\text {st }}$ of March 2013) without having to give reasons or without penalty of any sort.

I understand how the data will be stored and what will happen to the data at the end of the project.

I understand that the research will be conducted on a confidential basis. The published results will not use my name or name of my organisation, and that no opinions will be attributed to me in any way that will identify me and the organisation I work for.

I understand that the data I provide will not be used for any other purposes or released to others without my written consent.

I would like to receive a summary of the results of this research when it is completed by

e-mail:

post:

I understand that this project has been reviewed by, and received ethics clearance through, Victoria University of Wellington Human Ethics Committee.

Yes No
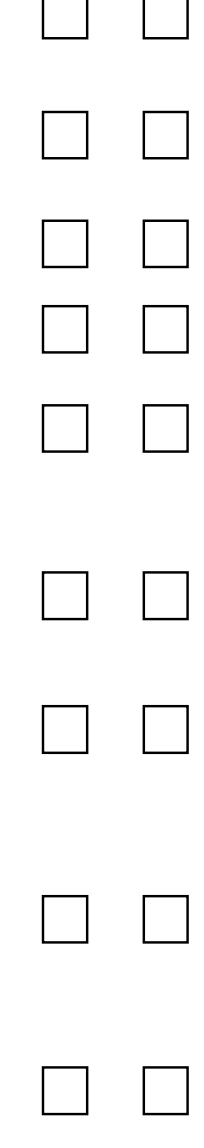

Signed:

Name of participant Date: 


\section{NGO INTERVIEW CHECKLIST}

\section{Semi-structured interview questions:}

1. What are your views on the changes and redirection of NZODA policy which occurred from 2008 ?

2. What did these changes mean for your organisation?

3. Did these transformations affect NGO's development projects? Could you tell me how?

4. Did the changed policy influence your NGO's financial situation and if yes, how?

5. What could you say about the impact of these changes on the organisational processes (NGO's procedures, policies including recruitment, fundraising regulations and etc.)?

6. Did new policy affect NGO's system of development instruments and tools (monitoring and evaluation system, participation approaches and etc.) within your and your partner organisations? Could you explain how?

7. Was your reporting system with the New Zealand Aid Programme and developing country partners modified due to a redirection of the NZODA Policy? If yes, in what ways?

8. Were your relationships with partners in developing countries affected and how?

9. Did your NGO experience any positive influences because of the changed course of the NZODA policy?

10. What other consequences did your NGO face due to the policy transformations within last five years?

11. What do you expect from new contestable funds - New Zealand Partnerships for International Development Fund ("Partnerships Fund") and New Zealand Disaster Response Partnership?

12. How would you characterise your current relationships with the New Zealand Aid Programme?

13. a) Could you please choose a type of NGO-government relationships outlined in the table below that most precisely describes your current relationships with the Government? 


\begin{tabular}{|l|l|l|}
\hline \multicolumn{1}{|c|}{ Supplementary } & \multicolumn{1}{|c|}{ Complementary } & \multicolumn{1}{c|}{ Adversarial } \\
\hline $\begin{array}{l}\text { NGOs operate } \\
\text { independently as } \\
\text { supplements to } \\
\text { government. NGOs } \\
\text { provide services that } \\
\text { are not delivered by } \\
\text { government. }\end{array}$ & $\begin{array}{l}\text { NGOs and government } \\
\text { work in a partnership } \\
\text { relationship. NGOs } \\
\text { deliver services that are } \\
\text { mostly financed by } \\
\text { government. }\end{array}$ & $\begin{array}{l}\text { NGOs and government } \\
\text { are engaged in an } \\
\text { adversarial relationship } \\
\text { of mutual } \\
\text { accountability. } \\
\end{array}$ \\
& $\begin{array}{l}\text { NGOs encourage } \\
\text { government to make } \\
\text { changes in public } \\
\text { policy. Meanwhile, } \\
\text { government influences } \\
\text { behaviour of NGOs } \\
\text { through different } \\
\text { regulations. }\end{array}$ \\
& & \\
& & \\
& &
\end{tabular}

Source: Young, 2000; Teamey, 2007

b) If you have chosen a complementary type of relationships could you specify in what partnership indicated in the table below you are involved?

\begin{tabular}{|l|l|}
\hline \multicolumn{1}{|c|}{ Active Partnership } & \multicolumn{1}{c|}{ Dependent Partnership } \\
\hline Process & Blueprint, fixed term \\
Negotiated, changing roles & Rigid roles \\
Clear purposes, roles and linkages & Unclear purposes, roles and linkages \\
Shared risks & Individual interests \\
Debate and dissent & Consensus \\
Learning and information exchange & Poor communication flows \\
'Activity-based' origins - emerging from & 'Resource-based' origins - primarily to \\
practice & gain access to funds \\
\hline
\end{tabular}

Source: Lewis, 1997

14. Using a five-point rating scale how could you evaluate your current relationships with New Zealand Aid Programme?

\begin{tabular}{|l|l|l|l|l|}
\hline Very poor & Poor & $\begin{array}{c}\text { Neither Good } \\
\text { nor Poor }\end{array}$ & Good & Excellent \\
\hline & & & & \\
\hline
\end{tabular}

15. What could you recommend to improve relationships with New Zealand Aid Programme? 


\section{MFAT PARTICIPANT INFORMATION SHEET}

Title of project: Understanding the impact of changes to New Zealand Official Development Assistance policy on New Zealand non-government organisations.

Researcher: Valeria Openko, a Masters student in Development Studies at Victoria University of Wellington. A research project will be undertaken as part of this degree and lead to a thesis. The University requires that ethics approval be obtained for research involving human participants.

The purpose of the study: This study is designed to better understand how a redirection of New Zealand Official Development Assistance policy that took place from 2008, affected local development non-government organisations (NGOs). In other words, the study examines what these changes meant to NGOs and what they led to. The research project aims to collect and analyse data that will contribute to building a strong partnership between New Zealand Government and NGOs.

Participation and withdrawal: The New Zealand Aid Programme is invited to participate in the study. The participant will be asked to take part in a semi-structured interview that will probably last about one hour depending on how much time you have available. I will record the interview with your permission. A group of topics and questions for the interview discussion is presented in an interview checklist.

Participation in this study is completely voluntary. If you decide to take part you will be given this information sheet to keep. You will also be asked to sign a consent form and provided with a copy of this. Should the participant feel the need to withdraw from the project, the New Zealand Aid Programme may do so without question at any time before the data is analysed. The deadline for this is 30th of April 2013.

Confidentiality and security of data: Collected data will be put into a written report neither on anonymous or confidential basis. Any quotes published in the research work will be presented on the behalf of the New Zealand Aid Programme. Meanwhile, a name of the government official participated in the interview will be kept confidential.

No other person besides me and my supervisor, Professor John Overton, will have an access to the transcripts of your interview. All interview recordings will be destroyed one year after the conclusion of the research. The thesis will be submitted for marking to the School of Geography, Environment and Earth Sciences, deposited in the University Library, presented in research publications and disseminated at professional conferences.

Additional information and contacts: If you have any questions or would like to receive further information about the project, please contact me (ph.: 0212672 371, e-mail: openkovale@myvuw.ac.nz) or my supervisor, Professor John Overton (ph.: 04463 5281, e-mail: john.overton@vuw.ac.nz) at the School of Geography, Environment and Earth Sciences at Victoria University of Wellington, PO Box 600, Wellington.

Signed:

Date: 31.08 .2012

Valeria Openko 


\section{MFAT CONSENT TO PARTICIPATION IN RESEARCH}

Title of project: Understanding the impact of changes to New Zealand Official Development Assistance Policy on New Zealand non-government organisations.

Researcher: Valeria Openko, a Masters student in Development Studies at Victoria University of Wellington.

\section{Please tick the appropriate boxes}

Yes No

I have read and understood the participant information sheet dated 31.08.2012

I have been given the opportunity to ask questions about the project and have received satisfactory answers to questions and any additional details requested.

I agree to take part in the research project.

I agree to the interview being recorded.

I understand that my participation is voluntary. I can withdraw from the study (before 30th of April 2013) without having to give reasons or without penalty of any sort.

I understand how the data will be stored and what will happen to the data at the end of the project.

I understand that the collected data will be used neither on anonymous or confidential basis. The published results will be attributed to the New Zealand Aid Programme. The name of the official granted the interview will be kept confidential.

I would like to receive a summary of the results of this research when it is completed by

Agreed on the opportunity to review responses prior to submission of the thesis

e-mail:

post:

Signed:

Name of participant

Date: 


\section{MFAT INTERVIEW CHECKLIST}

\section{Semi-structured interview questions:}

1. What have been the main changes in the NZODA policy since 2008 (especially with regard to government funding for NGOs)?

1.1 How did these changes affect New Zealand NGOs working in international development?

2. How did these transformations impact the number, type and size of development activities funded by the New Zealand Aid Programme and delivered by New Zealand NGOs?

3. How have changes in New Zealand aid policies since 2008 affected the size of Official Development Assistance and its annual allocations?

4. What could you say about the impact of policy changes on the organisational processes (accepting of NGOs' project applications, appraisal and decision making processes, recruitment policy and etc.) within the New Zealand Aid Programme?

\subsection{What did this mean to New Zealand NGOs?}

5. How did new policy affect a system of development instruments and tools (monitoring and evaluation system, participatory approaches, baseline survey and etc.) in the New Zealand Aid Programme?

5.1. What was the impact of these alterations on New Zealand NGOs?

6. How was your reporting system with New Zealand NGOs modified due to the redirection of the NZODA Policy?

6.1 How could you evaluate the effect of the reporting system on New Zealand NGOs and their partners on the ground?

7. Were your relationships with New Zealand NGOs affected by the transformations in the NZODA Policy? If yes, how?

7.1 Do you think the relationships between New Zealand NGOs and their partners in developing countries were affected? If yes, how?

8. What did the New Zealand Aid Programme expect from new contestable funds New Zealand Partnerships for International Development Fund and New Zealand Disaster Response Partnership? Were the expectations met?

8.1 How do you think new contestable funding schemes affected New Zealand NGOs? 
9. How would you characterise your current relationships with New Zealand NGOs?

10. a) Could you please choose a type of NGO-government relationships outlined in the table below that most precisely describes your current relationships with the NGO sector?

\begin{tabular}{|l|l|l|}
\hline \multicolumn{1}{|c|}{ Supplementary } & \multicolumn{1}{|c|}{ Complementary } & \multicolumn{1}{c|}{ Adversarial } \\
\hline $\begin{array}{l}\text { NGOs operate } \\
\text { independently as } \\
\text { supplements to } \\
\text { government. NGOs } \\
\text { provide services that } \\
\begin{array}{l}\text { are not delivered by } \\
\text { government. }\end{array}\end{array}$ & $\begin{array}{l}\text { NGOs and government } \\
\text { work in a partnership } \\
\text { relationship. NGOs } \\
\text { deliver services that are } \\
\text { mostly financed by } \\
\text { government. }\end{array}$ & $\begin{array}{l}\text { NGOs and government } \\
\text { are engaged in an } \\
\text { adversarial relationship } \\
\text { of mutual accountability. } \\
\text { NGOs encourage } \\
\text { government to make } \\
\text { changes in public policy. } \\
\text { Meanwhile, government } \\
\text { influences behaviour of } \\
\text { NGOs through different } \\
\text { regulations. }\end{array}$ \\
& & \\
& & \\
\hline
\end{tabular}

Source: Young, 2000; Teamey, 2007

b) If you have chosen a complementary type of relationships could you specify in what partnership indicated in the table below you are involved?

\begin{tabular}{|l|l|}
\hline \multicolumn{1}{|c|}{ Active Partnership } & \multicolumn{1}{c|}{ Dependent Partnership } \\
\hline Process & Blueprint, fixed term \\
Negotiated, changing roles & Rigid roles \\
Clear purposes, roles and linkages & Unclear purposes, roles and linkages \\
Shared risks & Individual interests \\
Debate and dissent & Consensus \\
$\begin{array}{l}\text { Learning and information exchange } \\
\text { 'Activity-based' origins - emerging from } \\
\text { practice }\end{array}$ & $\begin{array}{l}\text { Poor communication flows } \\
\text { 'Resource-based' origins - primarily to } \\
\text { gain access to funds }\end{array}$ \\
\hline
\end{tabular}

Source: Lewis, 1997

11. Using a five-point rating scale how could you evaluate your current relationships with the NGO sector?

\begin{tabular}{|l|l|l|l|l|}
\hline Very poor & Poor & $\begin{array}{c}\text { Neither Good } \\
\text { nor Poor }\end{array}$ & Good & Excellent \\
\hline & & & & \\
\hline
\end{tabular}

12. What do you think should be done by both sides to improve relationships between the Government and NGO sector? 


\section{Appendix 2 - Figures and Tables}

Figure A.1 NGOs' Income from the New Zealand Government in 2009

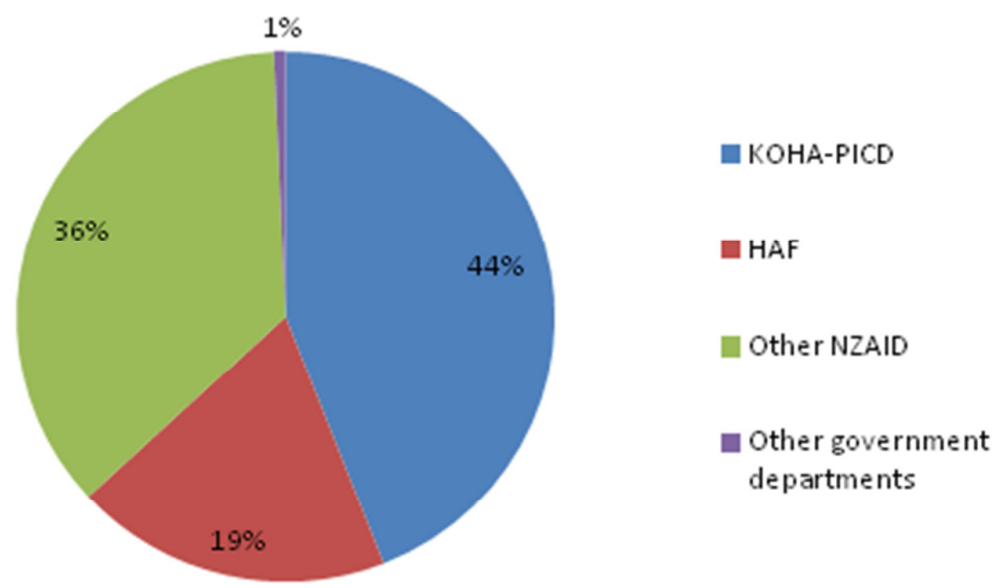

Source: CID 2009 
Figure A.2 NGOs' Income by Donor in 2010

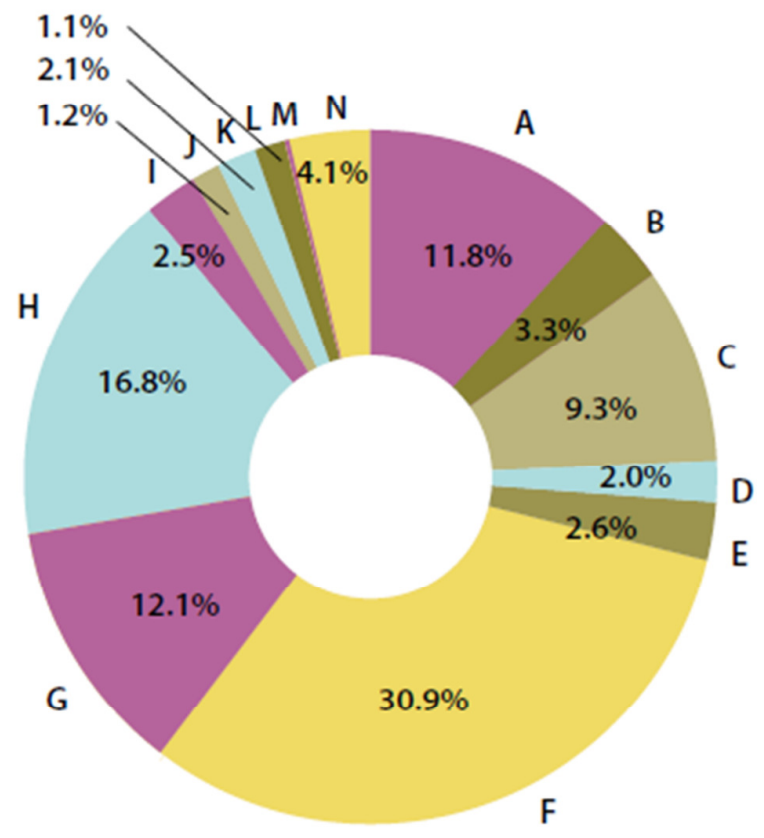

A: $\mathrm{KOHA}$

B: $\mathrm{HAF}$

C: Other MFAT

D: Other NZ Govt

E: Emergency

F: Child Sponsorships

G: Regular

H: One-off

I: Endowments

J: Private Sector

K: Foundations

L: Sales

$\mathrm{M}$ : Contracts

$\mathrm{N}$ : Other

Source: CID 2010 
Figure A.3 NGOs' Income from the New Zealand Government in 2011

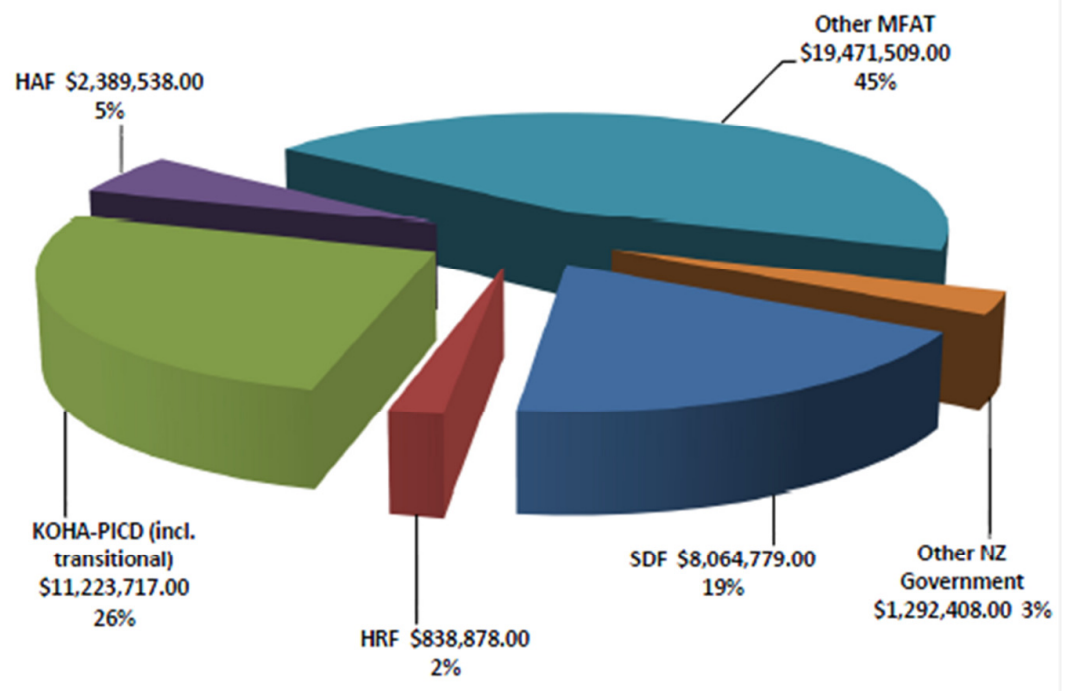

Source: CID 2011 
Figure A.4 NGOs' Income from the New Zealand Government in 2012

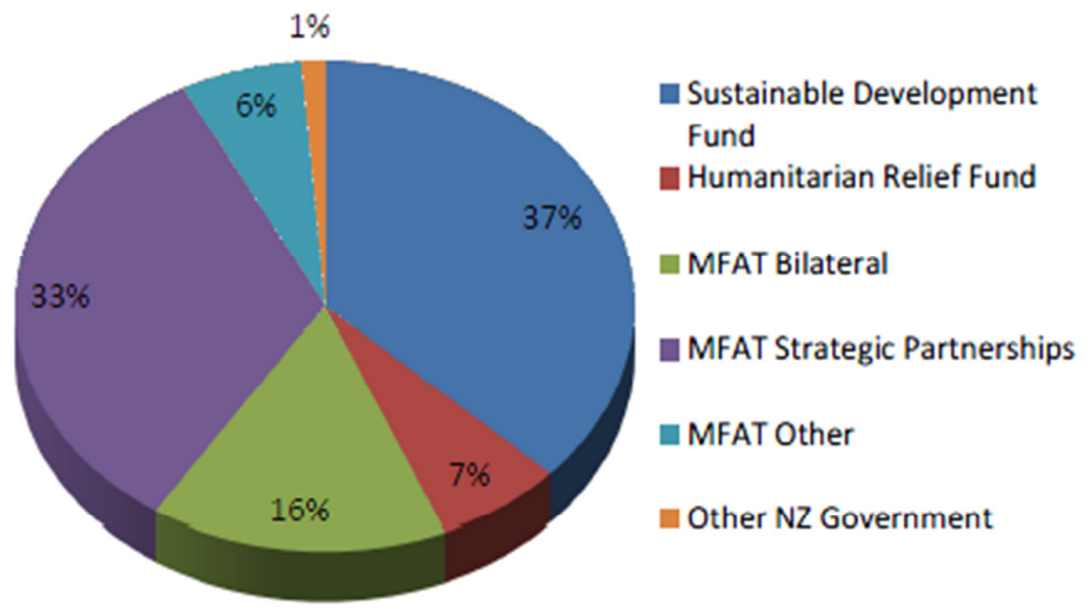

Source: $C I D 2012 b$ 
Figure A.5 NGOs' Income from the New Zealand Public in 2009

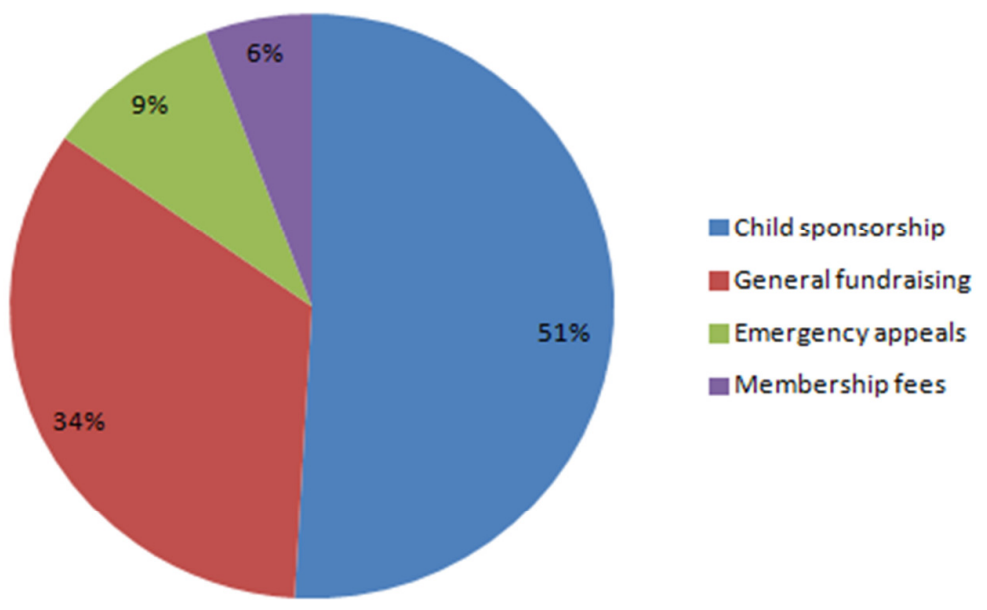

Source: CID 2009 
Figure A.6 NGOs' Income from the New Zealand Public in 2011

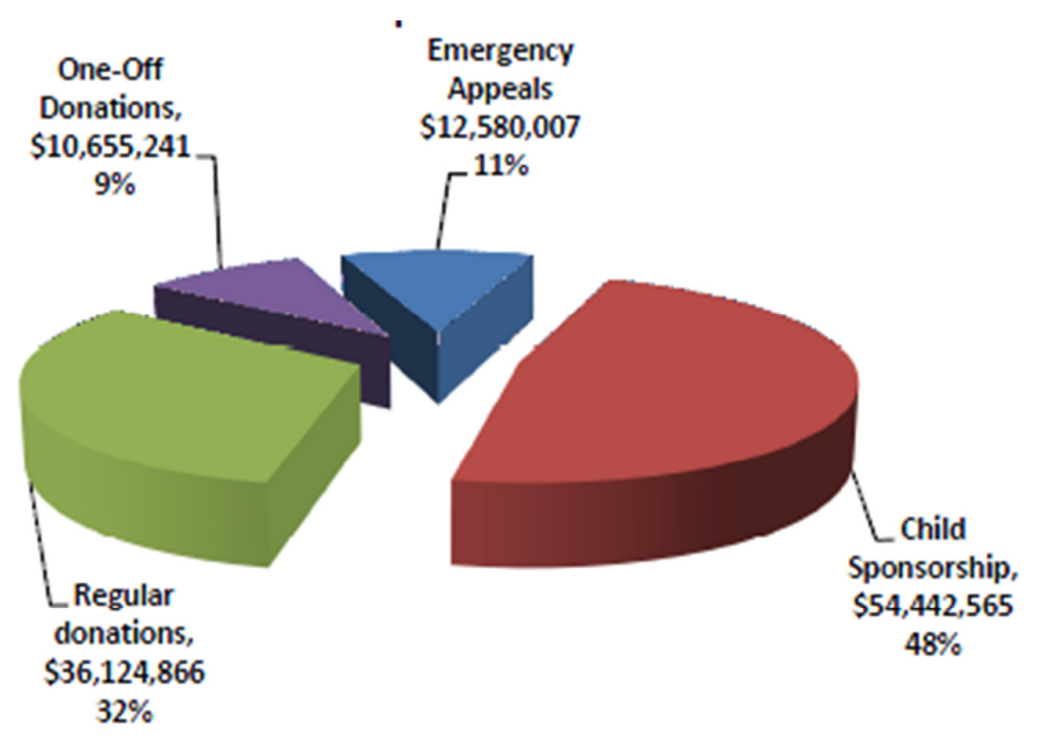

Source: CID 2011 
Figure A.7 NGOs' Income from the New Zealand Public in 2012

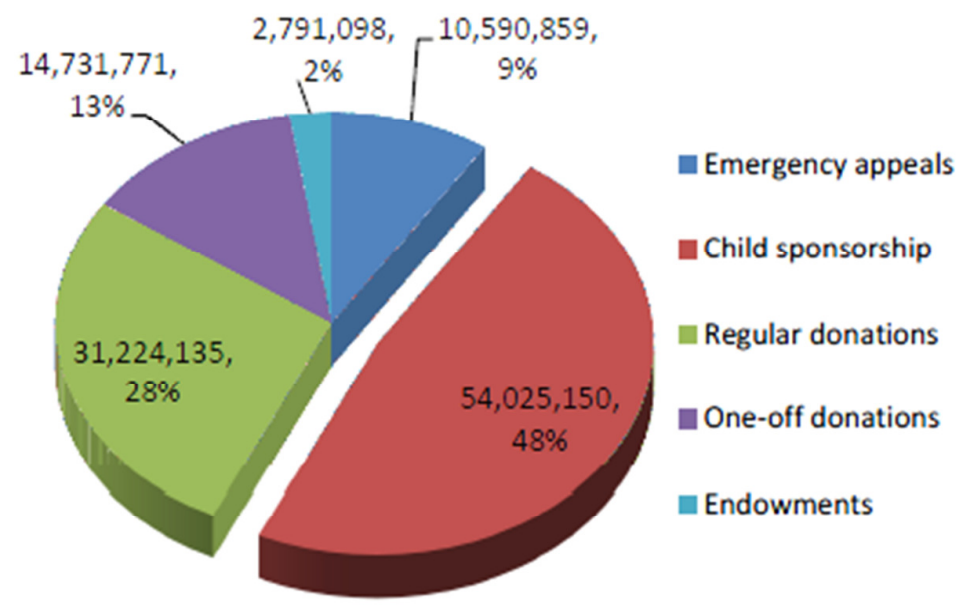

Source: $C I D 2012 b$ 


\section{Figure A.8 KOHA-PICD Sample Process}

Every organisation has its oun story. Theprocess below outlines one pos sible joumey through KOHA-PICD. Your oun process will depend onyour organisation, your partners and the communities you workwith.

\begin{tabular}{|ll|}
\hline NeW & $\begin{array}{l}\text { 'Organisations applying to KOHA need to be non-government and notfor profit. } \\
\text {-Need to be a legal entity, either as a Trust or an Incorporated Society. }\end{array}$ \\
$\mathrm{NGO}$ & $\begin{array}{l}\text { 'Must be willing to abide by KOHA-PICD's Principles and Criteria. } \\
\text { 'May consider becoming a member of the Council for International Development. See bottom box.* }\end{array}$ \\
\hline
\end{tabular}

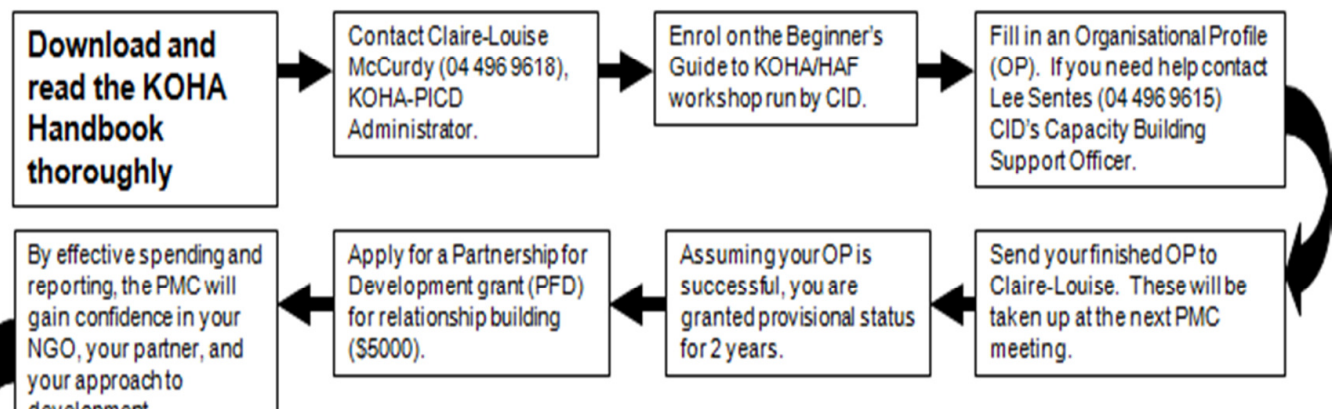

development.

Apply for a PFD grant for a Joint Activity with yourpartner (i.e.

training, exchange visit, joint

research) $\$ 10,000$. Up to 3

followup grants may be

available.

Onceyouknowyour NGO and your partner's capacity forwork make an Individual Project (IP) application (bandedup to $\$ 300,000$ based on proven track record).

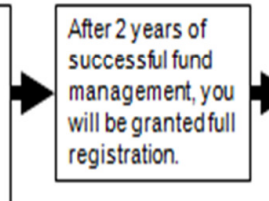
registration.
Fully registeredNGOs are eligible to progress through IPfunding bands up to S1 million+

$$
\begin{array}{|l|l|}
\hline \begin{array}{l}
\text { NGOs who wish to become BG NGOs } \\
\text { will have to undergo an Independent } \\
\begin{array}{l}
\text { Review. If they remain BG NGOs, they } \\
\text { will be reviewed every 5years. }
\end{array}
\end{array} & \begin{array}{l}
\text { After } 2 \text { years of full registrationand } \\
\text { successful IP management, NGOs } \\
\text { are eligibleto move to BlockGrant } \\
\text { (BG) status if they wish. }
\end{array} \\
\hline
\end{array}
$$

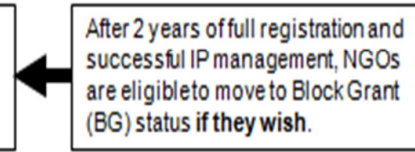

Independent Reviewers look at 4 to $5 \mathrm{KOHAVHAF}$ recipients per year, as decided by the PMC.

*It is not a prerequisite to be a CID member to be eligible for KOHA funding. However, membership gives you access to discounted $\mathrm{CID}$ workshops, gets you involved in a network, and allows the Capacity Building Sup port Officer to work clos ely withyour NGO.

Source: Docstoc 2009 
Table A.1 Comparison of KOHA - PICD, SDF and NZPfID

\begin{tabular}{|c|c|c|c|}
\hline Parameter & КОНА-PICD & SDF & NZPfID \\
\hline $\begin{array}{l}\text { 1. Year and } \\
\text { reason of } \\
\text { establishment }\end{array}$ & $\begin{array}{l}2006 \\
\text { VASS scheme was renamed to } \\
\text { KOHA - PICD to describe and reflect } \\
\text { VASS purpose better (with } \\
\text { contribution of major review of } \\
\text { VASS in 2004) }\end{array}$ & 2010 & $\begin{array}{l}2012 \\
\text { Has been established to harness the expertise of } \\
\text { New Zealand charitable, other not-for-profit, } \\
\text { private, and state sector organisations to help } \\
\text { achieve the objectives of the New Zealand Aid } \\
\text { Programme. }\end{array}$ \\
\hline $\begin{array}{l}\text { 2. Purpose of the } \\
\text { Fund }\end{array}$ & $\begin{array}{l}\text { Improve the lives of people in } \\
\text { developing countries by addressing } \\
\text { poverty and injustice internationally } \\
\text { through: } \\
\text { Providing funding to New Zealand } \\
\text { NGOs for high quality community } \\
\text { development projects } \\
\text { Development of strong and effective } \\
\text { New Zealand development sector } \\
\text { Partnership between New Zealand }\end{array}$ & $\begin{array}{l}\text { (2010) - to provide funding for } \\
\text { effective activities that develop } \\
\text { self-reliant communities and } \\
\text { complement the New Zealand } \\
\text { Government development } \\
\text { priorities. } \\
\text { (2011) - to support development } \\
\text { outcomes in developing } \\
\text { courtiers through partnerships } \\
\text { with New Zealand NGOs. }\end{array}$ & $\begin{array}{l}\text { To support sustainable development in developing } \\
\text { countries in order to reduce poverty and } \\
\text { contribute to a more secure, equitable and } \\
\text { prosperous world by encouraging partnerships } \\
\text { between New Zealand organisations and in- } \\
\text { country partners. }\end{array}$ \\
\hline
\end{tabular}




\begin{tabular}{|c|c|c|c|}
\hline & $\begin{array}{l}\text { community and New Zealand } \\
\text { international development NGOs. }\end{array}$ & & \\
\hline 3. Focus areas & $\begin{array}{l}\text { Community development } \\
\text { projects/programmes } \\
\text { Wide variety of projects and } \\
\text { programmes: } \\
\text { - basic needs } \\
\text { - health, water sanitation } \\
\text { - education } \\
\text { - livelihoods, economic development } \\
\text { - environmental issues } \\
\text { - good governance } \\
\text { - building of organisational capacities } \\
\text { of NGOS } \\
\text { - other projects and programmes } \\
\text { Partnerships for development } \\
\text { Administration } \\
\text { Organisational support grants for } \\
\text { NGOs } \\
\text { Appraisal, M\&E }\end{array}$ & $\begin{array}{l}\text { Sustainable economic growth } \\
\text { As well as: } \\
\text { - health and education to } \\
\text { support sustainable economic } \\
\text { development } \\
\text { - basic human needs as water } \\
\text { and sanitation } \\
\text { - protection communities from } \\
\text { disasters }\end{array}$ & $\begin{array}{l}\text { Sustainable economic development: } \\
\text { - agriculture } \\
\text { - fisheries } \\
\text { - tourism } \\
\text { - business enabling environment and private } \\
\text { - } \text { sector development } \\
\text { Social development: } \\
\text { - health and education } \\
\text { - water and sanitation } \\
\text { - building safer communities } \\
\text { - improved resilience to disasters }\end{array}$ \\
\hline
\end{tabular}




\begin{tabular}{|c|c|c|c|}
\hline & $\begin{array}{l}\text { Support for travel to training and } \\
\text { NGO NZAID Meetings }\end{array}$ & & \\
\hline $\begin{array}{l}\text { 4. Geographic } \\
\text { Focus }\end{array}$ & World Regions & $\begin{array}{l}\text { Pacific- } 75 \% \\
\text { Southeast Asia- } 15 \% \\
\text { Rest of the world }-10 \%\end{array}$ & $\begin{array}{l}\text { Pacific- } 75 \% \\
\text { Southeast Asia- } 15 \% \\
\text { Rest of the world }-10 \%\end{array}$ \\
\hline $\begin{array}{l}\text { 5. Funding } \\
\text { allocation } \\
\text { mechanism }\end{array}$ & $\begin{array}{l}\text { Funding allocation is based on IP and } \\
\text { BG funding }\end{array}$ & $\begin{array}{l}\text { Funding allocation is based on } \\
\text { contestable basis. Funding will } \\
\text { be provided through a Grant } \\
\text { Funding Arrangement (GFA). }\end{array}$ & Funding allocation is based on contestable basis. \\
\hline $\begin{array}{l}\text { 6. Programme } \\
\text { duration and } \\
\text { budget }\end{array}$ & $\begin{array}{l}\text { IP Funding } \\
\text { - After being granted a provisional } \\
\text { status for } 2 \text { years NGOs apply for } \\
\text { IP up to } \$ 300000 . \\
\text { - After } 2 \text { years of successful fund } \\
\text { management, NGO will be granted } \\
\text { full registration. Fully registered } \\
\text { NGOs are eligible to progress } \\
\text { through IP funding bands up to } \$ 1 \\
\text { million and more. }\end{array}$ & $\begin{array}{l}\text { The SDF prioritises activities } \\
\text { over } \$ 500,000 \text { for the life of the } \\
\text { activity, but a modest allocation } \\
\text { will be retained to fund activities } \\
\text { smaller than this. } \\
\text { The SDF will accept multi-year } \\
\text { applications with a preference of } \\
\text { up to } 3 \text { years }\end{array}$ & $\begin{array}{l}\text { Only limited funding (a maximum of } 10 \% \text { of } \\
\text { available funds in any round) is available for } \\
\text { small (under } \$ 500,000 \text { ) activities or pilot } \\
\text { activities. } \\
\text { Funding will be for a maximum of five years. } \\
\text { Multi-year applications are encouraged. }\end{array}$ \\
\hline
\end{tabular}




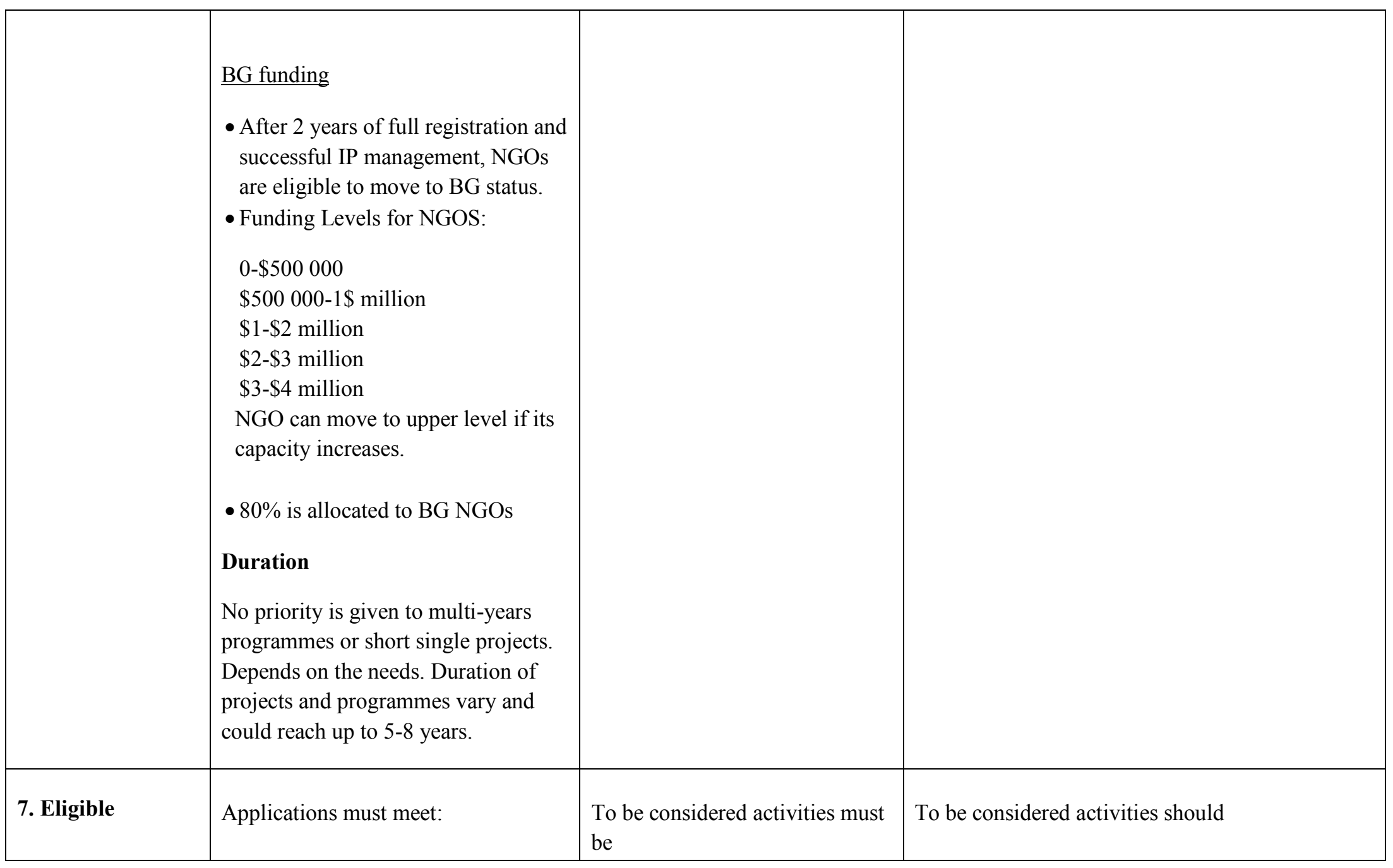




\begin{tabular}{|c|c|c|c|}
\hline activities & $\begin{array}{l}\text { Principles and criteria: } \\
\text { - Promotion of self-reliance } \\
\text { - Addressing poverty and injustice } \\
\text { - Community development and } \\
\text { participation } \\
\text { - Partnership } \\
\text { - Sustainability } \\
\text { - Capacity building is integral to } \\
\text { programme design } \\
\text { - Good practices in planning and } \\
\text { - design } \\
\text { Participatory in monitoring, } \\
\text { - evaluation and impact assessment } \\
\text { rissessment and management of } \\
\text { Key cross-cutting strategies: } \\
\text { - Gender equality and women's } \\
\text { - Human rights } \\
\text { - The environment }\end{array}$ & $\begin{array}{l}\text { - Results focused } \\
\text { - Consistent with New Zealand } \\
\text { aid policy } \\
\text { - Show where possible how } \\
\text { they contribute to the } \\
\text { outcomes in the Funding } \\
\text { Priorities Framework } \\
\text { - Demonstrate good value for } \\
\text { money } \\
\text { - New Zealand's expertise } \\
\text { contributes to the activity } \\
\text { Cross-cutting issues: Gender, } \\
\text { Human Rights, Environment }\end{array}$ & $\begin{array}{l}\text { - Contribute to sustainable economic } \\
\text { - } \text { - Fit objelopment or social development } \\
\text { - Tangible and measurable results } \\
\text { - Demonstrate good value for money } \\
\text { - Comply with local and New Zealand laws } \\
\text { - Meets New Zealand's international obligations } \\
\text { - Be in addition to existing initiatives or work } \\
\text { programmes (if development is not your core } \\
\text { business), i.e. is not "business as usual" and } \\
\text { would not take place without the support of the } \\
\text { Partnerships Fund } \\
\text { - Be a new proposal i.e. unsolicited resubmission } \\
\text { of proposals which have been declined through } \\
\text { another funding window in MFAT will not be } \\
\text { accepted } \\
\text { - 100\% of proposed MFAT contribution falls } \\
\text { within the OECD DAC definitions of ODA (i.e. } \\
\text { the main objective is the promotion of the } \\
\text { economic development and welfare of } \\
\text { developing countries). } \\
\text { Priority will be given to: } \\
\text { - Activities which are consistent with or } \\
\text { complement the New Zealand Aid Programme's } \\
\text { bilateral and regional priorities, in particular the }\end{array}$ \\
\hline
\end{tabular}




\begin{tabular}{|c|c|c|c|}
\hline & & & $\begin{array}{l}\text { priorities agreed with developing country } \\
\text { governments through bilateral "Joint } \\
\text { Commitments for Development" } \\
\text { - Establishment or continuation of long-term } \\
\text { partnerships between New Zealand and } \\
\text { developing country organisations } \\
\text { - Activities which demonstrate a commitment to } \\
\text { the cross-cutting issues of gender, environment } \\
\text { and human rights. } \\
\text { - The Partnerships Fund will consider proposals } \\
\text { from applicants wishing to pilot an innovative } \\
\text { or untested Activity, which offers the } \\
\text { opportunity for future scaling up. Pilots may be } \\
\text { no longer than three years in duration. }\end{array}$ \\
\hline $\begin{array}{l}\text { 8. Eligible } \\
\text { applicants }\end{array}$ & Registered New Zealand NGOs & $\begin{array}{l}\text { Registered, voluntary, not-for- } \\
\text { profit, non-government New } \\
\text { Zealand-based organisations that } \\
\text { are accredited with the SDF }\end{array}$ & $\begin{array}{l}\text { Accredited New Zealand charitable organisations, } \\
\text { not-for-profit, private and state sector } \\
\text { organisations }\end{array}$ \\
\hline $\begin{array}{l}\text { 9. Joint } \\
\text { applications }\end{array}$ & $\begin{array}{l}\text { Supports programmes that have been } \\
\text { developed jointly by the New Zealand } \\
\text { NGO and their partner(s).Funding is } \\
\text { not intended to allow New Zealand }\end{array}$ & & $\begin{array}{l}\text { Joint applications between eligible New Zealand } \\
\text { organisations }\end{array}$ \\
\hline
\end{tabular}




\begin{tabular}{|c|c|c|c|c|c|c|c|}
\hline & $\begin{array}{l}\text { NGO to co-opt partner programmes } \\
\text { as their own. }\end{array}$ & & & & & & \\
\hline \multirow[t]{10}{*}{$\begin{array}{r}\text { 10. Matched } \\
\text { Funding }\end{array}$} & \multirow{10}{*}{$\begin{array}{l}\text { Must provide evidence that it has } \\
\text { matched funds available. } \\
\text { - Community development projects } \\
\text { and programmes is } 4: 1 \text { funding ratio. } \\
\text { - Partnership for Development - up to } \\
100 \% \text { of costs } \\
\text { - Administration - } 8 \% \text { of the Projects } \\
\text { cost or BG } \\
\text { - NGO organisational support - Up to } \\
100 \% \text { of costs } \\
\text { - AM\&E - 5\% of project cost or } \\
\$ 5000 \text { whichever is the largest or } \\
5 \% \text { of BG }\end{array}$} & \multicolumn{3}{|c|}{$\begin{array}{l}\text { Matched funding was introduced } \\
\text { at the third round according to } \\
\text { the geographical location of the } \\
\text { Activity: }\end{array}$} & \multirow{2}{*}{\multicolumn{3}{|c|}{$\begin{array}{l}\text { The size of the contribution required by applicants } \\
\text { varies according to the type of organisation and } \\
\text { the geographical location of the Activity. State } \\
\text { sector applicants are not required to provide a } \\
\text { matched funding contribution. Minimum } \\
\text { contributions are set out in the table below: }\end{array}$}} \\
\hline & & Region & SDF & NGO & & & \\
\hline & & Pacific & 4 & 1 & Region & $\begin{array}{c}\text { Charitable } \\
\text { organisation, } \$\end{array}$ & $\begin{array}{l}\text { Partnerships } \\
\text { Fund, \$ }\end{array}$ \\
\hline & & \multirow{2}{*}{\begin{tabular}{|l|} 
South East \\
Asia
\end{tabular}} & \multirow{2}{*}{3} & \multirow{2}{*}{1} & Pacific & 1 & 4 \\
\hline & & & & & $\begin{array}{l}\text { South-East } \\
\text { Asia }\end{array}$ & 1 & 3 \\
\hline & & $\begin{array}{l}\text { Rest of the } \\
\text { World }\end{array}$ & 2 & 1 & $\begin{array}{l}\text { Rest of the } \\
\text { world }\end{array}$ & 1 & 2 \\
\hline & & & & & & $\begin{array}{c}\text { Private Sector/ } \\
\text { other Non-for- } \\
\text { profit } \\
\text { organisation, \$ }\end{array}$ & $\begin{array}{c}\text { Partnerships } \\
\text { Fund, } \\
\$\end{array}$ \\
\hline & & & & & Pacific & 1 & 2 \\
\hline & & & & & $\begin{array}{l}\text { South-East } \\
\text { Asia }\end{array}$ & 1 & 2 \\
\hline & & & & & $\begin{array}{l}\text { Rest of the } \\
\text { world }\end{array}$ & 1 & 2 \\
\hline
\end{tabular}




\begin{tabular}{|c|c|c|c|}
\hline & & & $\begin{array}{l}\text { - In-Kind funding (use of plant and equipment, } \\
\text { raw materials and etc.) the acceptance of these } \\
\text { contributions is at the discretion of MFAT. In- } \\
\text { kind contributions cannot represent more than } \\
30 \% \text { of the matched funding requirement. }\end{array}$ \\
\hline $\begin{array}{l}\text { 11. The application } \\
\text { process }\end{array}$ & $\begin{array}{l}\text { 1. Registered NGO entitled for IP } \\
\text { applies for a single or multi-years } \\
\text { application within the funding bands. } \\
\text { BG NGOs apply for community } \\
\text { development projects, administration, } \\
\text { AM\&E activities. Projects are paid in } \\
\text { a lump sum annually. This makes the } \\
\text { application process easier and } \\
\text { quicker, and helps to reduce } \\
\text { administration costs. } \\
\text { 2. PMC assesses application against } \\
\text { principles and specific criteria, and } \\
\text { recommends if NGO should move to } \\
\text { a higher level. } \\
\text { 3. Funding is approved by NZAID } \\
\text { and MFAT. } \\
\text { Project applications: }\end{array}$ & $\begin{array}{l}\text { 1. Applicants submit concept not } \\
\text { or full design depending on the } \\
\text { value of activity. } \\
\text { 2. The MFAT assesses proposals } \\
\text { against criteria. The process } \\
\text { includes comments by the Head } \\
\text { of the relevant offshore MFAT } \\
\text { Office who must endorse the } \\
\text { proposal. } \\
\text { 3. External selection panel } \\
\text { considers applications and gives } \\
\text { recommendations. } \\
\text { 4. External selection panel's } \\
\text { recommendations are approved } \\
\text { at the appropriate level in } \\
\text { MFAT. }\end{array}$ & $\begin{array}{l}\text { 1. Accreditation } \\
\text { 2. Submission of Proposals } \\
\text { 3. Proposal assessment- The Partnerships and } \\
\text { Funds Team will check each proposal meets the } \\
\text { eligibility criteria. You will be notified if your } \\
\text { proposal does not meet these criteria. } \\
\text { MFAT will then appraise all eligible proposals } \\
\text { against the Partnerships Fund focus areas and } \\
\text { quality criteria: eligibility, assessment, relevance, } \\
\text { effectiveness, efficiency, development impact, } \\
\text { sustainability, cross-cutting issues, M\&E. } \\
\text { It provides the Panel with a written comment on } \\
\text { each proposal. This draws on advice from MFAT } \\
\text { specialists and Heads of Mission (ie New Zealand } \\
\text { Ambassadors and High Commissioners in } \\
\text { MFATe's overseas offices). }\end{array}$ \\
\hline
\end{tabular}




\begin{tabular}{|c|c|c|c|}
\hline & $\begin{array}{l}\text { Approved: conditional - if more info } \\
\text { required to present at the next } \\
\text { meeting with PMC or when final } \\
\text { report submitted. } \\
\text { Tabled: project meets KOHA criteria } \\
\text { but not enough info to make any } \\
\text { decision so postponed to the next } \\
\text { PMC meeting. } \\
\text { Deferred: PMC concerns about } \\
\text { KOHA criteria, application are not } \\
\text { appropriate for funding, more info } \\
\text { needed. Only once can be. } \\
\text { Declined: } \\
\text { Does not meet KOHA criteria. } \\
\text { Cannot be submitted in the same year }\end{array}$ & $\begin{array}{l}\text { 5. Applicants are notified about } \\
\text { the decision (approved or } \\
\text { declined). } \\
\text { 6. Approved application. SDF } \\
\text { GFA is sent to NGO for signing. }\end{array}$ & $\begin{array}{l}\text { 4. Decision making - conducted by the Panel. } \\
\text { Proposals could be proceed to design, proceed to } \\
\text { design with conditions, be resubmitted or } \\
\text { declined. } \\
\text { 5. Developing the Activity Design Document } \\
\text { (ADD). If ADD is accepted NGO receives a } \\
\text { payment from MFAT as a contribution to } \\
\text { development of the final design: } \$ 5000 \text { for } \\
\text { activities that are less } \$ 500000 \text { and } \$ 20000 \text { for } \\
\text { activities with budget over } \$ 500000 \text {. } \\
\text { 6. ADD appraisal and decision. The appraisal } \\
\text { process follows standard MFAT processes that } \\
\text { includes a written appraisal, and depending on } \\
\text { size and risk, an internal appraisal meeting. } \\
\text { 7. Contracting and implementation }\end{array}$ \\
\hline $\begin{array}{l}\text { 12. Decision } \\
\text { making body and } \\
\text { supporting } \\
\text { personnel }\end{array}$ & $\begin{array}{l}\text { Programme Management } \\
\text { Committee } \\
\text { Comprised of } 4 \text { elected NGO reps, } 1 \\
\text { NZAID rep, } 1 \text { NGO Disaster Relief } \\
\text { Forum (NDRF) rep, and } 1 \\
\text { Independent Chair, as well as }\end{array}$ & $\begin{array}{l}\text { Independent Panel at the first } \\
\text { round of the SDF was changed } \\
\text { to external Panel at the second } \\
\text { round of the SDF. The CEO of } \\
\text { MFAT had a final decision. } \\
\text { Consultative group of } 3\end{array}$ & $\begin{array}{l}\text { International Development Advisory and } \\
\text { Selection Panel has been appointed to assess } \\
\text { proposals and make recommendations to the } \\
\text { MFAT CEO on which proposals proceed to the } \\
\text { design stage. } \\
\text { The Partnerships and Funds Team is employed }\end{array}$ \\
\hline
\end{tabular}




\begin{tabular}{|c|c|c|c|}
\hline & $\begin{array}{l}2 \text { administrators. } \\
\text { PMC draw line for annual allocation. } \\
\text { Selection panel ( } 2 \text { NZAID } \\
\text { representatives and } 2 \text { members of } \\
\text { KOHA-PICD development } \\
\text { community) chooses an Independent } \\
\text { Chair. }\end{array}$ & $\begin{array}{l}\text { representatives from } \\
\text { organisations accredited with the } \\
\text { SDF. Meet once in } 3 \text { months to } \\
\text { give feedback on SDF } \\
\text { performance. }\end{array}$ & $\begin{array}{l}\text { within MFAT to manage the Partnerships Fund } \\
\text { and support the Panel. } \\
\text { MFAT specialists, Heads of Mission and } \\
\text { contracted advisers are responsible for } \\
\text { completing a preliminary written comment on } \\
\text { each proposal. } \\
\text { MFAT Design Support Lead appointed at the } \\
\text { ADD stage. }\end{array}$ \\
\hline 13. Reporting & $\begin{array}{l}\text { IP } \\
\text { - Final Project Report - in } 3 \text { months } \\
\text { of completion or } 15 \text { months after } \\
\text { approval; } \\
\text { - Report on multi-year projects } \\
\text { (interim and final reports) -Interim } \\
9 \text { months after project funded in } 1^{\text {st }} \\
\text { year/financial report } 15 \text { months } \\
\text { from funding. } \\
\text { - Final -3 months after completion } \\
\text { of the project. } \\
\text { - Administration funds - Statement } \\
\text { of expenditures (annually). }\end{array}$ & $\begin{array}{l}\text { Organisations are required to } \\
\text { provide a brief annual report on } \\
\text { the progress of multi-year } \\
\text { activities. Further funding for } \\
\text { the activity is dependent on } \\
\text { receipt of a satisfactory report. A } \\
\text { completion report is required at } \\
\text { the end of the activity and is to } \\
\text { be submitted within three } \\
\text { months of completion. Further } \\
\text { funding through the New } \\
\text { Zealand Aid Programme is } \\
\text { dependent on satisfactory annual } \\
\text { reporting. }\end{array}$ & $\begin{array}{l}\text { All Implementing Partners are required to report } \\
\text { results in line with the monitoring and reporting } \\
\text { milestones set out in their contract. Typically } \\
\text { these include financial reports, progress reports, } \\
\text { and completion reports. }\end{array}$ \\
\hline
\end{tabular}




\begin{tabular}{|c|c|c|}
\hline & $\begin{array}{l}\text { BG funding } \\
\text { - } \text { Annual notifications; } \\
\text { - Letter of variations for BG } \\
\text { programmes; } \\
\text { - } 2-5 \text { in-depth reports on BG } \\
\text { projects (annually); } \\
\text { - Annual BG programme report; } \\
\text { - Final BG programme report at } \\
\text { least every } 5 \text { years; } \\
\text { - AM\&E reports (annually); } \\
\text { - Additional: NGO's Annual } \\
\text { Report; } \\
\text { - Organisational profile, audited } \\
\text { financial statements, } \\
\text { reconciliation, letter from } \\
\text { independent auditor, report on the } \\
\text { use of administration funds. } \\
\text { Managing Changes: } \\
\text { Individual Grant organisations } \\
\text { Approval from the PMC should be } \\
\text { sought for: } \\
\text { - changes to the objectives of a } \\
\text { project or significant changes in }\end{array}$ & $\begin{array}{l}\text { Financial and narrative progress } \\
\text { reports for multi-year activities. } \\
\text { Further funding for the activity } \\
\text { is dependent on receipt of } \\
\text { satisfactory reports. } \\
\text { A completion report in required } \\
\text { at the end of the activity and is } \\
\text { to be submitted within } 3 \text { months } \\
\text { of completion. } \\
\text { Further funding through the New } \\
\text { Zealand Aid Programme is } \\
\text { dependent on satisfactory annual } \\
\text { report. } \\
\text { Requirement around results } \\
\text { measurement have grown from } \\
\text { SDF Round One to SDF Round } \\
\text { Tow and Three. } \\
\text { Substantive changes to } \\
\text { objectives, outcomes and change } \\
\text { in more than } 10 \% \text { of total budget } \\
\text { need to be reported }\end{array}$ \\
\hline
\end{tabular}




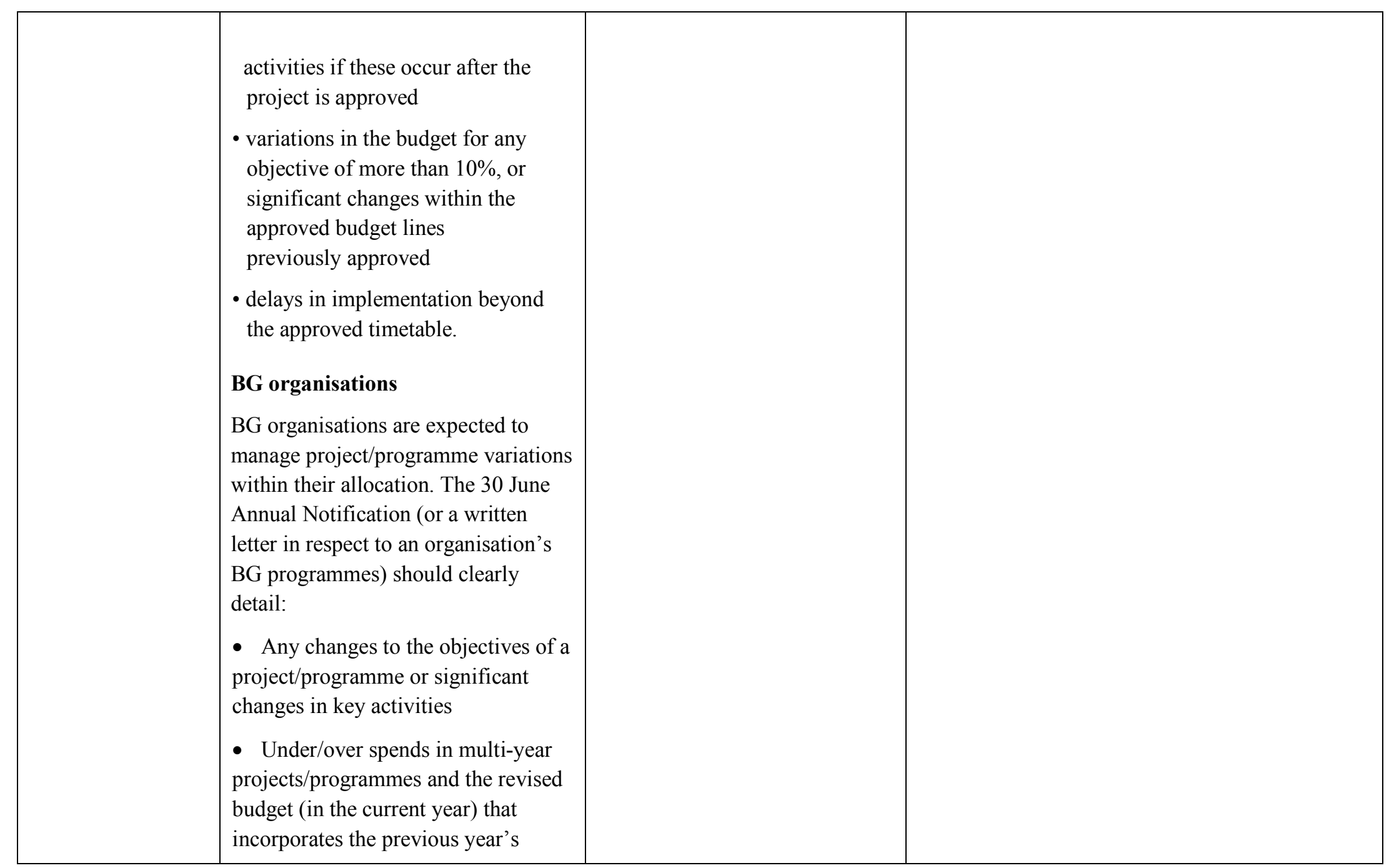




\begin{tabular}{|c|c|c|c|}
\hline & $\begin{array}{l}\text { under/over spending } \\
\text { - Delays in implementation beyond } \\
\text { the planned timetable. }\end{array}$ & & \\
\hline $\begin{array}{l}14 . \\
\text { Accountability } \\
\text { and Review }\end{array}$ & $\begin{array}{l}\text { - Self-Evaluation by NGOs and } \\
\text { sharing experiences; } \\
\text { - Monitoring and Reporting - } \\
\text { responsibility of NGOs } \\
\text { - Organisational review - every 4-5 } \\
\text { years. } \\
\text { - Peer-based learning that examines } \\
\text { topical themes. }\end{array}$ & $\begin{array}{l}\text { Each year } 5-10 \% \text { of SDF } \\
\text { activities will be selected for } \\
\text { independent M\&E. Visits will be } \\
\text { conducted according to } \\
\text { monitoring standards for the } \\
\text { New Zealand Aid Funding. } \\
\text { After } 3 \text { years effectiveness of } \\
\text { SDF funding in general will be } \\
\text { assessed. }\end{array}$ & $\begin{array}{l}\text { Each year, MFAT will select a sample of } \\
\text { activities that will be subject to additional } \\
\text { independent monitoring or evaluation. Each year, } \\
\text { up to two independent evaluations of completed } \\
\text { activities of strategic importance to the overall aid } \\
\text { programme will also be undertaken. }\end{array}$ \\
\hline $\begin{array}{l}\text { 15. Period of } \\
\text { functioning }\end{array}$ & $\begin{array}{l}\text { 2006-2010 } \\
\text { (19 April } 2010 \text { was closed) }\end{array}$ & $\begin{array}{l}\text { 2010-2012 } \\
9 \text { September } 2010 \text { - Round One; } \\
15 \text { April } 2011 \text { - Round Two; } \\
16 \text { April } 2012 \text { - Round Three }\end{array}$ & $1^{\text {st }}$ Round 16 November 2012 \\
\hline
\end{tabular}

Source: NZAID 2008; MFAT 2011; MFAT n.d. 
Table A.2 Comparison of HAF, HRF and NZDRP

\begin{tabular}{|c|c|c|c|}
\hline Parameter & HAF & HRF & NZDRP \\
\hline $\begin{array}{l}\text { 1. Year and } \\
\text { reason of } \\
\text { establishment }\end{array}$ & $\begin{array}{l}2006 \\
\text { In } 2004 \text { an evaluation of NZAID's } \\
\text { programme of funding to New Zealand } \\
\text { NGOs confirmed the need to overhaul the } \\
\text { existing Emergency Management and } \\
\text { Disaster Relief funding mechanism. }\end{array}$ & 2010 & $\begin{array}{l}2012 \\
\text { New Zealand NGOs raised areas for improvement } \\
\text { with MFAT. MFAT took the initiative to develop } \\
\text { options for how the NGO funding mechanism can be } \\
\text { made to work more effectively and efficiently. }\end{array}$ \\
\hline $\begin{array}{l}\text { 2. Fund's } \\
\text { Purpose }\end{array}$ & $\begin{array}{l}\text { To help save lives, alleviate suffering and } \\
\text { maintain human dignity during and after } \\
\text { emergencies via NGOs. This will be } \\
\text { achieved by: } \\
\text { - Facilitate partnership between the New } \\
\text { Zealand community and New Zealand } \\
\text { NGOs } \\
\text { - Providing funding for New Zealand } \\
\text { NGOs working with overseas partners } \\
\text { - Develop strong New Zealand NGO } \\
\text { sector involved in humanitarism. }\end{array}$ & $\begin{array}{l}\text { To deliver fast and effective } \\
\text { relief, recovery and } \\
\text { reconstruction via NGOs } \\
\text { following a disaster. } \\
\text { Removes the capacity to help } \\
\text { in the aftermath of disaster } \\
\text { with rebuilding and in trauma } \\
\text { care on a long term basis. }\end{array}$ & $\begin{array}{l}\text { To provide a transparent funding mechanism, for New } \\
\text { Zealand NGOs, to facilitate the effective and efficient } \\
\text { mobilisation of humanitarian assistance following } \\
\text { natural disaster or armed conflict. }\end{array}$ \\
\hline
\end{tabular}




\begin{tabular}{|c|c|c|c|}
\hline $\begin{array}{l}\text { 3. Focus } \\
\text { areas }\end{array}$ & $\begin{array}{l}\text { Support for project funded NGOs: } \\
\text { - } \text { Prevention and preparedness } \\
\text { - } \quad \text { Recorgency response } \\
\text { Support to strengthen New Zealand } \\
\text { NGOs: } \\
\text { - Administration and AM\&E } \\
\text { Recovery - to get economic and social } \\
\text { systems work normally } \\
\text { Reconstruction - to rebuild infrastructure } \\
\text { system } \\
\text { Rehabilitation - assistance to people from } \\
\text { hum disasters } \\
\text { Relief - basic support to people in } \\
\text { emergency. }\end{array}$ & $\begin{array}{l}\text { Emphasis on funding disaster } \\
\text { response activities. } \\
\text { - Relief } \\
\text { - Recovery } \\
\text { - Reconstruction }\end{array}$ & $\begin{array}{l}\text { - Rapid humanitarian assistance to natural disasters in } \\
\text { the Pacific through essential NGO prepositioned } \\
\text { relief supplies; } \\
\text { - Humanitarian assistance to meet initial } \\
\text { assessed needs arising from natural disasters in the } \\
\text { Pacific through NGO response (relief and early } \\
\text { recovery) activities; } \\
\text { - Humanitarian assistance to significant natural } \\
\text { disasters outside the Pacific through NGO response } \\
\text { (relief and early recovery) activities; } \\
\text { - The NZDRP may also be utilised to provide } \\
\text { humanitarian assistance in the case of civil or armed } \\
\text { conflict in the Pacific. } \\
\text { - Integration of DRR into response and early recovery } \\
\text { activities is an effective way of reducing the impact } \\
\text { of future shocks on communities, offering more } \\
\text { sustainable solutions. The NZDRP provides up to } \\
20 \% \text { of NGO funding to be targeted to DRR } \\
\text { activities in both Pacific and non-Pacific responses. }\end{array}$ \\
\hline $\begin{array}{l}5 . \\
\text { Geographic } \\
\text { Focus }\end{array}$ & Europe, Africa, America, Asia, Pacific & Mostly Pacific. & $\begin{array}{l}\text { Mostly Pacific and large scale natural disasters in the } \\
\text { rest of the world. }\end{array}$ \\
\hline
\end{tabular}




\begin{tabular}{|c|c|c|c|}
\hline $\begin{array}{l}6 . \text { Funding } \\
\text { allocation } \\
\text { mechanism }\end{array}$ & $\begin{array}{l}\text { Contestable fund. Registration does not } \\
\text { automatically guarantee funding. Funding } \\
\text { was distributed in advance before disaster } \\
\text { happened. }\end{array}$ & $\begin{array}{l}\text { Funding is based on } \\
\text { contestable basis. Funds were } \\
\text { allocated shortly after } \\
\text { disaster happened. }\end{array}$ & $\begin{array}{l}\text { Funding is based on contestable basis. Funds are } \\
\text { allocated shortly after disaster happened. }\end{array}$ \\
\hline $\begin{array}{l}\text { 7. Project } \\
\text { timeframes } \\
\text { and budget }\end{array}$ & $\begin{array}{l}\text { Support for project funded NGOs : } \\
\text { - Individual Grant NGOs: maximum } \\
\$ 125,000 \text { per project. } \\
\text { - The limit for BG- funded projects is } \\
\$ 200,000 \text {, but BG-funded organisations } \\
\text { are required to use at least } 50 \% \text { of their } \\
\text { grant for emergency response projects. } \\
\text { Support to strengthen New Zealand } \\
\text { NGOs: } \\
\text { - } 8 \% \text { of BG or project cost, of which } 3 \% \\
\text { is to be spent on AM\&E. } \\
\text { As a general rule, HAF will only fund } \\
\text { projects with a one-year timescale, with a } \\
\text { possibility for follow-on funding for a } \\
\text { further two years if the project continues } \\
\text { to meet a humanitarian need. }\end{array}$ & & $\begin{array}{l}\text { - Funding up to a maximum value of } \$ 250,000 \text { per } \\
\text { activity. } \\
\text { - New Zealand based support costs should not } \\
\text { exceed } 10 \% \text { of the total activity budget. For both } \\
\text { Pacific and non-Pacific activities, the NZDRP will } \\
\text { contribute up to } 50 \% \text { of New Zealand based } \\
\text { activity support costs. } \\
12 \text { months maximum for Pacific and non-Pacific }\end{array}$ \\
\hline
\end{tabular}




\begin{tabular}{|c|c|c|}
\hline $\begin{array}{l}\text { 8. Eligible } \\
\text { applications }\end{array}$ & $\begin{array}{l}\text { Applications should match HAF } \\
\text { principles: } \\
\text { - the right to life with dignity } \\
\text { - distinction between combatants and } \\
\text { non-combatants } \\
\text { - non-refoulement } \\
\text { - independence } \\
\text { - neutrality } \\
\text { - impartiality } \\
\text { All applications need to demonstrate core } \\
\text { criteria and practices: } \\
\text { HAF criteria: } \\
\text { - Partnership } \\
\text { - Be based on a thorough needs } \\
\text { - Ossessment } \\
\text { - Crganisational capacity to respond to } \\
\text { - Coordination } \\
\text { HAF practices: } \\
\text { - Participation } \\
\text { - Gender } \\
\text { - Vulnerable groups } \\
\text { - Capacity building }\end{array}$ & $\begin{array}{l}\text { - DAC criteria (Relevance, Effectiveness, } \\
\text { Efficiency, Impact, Sustainability) } \\
\text { - Demonstrated value for money } \\
\text { - Clearly articulate outputs and outcomes } \\
\text { - New Zealand NGO expertise and comparative } \\
\text { advantage that includes strong and effective } \\
\text { partnerships with in-country partners } \\
\text { - The cross cutting issues of environment, gender } \\
\text { and human rights }\end{array}$ \\
\hline
\end{tabular}




\begin{tabular}{|c|c|c|c|}
\hline & $\begin{array}{l}\text { - Sustainability } \\
\text { - Project management practices and } \\
\text { requirements } \\
\text { - } \mathrm{M \& E}\end{array}$ & & \\
\hline $\begin{array}{l}\text { 9. Eligible } \\
\text { applicants }\end{array}$ & Accredited New Zealand NGOs & $\begin{array}{l}\text { Accredited New Zealand } \\
\text { NGOs }\end{array}$ & $\begin{array}{l}\text { NGOs accredited to apply for funding under the HRF } \\
\text { remain eligible for funding under the NZDRP. No new } \\
\text { accreditation will occur until } 2014 \text {. }\end{array}$ \\
\hline $\begin{array}{l}\text { 10. Matched } \\
\text { Funds }\end{array}$ & $\begin{array}{l}\text { IP } \\
\text { NGOs do not need to raise any set amount } \\
\text { of matched funds per individual project to } \\
\text { receive HAF funding. NGOs need to } \\
\text { demonstrate they have contributed at least } \\
10 \% \text { of the funds applied for each year } \\
\text { from the New Zealand public and remit } \\
\text { these funds overseas for emergencies. } \\
\text { BG NGOs } \\
\text { The amount of public funds raised by each } \\
\text { NGO in the previous year is factored into } \\
\text { the overall BG allocation formula. In order } \\
\text { to be able to receive a BG, an organisation } \\
\text { would need to be able to raise at least }\end{array}$ & & $\begin{array}{l}\text { - For selected activities outside the Pacific, the } \\
\text { NZDRP will match NZ NGO contributions } \\
\text { committed, up to } \$ 250,000 \text { per project, based on the } \\
\text { NGO contribution over the life of the activity. } \\
\text { - This NGO contribution will need to be reported on } \\
\text { as part of the normal NZDRP financial reporting } \\
\text { process. } \\
\text { - In the Pacific there is no matched funding } \\
\text { requirement for NZDRP activities to ensure rapid } \\
\text { mobilisation of both Government and NGO } \\
\text { resources. }\end{array}$ \\
\hline
\end{tabular}




\begin{tabular}{|c|c|c|}
\hline & $\begin{array}{l}\$ 44,400 \text { per year. This is } 10 \% \text { of the } \\
\text { lowest BG allocation. NGOs need to keep } \\
\text { this in mind when they are applying for a } \\
\text { BG each year. }\end{array}$ & \\
\hline $\begin{array}{l}\text { 11. The } \\
\text { application } \\
\text { process }\end{array}$ & $\begin{array}{l}\text { Individual Grants } \\
\text { An application for a HAF grant is made on } \\
\text { the application form HAF } \\
\text { Applications can be considered at each } \\
\text { PMC meeting where they are assessed } \\
\text { against the established criteria. Funding is } \\
\text { approved within NZAID. } \\
\text { Block Funding } \\
\text { BG organisations do not have to apply for } \\
\text { funds on a project-by-project basis. They } \\
\text { apply for a BG annually. } \\
\text { PMC must be confident that the NGO has } \\
\text { the necessary understanding and skills to } \\
\text { apply humanitarian principles and HAF } \\
\text { criteria, as well as the capacity and } \\
\text { systems to manage projects effectively. } \\
\text { PMC must be confident that an NGO has }\end{array}$ & $\begin{array}{l}\text { - Calls for NZDRP applications will be made } \\
\text { following approval of a funding round by the New } \\
\text { Zealand Minister of Foreign Affairs. } \\
\text { - NZDRP applications will be submitted using the } \\
\text { NZDRP proposal and budget templates. } \\
\text { - For Pacific responses, NZ NGOs will have three } \\
\text { working days, following a call for } \\
\text { proposals, to submit NZDRP applications. } \\
\text { - For non-Pacific responses, NZ NGOs will have } \\
\text { seven working days, following a call for } \\
\text { proposals, to submit NZDRP applications. } \\
\text { - For Pacific responses, MFAT will appraise NZDRP } \\
\text { applications and provide funding decisions within } \\
\text { two working days from receipt of proposals. } \\
\text { - For Non-Pacific responses, MFAT will appraise } \\
\text { NZDRP applications and provide funding decisions } \\
\text { within five working days from receipt of proposals. }\end{array}$ \\
\hline
\end{tabular}




\begin{tabular}{|l|l|l|l|}
\hline & $\begin{array}{l}\text { the necessary understanding and skills to } \\
\text { apply humanitarian principles and HAF } \\
\text { criteria, as well as the capacity and } \\
\text { systems to manage projects effectively. } \\
\text { Funds are sent to NGOs within 3 weeks } \\
\text { after approval. }\end{array}$ & MFAT & MFAT \\
\hline $\begin{array}{l}\text { 12. Decision } \\
\text { making body } \\
\text { and } \\
\text { supporting } \\
\text { personnel }\end{array}$ & $\begin{array}{l}\text { Programme Management Committee: } \\
\text { 1 independent Chair, 4 representatives } \\
\text { elected by NGOs, vice-chair of NDRF, } \\
\text { manager, civil society KOHA/HAF. } \\
\text { manelopment programme }\end{array}$ & Funding is approved within NZAID. & Established in 2012 \\
\hline $\begin{array}{l}\text { 13. Period of } \\
\text { functioning }\end{array}$ & 2006- 2010 & 2010-2011 & \\
\hline
\end{tabular}

Source: NZAID 2006, MFAT 2010b, MFAT $2012 a$. 
Table A.3 Administration Costs of New Zealand NGOs

\begin{tabular}{|c|c|c|c|c|c|c|c|c|c|c|c|}
\hline \multirow{2}{*}{ NGO } & \multicolumn{11}{|c|}{ Administrative Expenditure } \\
\hline & 2007 & 2008 & $\begin{array}{c}\text { Annual } \\
\text { Change, } \\
\%\end{array}$ & 2009 & $\begin{array}{c}\text { Annual } \\
\text { Change, } \\
\%\end{array}$ & 2010 & $\begin{array}{c}\text { Annual } \\
\text { Change, } \\
\% \\
\end{array}$ & 2011 & $\begin{array}{c}\text { Annual } \\
\text { Change } \\
, \%\end{array}$ & 2012 & $\begin{array}{c}\text { Annual } \\
\text { Change, } \\
\%\end{array}$ \\
\hline ADRA New Zealand & - & 400083 & - & 569858 & 42,4 & 634560 & 11,4 & 655806 & 3,3 & 628705 & $-4,1$ \\
\hline BANZAid & - & 10717 & - & 22542 & 110,3 & 38849 & 72,3 & 63916 & 64,5 & 67768 & 6,0 \\
\hline $\begin{array}{l}\text { Caritas Aotearoa } \\
\text { New Zealand }\end{array}$ & 343749 & 337541 & $-1,8$ & 351087 & 4 & 383893 & 9,3 & 393468 & 2,5 & - & - \\
\hline cbm New Zealand & 69580 & 68203 & -2 & 47674 & $-30,1$ & 123625 & 159,3 & 79274 & $-35,8$ & - & - \\
\hline $\begin{array}{l}\text { ChidFund New } \\
\text { Zealand }\end{array}$ & 1061000 & 1304000 & 22,9 & 1321000 & 1,3 & 1356000 & 2,68 & 986000 & $-27,3$ & $\begin{array}{c}1032 \\
000\end{array}$ & 4,7 \\
\hline $\begin{array}{l}\text { Christian World } \\
\text { Service }\end{array}$ & 270110 & 236286 & $-12,5$ & 289529 & 22,5 & 327395 & 13,1 & 306627 & $-6,3$ & 542523 & 76,9 \\
\hline Oxfam New Zealand & 246890 & 287296 & 16,4 & 359709 & 25,2 & 410666 & 14,2 & 754367 & 83,7 & 383753 & $-49,1$ \\
\hline $\begin{array}{l}\text { Save the Children } \\
\text { New Zealand }\end{array}$ & - & - & - & 1365000 & - & 1369000 & 0,3 & 1552000 & 13,4 & $\begin{array}{c}1300 \\
000\end{array}$ & $-16,2$ \\
\hline TEAR Fund & 1939795 & 1885731 & $-2,8$ & 2012710 & 6,7 & 2119403 & 5,3 & 2798326 & 32 & $\begin{array}{c}1658 \\
237 \\
\end{array}$ & $-40,7$ \\
\hline $\begin{array}{l}\text { The New Zealand } \\
\text { China Friendship } \\
\text { Society Incorporated }\end{array}$ & 2294 & 3387 & 47,6 & 2332 & $-31,1$ & 1130 & 51,5 & 906 & $-19,8$ & 1441 & 59,1 \\
\hline The Leprosy Mission & - & 300 & - & 289 & $-3,7$ & 258 & 10,7 & 243964 & $-5,4$ & 202601 & -17 \\
\hline $\begin{array}{l}\text { World Vision New } \\
\text { Zealand }\end{array}$ & 4049951 & 4194214 & 3,6 & 4512649 & 7,6 & 3980155 & $-11,8$ & 4251000 & 6,8 & $\begin{array}{c}4429 \\
000\end{array}$ & 4,2 \\
\hline $\begin{array}{l}\text { Average rate of } \\
\text { growth }\end{array}$ & & & 22,6 & & 27,5 & & 32 & & 29,5 & & 30,2 \\
\hline Average decline rate & & & $-4,8$ & & $-21,6$ & & $-4,7$ & & -19 & & $-25,4$ \\
\hline
\end{tabular}


Source: ADRA 2009, ADRA 2011, ADRA 2012, BANZAid 2008, BANZAid 2009, BANZAid 2010, BANZAid 2011, BANZAid 2012, Caritas 2008, Caritas 2009a, Caritas 2010a, Caritas 2011, cbm 2007, cbm 2008, cbm 2009, cbm 2010, cbm 2011, ChildFund New Zealand 2007, ChildFund New Zealand 2008, ChildFund New Zealand 2009, ChildFund New Zealand 2010, ChildFund New Zealand 2011, ChildFund New Zealand 2012, CWS 2008, CWS 2009, CWS 2010a, CWS 2011b, CWS 2012, Oxfam 2007, Oxfam 2008, Oxfam 2009a, Oxfam 2010, Oxfam 2011, Oxfam 2012, Save the Children 2010, Save the Children 2011, Save the Children 2012, TEAR Fund 2007, TEAR Fund 2009a, TEAR Fund 2010, TEAR Fund 2011, TEAR Fund 2012, NZCFS 2008, NZCFS 2010, NZCFS 2011, NZCFS 2012, The Leprosy Mission New Zealand 2008, The Leprosy Mission New Zealand 2009, The Leprosy Mission New Zealand 2010, The Leprosy Mission New Zealand 2011, The Leprosy Mission New Zealand 2012, World Vision of New Zealand Trust Board 2008, World Vision of New Zealand Trust Board 2009, World Vision of New Zealand Trust Board 2011, World Vision of New Zealand Trust Board 2012. 
Table A.4 Dependency Ratio of New Zealand NGOs on Government Grants/Contracts

\begin{tabular}{|l|c|c|c|c|c|c|}
\hline \multirow{2}{*}{ NGO } & \multicolumn{5}{c|}{ Proportion of Government Grant/Contract to Total Income, \% } \\
\cline { 2 - 7 } & $\mathbf{2 0 0 7}$ & $\mathbf{2 0 0 8}$ & $\mathbf{2 0 0 9}$ & $\mathbf{2 0 1 0}$ & $\mathbf{2 0 1 1}$ & $\mathbf{2 0 1 2}$ \\
\cline { 2 - 7 } & - & 59,8 & 61,5 & 60,8 & 32,7 & 62,7 \\
\hline ADRA New Zealand & - & 73,2 & 0 & 55,8 & 72,8 & 52,1 \\
\hline BANZAid* * & 53 & 49,8 & 50 & 9,2 & 20,1 & - \\
\hline Caritas Aotearoa New Zealand & 6,6 & 14,1 & 19,3 & 21,8 & 24,8 & - \\
\hline cbm New Zealand* & 6 & 7,2 & 7,1 & 8,5 & 13,7 & 9 \\
\hline ChidFund New Zealand & 64,3 & 65,2 & 65,8 & 62,1 & 20,8 & 0 \\
\hline Christian World Service* & - & 0 & - & 17,4 & 49 & - \\
\hline Engineers Without Borders New Zealand & 0,2 & 0,2 & 0,2 & 0,2 & 0 & 6 \\
\hline Family Planning International & 42,4 & 41,1 & 46,2 & 40 & 23,9 & 38 \\
\hline Oxfam New Zealand & - & - & 37,5 & 47,7 & 30,2 & 45 \\
\hline Save the Children New Zealand & 15,8 & 17,6 & 20,8 & 18,3 & 4,4 & 8,6 \\
\hline TEAR Fund & & & & & & \\
\hline The New Zealand China Friendship Society & 0 & 59,8 & 49,6 & 25,3 & 55,5 \\
\hline Incorporated & - & 42,8 & 49 & 46 & 0,02 & 33 \\
\hline The Leprosy Mission & - & 91,5 & 93,3 & 94,4 & - & - \\
\hline Volunteer Service Abroad & 6,1 & 4,5 & 7,7 & 5,7 & 2,7 & 4,1 \\
\hline World Vision New Zealand & & & & \\
\hline
\end{tabular}

* Government support for administration expenses, organisational support have been included in Government Grants/Contracts

- Data not available 
Source: ADRA 2009, ADRA 2011, ADRA 2012, BANZAid 2008, BANZAid 2009, BANZAid 2010, BANZAid 2011, BANZAid 2012, Caritas 2008, Caritas 2009a, Caritas 2010a, Caritas 2011, cbm 2007, cbm 2008, cbm 2009, cbm 2010, cbm 2011, ChildFund New Zealand 2007, ChildFund New Zealand 2008, ChildFund New Zealand 2009, ChildFund New Zealand 2010, ChildFund New Zealand 2011, ChildFund New Zealand 2012, CWS 2008, CWS 2009, CWS 2010a, CWS 2011b, CWS 2012, EWBNZ 2008, EWBNZ 2009, EWBNZ 2010, New Zealand Family Planning Association 2008, Family Planning International 2009, Family Planning International 2011, Family Planning International 2012, Oxfam 2007, Oxfam 2008, Oxfam 2009a, Oxfam 2010, Oxfam 2011, Oxfam 2012, Save the Children 2010, Save the Children 2011, Save the Children 2012, TEAR Fund 2007, TEAR Fund 2009a, TEAR Fund 2010, TEAR Fund 2011, TEAR Fund 2012, NZCFS 2008, NZCFS 2010, NZCFS 2011, NZCFS 2012, The Leprosy Mission New Zealand 2008, The Leprosy Mission New Zealand 2009, The Leprosy Mission New Zealand 2010, The Leprosy Mission New Zealand 2011, The Leprosy Mission New Zealand 2012, VSA 2009, VSA 2010, World Vision of New Zealand Trust Board 2008, World Vision of New Zealand Trust Board 2009, World Vision of New Zealand Trust Board 2011, World Vision of New Zealand Trust Board 2012. 